\author{
Universidade de São Paulo \\ Instituto de Física
}

\title{
Estudos estruturais do processo de agregação entre proteínas amilóides em solução
}

\author{
Elisa Morandé Sales
}

Orientadora: Prof ${ }^{\mathrm{a}} \mathrm{Dr}^{\mathrm{a}}$ Rosangela Itri

Dissertação de mestrado apresentada ao Instituto de Física para a obtenção do título de Mestre em Ciências

Comissão examinadora:

Prof ${ }^{\mathrm{a}}$. Dr ${ }^{\mathrm{a}}$. Rosangela Itri (orientadora - IF-USP)

Prof ${ }^{a}$. Dra ${ }^{\mathrm{a}}$. Ana Paula Araújo (IFSC-USP)

Prof. Dr. Ricardo Aparício (IQ-UNICAMP)

São Paulo

2012 


\section{FICHA CATALOGRÁFICA}

\section{Preparada pelo Serviço de Biblioteca e Informação}

do Instituto de Física da Universidade de São Paulo

Sales, Elisa Morandé

Estudos estruturais do processo de agregação entre proteínas amiloides em solução.- São Paulo, 2012

Dissertação (Mestrado) - Universidade de São Paulo. Instituto de Física, Depto. Física Aplicada.

Orientadora: $\operatorname{Prof}^{\mathrm{a}} \operatorname{Dr}^{\mathrm{a}}$ Rosangela Itri

Área de Concentração: Física da Matéria Condensada

Unitermos: 1. Física; 2. Física da Matéria Condensada; 3. Biofísica Molecular 


\section{Agradecimentos}

Gostaria de manifestar meus sinceros agradecimentos:

À Prof. Dra. Rosangela Itri, por todas as oportunidades; pelo incentivo, confiança e amizade durante esses 6 anos de orientação profissional e pessoal. Pelo apoio, paciência e compreensão nos momentos de enfermidade;

À minha família, pelo apoio incondicional não apenas nesse projeto, mas em todos os momentos da minha vida. Sem vocês, nada disso seria possível;

Ao Leo, pela presença constante, carinho e principalmente pela paciência (e que paciência!!!). Muitíssimo obrigada também pela ajuda imprescindível e incansável nos estudos e pelo auxílio (com todo o seu preciosismo!) com $\mathrm{LT}_{\mathrm{E} X}$;

Ao Dr. Julio C. P. Damalio e à Prof. Dra. Ana Paula Araújo do Instituto de Física da USP de São Carlos, pelo fornecimento das septinas utilizadas e por todas as explicações e discussões pertinentes a esse trabalho;

Ao Prof. Dr. Leandro R. S. Barbosa do Instituto de Física da Universidade de São Paulo, pela ajuda com as técnicas, equipamentos, amostras e por ser um manual vivo do programa GENFIT. Além, é claro, dos vários e vários cafés... ;

Ao Prof. Dr. Francesco Spinozzi e ao Prof. Dr. Paolo Mariani da Università Politecnica delle Marche, pelo fornecimento do programa de ajuste GENFIT, assim como todas as discussões envolvendo não apenas o seu funcionamento, mas como as análises desenvolvidas; 
Aos Drs. José Celso R. de Souza, Madge L. Ballock, Maria Cristina Chavantes e Ronaldo Frizzarini pela assistência médica prestada;

Aos colegas, secretárias e técnicos do Laboratório de Cristalografia do Instituto de Física da USP, pela amizade e colaboração;

A todos que, de alguma forma, me ajudaram com os estudos e com $\mathrm{LT}_{\mathrm{EX}} \mathrm{X}$

Por último, mas não menos importante, agradeço aos amigos por não me deixarem esquecer que, sim, existem outras coisas importantes além da dissertação; pelas conversas, risadas e, muitas vezes, apenas por entenderem meus momentos de ausência (e não desistirem de mim por isso);

Ao Laboratório Nacional de Luz Sincroton (LNLS) pelo uso de suas instalações;

À FAPESP e CNPq pelo apoio financeiro. 


\section{Sumário}

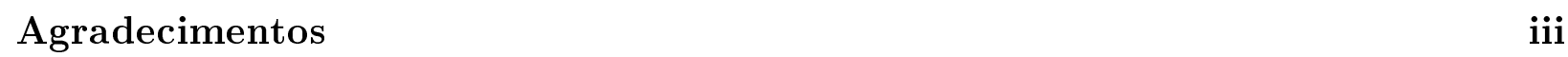

Resumo xiii

\begin{tabular}{ll}
\hline Abstract & xv
\end{tabular}

\begin{tabular}{lll}
\hline 1 & Introdução & 1
\end{tabular}

1.1 Proteínas Amilóides . . . . . . . . . . . . . . . . . . . . . . 1

1.2 Septinas . . . . . . . . . . . . . . . . . . . 6

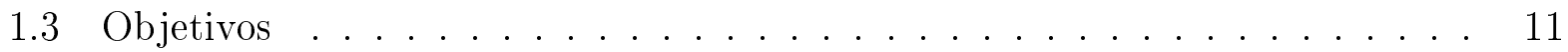

1.4 Estrutura da dissertação . . . . . . . . . . . . . . . . . . 12

2 Materiais e Métodos 13

2.1 Amostras de Septinas . . . . . . . . . . . . . . . . . . . . . . 13

2.2 Espalhamento de Raios-X a Baixos Ângulos . . . . . . . . . . . . . . . 13

2.2.1 SAXS no Laboratório Nacional de Luz Sincroton (LNLS) . . . . . . . 13

2.2 .2 Teoria . . . . . . . . . . . . . . . . . . . 15

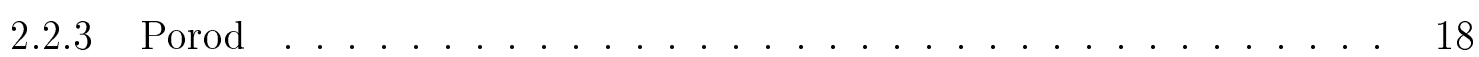

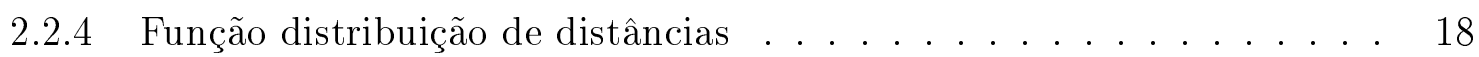

2.2 .5 Modelos para análise das curvas de SAXS . . . . . . . . . . 20

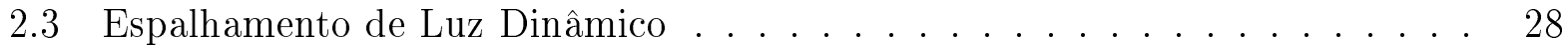

2.3.1 DLS no Laboratório de Cristalografia do Instituto de Física da USP

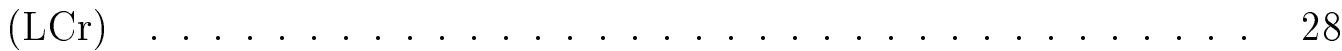

2.3 .2 Cálculo do diâmetro hidrodinâmico . . . . . . . . . . . . . . 30 
3 Resultados e Análise Modelo-Independente 33

3.1 Resultados: amostras a $0,5 \mathrm{mg} / \mathrm{mL} \ldots \ldots \ldots$. . . . . . . . . . . 33

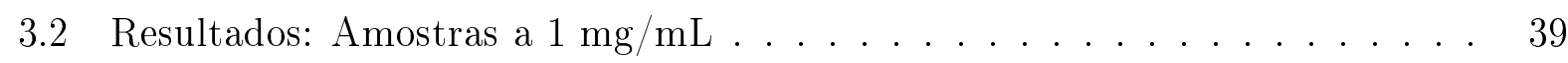

3.3 Raio de giro . . . . . . . . . . . . . . . . . . . . . 44

3.4 Massa molecular . . . . . . . . . . . . . . . . . . . . . 45

3.5 Função distribuição de distâncias $\ldots \ldots \ldots$. . . . . . . . . . . . 48

3.5.1 Amostras a $0,5 \mathrm{mg} / \mathrm{mL} \ldots \ldots \ldots \ldots$. . . . . . . . . . . . . . . . . . . . . . . . . . 48

3.5 .2 Amostras a $1 \mathrm{mg} / \mathrm{mL} \ldots \ldots \ldots \ldots \ldots \ldots$

3.6 Resultados de DLS . . . . . . . . . . . . . . . . . . . . . . . . 58

3.7 Conclusões Parciais . . . . . . . . . . . . . . . . . . . . 60

4 Análise Modelo-Dependente e Discussão $\quad 61$

$4.1 \quad$ Exemplo de ajuste teórico aos dados de SAXS utilizando modelos . . . . . . 62

4.2 Amostras a $0,5 \mathrm{mg} / \mathrm{mL} \ldots \ldots \ldots \ldots \ldots \ldots$

4.3 Amostras a $1 \mathrm{mg} / \mathrm{mL} \ldots \ldots \ldots \ldots \ldots \ldots$

$\begin{array}{lll}5 \text { Conclusão } & 91\end{array}$

\begin{tabular}{ll}
\hline Referências & 92
\end{tabular} 


\section{Lista de Figuras}

1.1 Representação esquemática de algumas de vias de formação de fibras amilói-

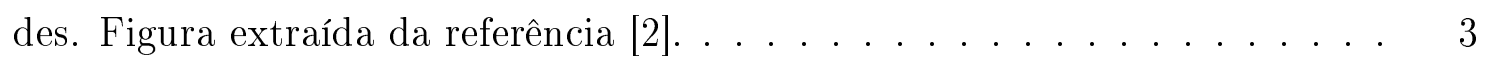

1.2 Esquema da estrutura das septinas. Figura adaptada da referência [27]. . . . 6

1.3 Classificação das septinas de mamíferos em grupos, considerando a homologia de suas seqüências primárias. Apesar de não estar representada, a SEPT14 pertence ao Grupo II. A SEPT13 é considerada um pseudogene, ou seja, a sequência tem homologia, mas não é funcional (comunicação pessoal da Profa. Dra. Ana Paula Araújo do IFSC-USP). Figura adaptada da referência [30].] 7

1.4 Funções das septinas humanas em situações de funcionamento celular e molecular normais e em casos de doenças e seu envolvimento em fenótipos celulares e tecidual. Figura extraída da referência [35]. . . . . . . . . . . . . . . 8

1.5 Representação de três monômeros da SEPT2, com as interfaces dímero-G e dímero-NC indicadas. As linhas tracejadas representam regiões desordenadas. Figura extraída da referência $[26] . \ldots \ldots$. . . . . . . . . . . 9 9

1.6 Representação de superfície do complexo SEPT2-SEPT6-SEPT7. Figura extraída da referência $[26] . \ldots \ldots \ldots \ldots$. . . . . . . . . . . . . 10

2.1 Representação esquemática da linha de SAXS do LNLS. Figura extraída da referência [38]. . . . . . . . . . . . . . . . . . . . . . . . . 14

2.2 Curva de SAXS da água. $\ldots \ldots \ldots \ldots \ldots \ldots \ldots$

2.3 Intensidades de espalhamento e funções distribuição de distâncias $p(r)$ de diferentes corpos geométricos. Figura extraída da referência [42]. . . . . . . 19 
2.4 Sequência primária das amostras de SEPT2G utilizadas. Os 20 primeiros aminoácidos marcados em verde representam a cauda de histidina ligada a cada monômero da proteína (sequência fornecida pelo grupo da Profa. Ana Paula Araújo). . . . . . . . . . . . . . . . . 21

2.5 Sequência primária referente ao arquivo pdb da SEPT2G (código 2QA5). A sequência inicia-se deslocada para uma melhor comparação com a sequência da Figura 2.4. O símbolo - representa aminoácidos que estão faltando nesta sequência primária. . . . . . . . . . . . . . . . 21

2.6 Estrutura cristalográfica da SEPT2G adaptada do arquivo pdb 2QA5 (ver

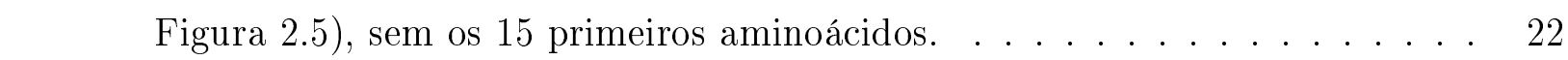

2.7 Curva de SAXS simulada a partir da estrutura cristalográfica do dímero (Figura 2.6). Em detalhe, vemos a função $p(r)$ referente a essa curva simulada.

2.8 Representação esquemática do equipamento de espalhamento de luz. No nosso \begin{tabular}{|c|}
\hline caso, o detector encontrava-se a $90^{\circ}$ em relação ao feixe incidente. Figura \\
\hline
\end{tabular} extraída da referência [50]. . . . . . . . . . . . . . . . 29

3.1 Evolução temporal das curvas de SAXS para a proteína SEPT2G a uma concentração de $0,5 \mathrm{mg} / \mathrm{mL}$ e $\mathrm{T}=4^{\circ} \mathrm{C}: \mathrm{t}=0 \mathrm{~s}$ corresponde à primeira medida experimental com acúmulo de intensidade de espalhamento durante 3 minutos; $\mathrm{t}=300 \mathrm{~s}$ corresponde à medida iniciada após 5 minutos do início da aquisição de dados, ou seja, após uma espera de 2 minutos da medida iniciada com $\mathrm{t}=0 \mathrm{~s}$ e assim sucessivamente para as medidas seguintes. . . . . . . . . . . . . 34

3.2 Evolução temporal das curvas de SAXS para a proteína SEPT2G a uma concentração de $0,5 \mathrm{mg} / \mathrm{mL}$ e $\mathrm{T}=15^{\circ} \mathrm{C}$. Para a indicação de tempo de medida, verificar legenda da Figura 3.1$] \ldots \ldots . \ldots . \ldots . \ldots 35$

3.3 Evolução temporal das curvas de SAXS para a proteína SEPT2G a uma concentração de $0,5 \mathrm{mg} / \mathrm{mL}$ e $\mathrm{T}=25^{\circ} \mathrm{C}$. Para a indicação de tempo de medida, verificar legenda da Figura $3.1 . \ldots \ldots \ldots . \ldots . \ldots . \ldots 36$

3.4 Evolução temporal das curvas de SAXS para a proteína SEPT2G a uma \begin{tabular}{|c|}
\hline concentração de $0,5 \mathrm{mg} / \mathrm{mL}$ e $\mathrm{T}=37^{\circ} \mathrm{C}$. Para a indicação de tempo de medida, \\
\hline
\end{tabular} verificar legenda da Figura $\mid 3.1] \ldots \ldots . \ldots . \ldots . \ldots 37$ 
3.5 Evolução temporal das curvas de SAXS para a proteína SEPT2G a uma concentração de $0,5 \mathrm{mg} / \mathrm{mL}$ e $\mathrm{T}=45^{\circ} \mathrm{C}$. A linha preta indicada pela flecha representa a função $I(q) \propto q^{-4}$. Para a indicação de tempo de medida,

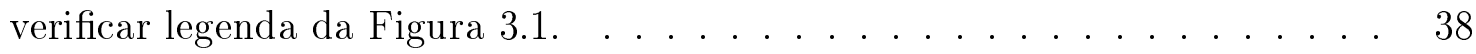

3.6 Evolução temporal das curvas de SAXS para a proteína SEPT2G a uma concentração de $1 \mathrm{mg} / \mathrm{mL}$ e $\mathrm{T}=4^{\circ} \mathrm{C}:$ : $\mathrm{t}=0$ s corresponde à primeira medida experimental com acúmulo de intensidade de espalhamento durante 2 minutos; $\mathrm{t}=300$ s corresponde à medida iniciada após 5 minutos do início da aquisição de dados, ou seja, após uma espera de 3 minutos da medida iniciada com $\mathrm{t}=0 \mathrm{~s}$ e assim sucessivamente para as medidas seguintes. . . . . . . . . . . . 39

3.7 Evolução temporal das curvas de SAXS para a proteína SEPT2G a uma concentração de $1 \mathrm{mg} / \mathrm{mL}$ e $\mathrm{T}=15^{\circ} \mathrm{C}$. Para a indicação de tempo de medida, verificar legenda da Figura $|3.6| \ldots \ldots$. . . . . . . . . . . . . 40

3.8 Evolução temporal das curvas de SAXS para a proteína SEPT2G a uma concentração de $1 \mathrm{mg} / \mathrm{mL}$ e $\mathrm{T}=25^{\circ} \mathrm{C}$. Para a indicação de tempo de medida, verificar legenda da Figura 3.6 . . . . . . . . . . . . . . . . . . . . 41

3.9 Evolução temporal das curvas de SAXS para a proteína SEPT2G a uma concentração de $1 \mathrm{mg} / \mathrm{mL}$ e $\mathrm{T}=37^{\circ} \mathrm{C}$. A linha preta indicada pela flecha representa a função $I(q) \propto q^{-4}$. Para a indicação de tempo de medida, verificar legenda da Figura $|3.6|] \ldots$. . . . . . . . . . . . . . . 42

3.10 Evolução temporal das curvas de SAXS para a proteína SEPT2G a uma concentração de $1 \mathrm{mg} / \mathrm{mL}$ e $\mathrm{T}=45^{\circ} \mathrm{C}$. A linha preta indicada pela flecha \begin{tabular}{|r|r|}
\hline representa a função $I(q) \propto q^{-4}$. Para a indicação de tempo de medida, \\
\hline
\end{tabular} verificar legenda da Figura $|3.6| \ldots \ldots$. . . . . . . . . . . . . 43

3.11 Alguns exemplos do ajuste linear da região de Guinier. . . . . . . . . . . . . 44

3.12 Gráfico do raio de giro em função do tempo para a SEPT2G. . . . . . . . . 45

3.13 Evolução temporal da massa molecular para a SEPT2G a 0,5 mg/mL. . . . 47

3.14 Evolução temporal da massa molecular para a SEPT2G a $1 \mathrm{mg} / \mathrm{mL}$. . . . . 47 
3.15 Média das curvas de SAXS para a proteína SEPT2G a uma concentração \begin{tabular}{|c|}
\hline de $0,5 \mathrm{mg} / \mathrm{mL}$ e $\mathrm{T}=4^{\circ} \mathrm{C}(+)$ e o melhor ajuste aos dados experimentais \\
\hline \hline obtido pelo programa GNOM (linha contínua em azul). No inserto temos a \\
\hline função $p(r)$ correspondente à curva de SAXS obtida pelo programa GNOM \\
\hline (em azul) e, para efeito de comparação, a função $p(r)$ calculada a partir da \\
\hline curva simulada obtida através da estrutura cristalográfica do dímero, como \\
\hline
\end{tabular}

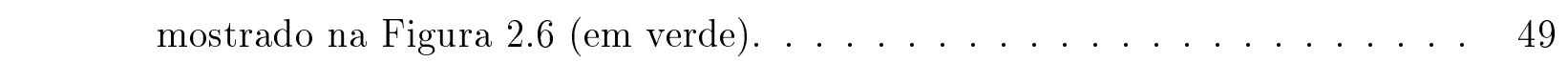

3.16 Evolução da função $p(r)$ com o tempo para a proteína SEPT2G a uma concentração de $0,5 \mathrm{mg} / \mathrm{mL}$ e $\mathrm{T}=15^{\circ} \mathrm{C} . \ldots \ldots \ldots \ldots$

3.17 Evolução da função $p(r)$ com o tempo para a proteína SEPT2G a uma concentração de $0,5 \mathrm{mg} / \mathrm{mL}$ e $\mathrm{T}=25^{\circ} \mathrm{C}$. . . . . . . . . . . . . . . 51

3.18 Evolução da função $p(r)$ com o tempo para a proteína SEPT2G a uma concentração de $0,5 \mathrm{mg} / \mathrm{mL} \mathrm{e} \mathrm{T}=37^{\circ} \mathrm{C} . \ldots \ldots \ldots \ldots \ldots \ldots$. . . . . . . . . 52

3.19 Evolução da função $p(r)$ com o tempo para a proteína SEPT2G a uma concentração de $0,5 \mathrm{mg} / \mathrm{mL} \mathrm{e} \mathrm{T}=45^{\circ} \mathrm{C}$. . . . . . . . . . . . . . 52

3.20 Média das curvas de SAXS para a proteína SEPT2G a uma concentração

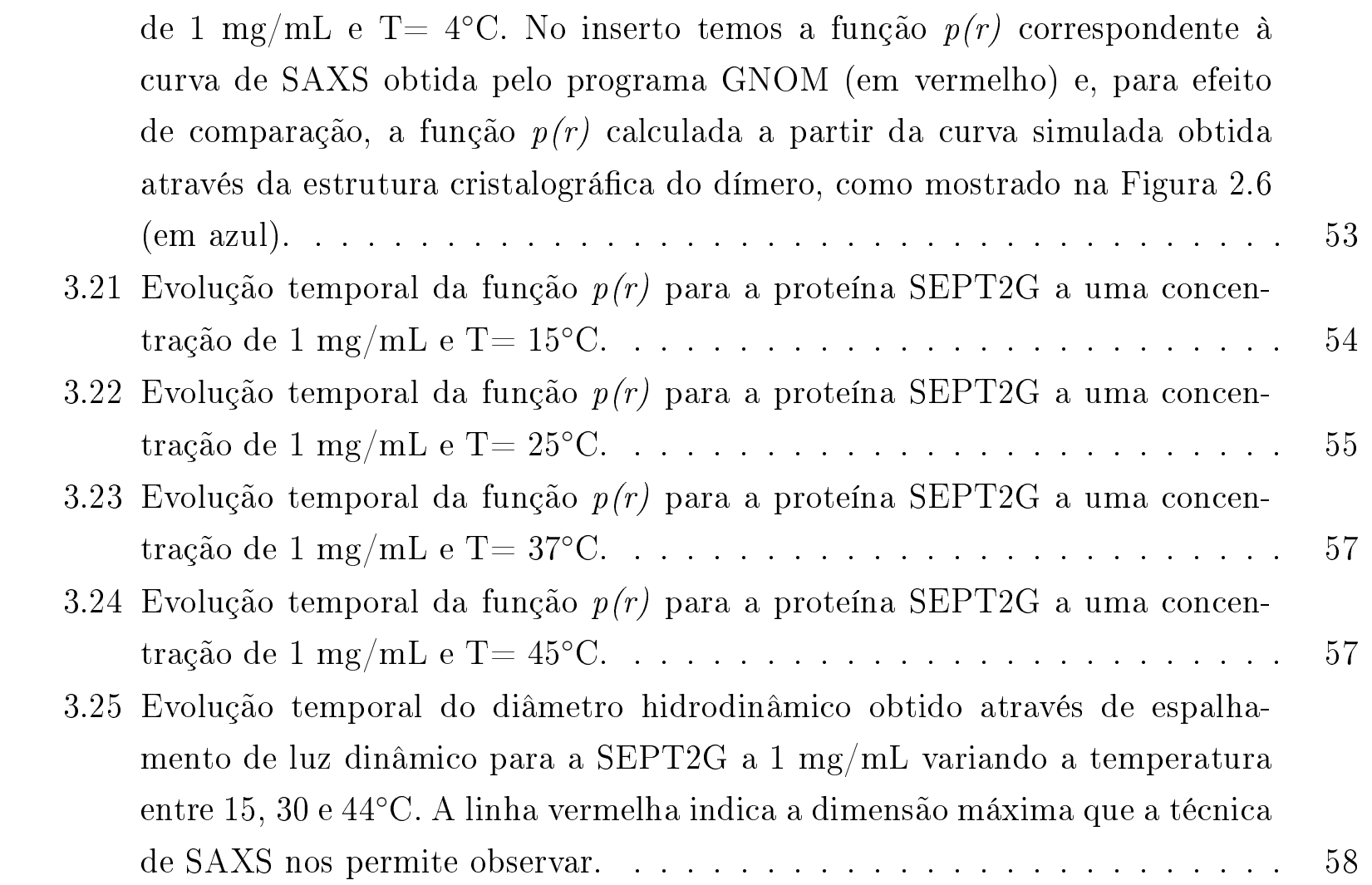


4.1 Exemplo de ajuste da curva de SAXS para a proteína SEPT2G a uma con-

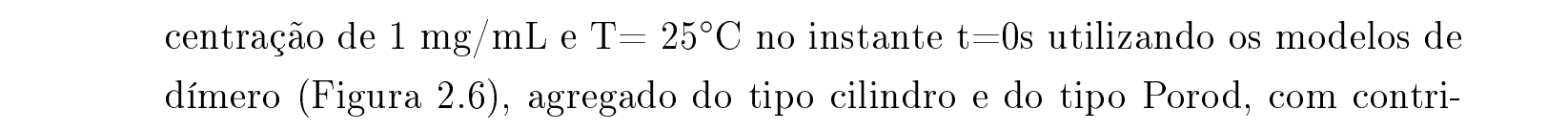

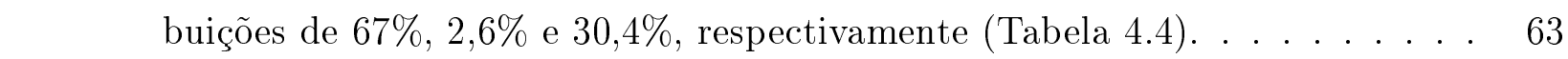

4.2 Melhor ajuste (linha contínua) aos dados experimentais de SAXS da SEPT2G \begin{tabular}{|c|c|}
\hline a $0,5 \mathrm{mg} / \mathrm{mL}$ e $\mathrm{T}=4^{\circ} \mathrm{C}(+)$, utilizando o modelo do dímero da SEPT2G \\
\hline
\end{tabular}

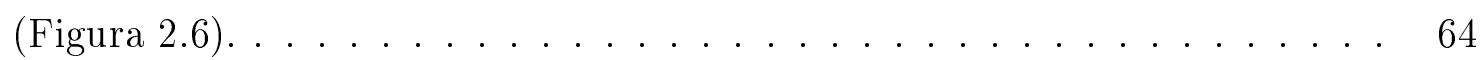

4.3 Melhor ajuste (linhas contínuas) SAXS da SEPT2G a $0,5 \mathrm{mg} / \mathrm{mL}$ e $\mathrm{T}=15^{\circ} \mathrm{C}$ nos instantes $\mathrm{t}=0(+), 900(\times)$ e $1800 \mathrm{~s}(*)$ agregado do tipo cilindro e agregado

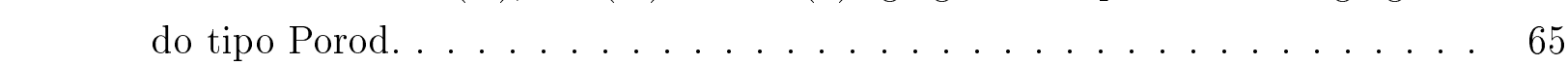

4.4 Estrutura formada por 14 monômeros de SEPT2G juntamente com o envelope \begin{tabular}{|c|}
\hline cilíndrico obtido através dos ajustes aos dados experimentais da SEPT2G a \\
\hline
\end{tabular}

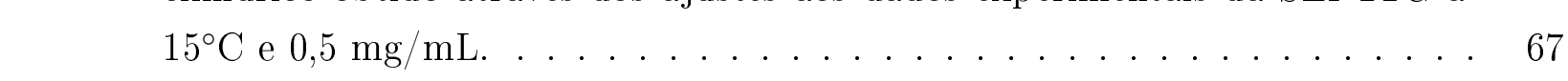

4.5 Curva de SAXS simulada a partir de um envelope cilíndrico (linha tracejada em verde) com dimensões obtidas através dos ajustes aos dados experimentais da SEPT2G a $15^{\circ} \mathrm{C}$ e $0,5 \mathrm{mg} / \mathrm{mL}$ (Tabela 4.1 ) juntamente com a curva simulada a partir da estrutura formada pela composição de 14 monômeros (linha contínua em azul). . . . . . . . . . . . . . 67 67

$4.6 \quad$ Melhor ajuste (linhas contínuas) aos dados experimentais de SAXS da SEPT2G \begin{tabular}{|c|}
\hline $\mathrm{a} 0,5 \mathrm{mg} / \mathrm{mL} \mathrm{e} \mathrm{T}=25^{\circ} \mathrm{C}$ nos instantes $\mathrm{t}=0(+), 1200(\times)$ e $2100 \mathrm{~s}(*)$, utilizando \\
\hline
\end{tabular} \begin{tabular}{|c|c|c|}
\hline os modelos de dímero da SEPT2G (Figura & $2.6)$, agregado do tipo cilindro e \\
\hline
\end{tabular}

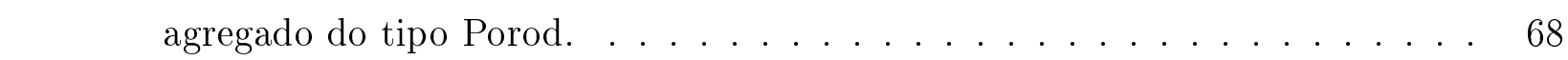

4.7 Melhor ajuste (linhas contínuas) aos dados experimentais de SAXS da SEPT2G \begin{tabular}{|c|}
\hline a $0,5 \mathrm{mg} / \mathrm{mL}$ e $\mathrm{T}=37^{\circ} \mathrm{C}$ nos instantes $\mathrm{t}=0(+), 1200(\times)$ e 2100s $(*)$, utili- \\
\hline \hline zando os modelos de dímero da SEPT2G (Figura 2.6$)$ e agregado do tipo \\
\hline
\end{tabular}

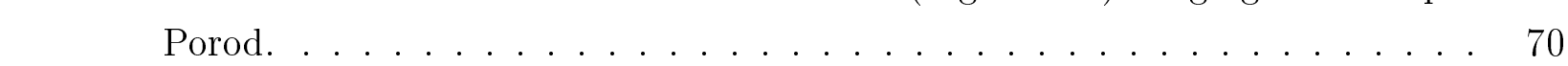

4.8 Melhor ajuste (linhas contínuas) aos dados experimentais de SAXS da SEPT2G a $0,5 \mathrm{mg} / \mathrm{mL}$ e $\mathrm{T}=45^{\circ} \mathrm{C}$ nos instantes $\mathrm{t}=0(+), 600(\times)$ e $1200 \mathrm{~s}(*)$, utilizando os modelos de dímero da SEPT2G (Figura $\mid 2.6)$ e agregado do tipo Porod. . . 71

4.9 Porcentagens da proteína na forma de dímero, agregados do tipo cilindro e agregados do tipo Porod para $0,5 \mathrm{mg} / \mathrm{mL}$ em temperaturas de $(\mathrm{A}): 4^{\circ} \mathrm{C} ;(\mathrm{B})$ : $15^{\circ} \mathrm{C} ;(\mathrm{C}): 25^{\circ} \mathrm{C} ;(\mathrm{D}): 37^{\circ} \mathrm{C}$ e $(\mathrm{E}): 45^{\circ} \mathrm{C}$. Os cilindros representados estão em escala entre si, mas não com a representação do dímero. . . . . . . . . . . . 77 
4.10 Evolução temporal da intensidade de fluorescência de ThT em uma solução de SEPT2G a $0,5 \mathrm{mg} / \mathrm{mL}$ e diferentes temperaturas. Dados fornecidos pelo Dr. Julio Damalio (IFSC-USP). . . . . . . . . . . . . . . . 78

4.11 Melhor ajuste (linha contínua) aos dados experimentais de SAXS da SEPT2G a $1 \mathrm{mg} / \mathrm{mL} \mathrm{e} \mathrm{T}=4^{\circ} \mathrm{C}(+) . \ldots \ldots \ldots . \ldots . \ldots . \ldots 80$

4.12 Melhor ajuste (linhas contínuas) aos dados experimentais de SAXS da SEPT2G a $1 \mathrm{mg} / \mathrm{mL} \mathrm{e} \mathrm{T}=15^{\circ} \mathrm{C}$ nos instantes $\mathrm{t}=0(+), 1200(\times)$ e $2100 \mathrm{~s}(*)$, utilizando os modelos de dímero da SEPT2G (Figura 2.6), agregado do tipo cilindro e agregado do tipo Porod. . . . . . . . . . . . . . . . 81

4.13 Melhor ajuste (linhas contínuas) aos dados experimentais de SAXS da SEPT2G $\mathrm{a} 1 \mathrm{mg} / \mathrm{mL} \mathrm{e} \mathrm{T}=25^{\circ} \mathrm{C}$ nos instantes $\mathrm{t}=0(+), 1200(\times)$ e $2100 \mathrm{~s}(*)$, utilizando

\begin{tabular}{|c|}
\hline os modelos de dímero da SEPT2G (Figura \\
\hline
\end{tabular}
agregado do tipo Porod. . . . . . . . . . . . . . . . 82

4.14 Melhor ajuste (linhas contínuas) aos dados experimentais de SAXS da SEPT2G

\begin{tabular}{|c|}
\hline $\mathrm{a} 1 \mathrm{mg} / \mathrm{mL} \mathrm{e} \mathrm{T}=37^{\circ} \mathrm{C}$ nos instantes $\mathrm{t}=0(+), 600(\times)$ e $1200 \mathrm{~s}(*)$, utilizando \\
\hline
\end{tabular}

\begin{tabular}{|r|r|r|}
\hline os modelos de dímero da SEPT2G (Figura & $2.6)$ & e agregado do tipo Porod. . . 83 \\
\hline
\end{tabular}

4.15 Melhor ajuste (linhas contínuas) aos dados experimentais de SAXS da SEPT2G \begin{tabular}{|c|}
\hline $\mathrm{a} 1 \mathrm{mg} / \mathrm{mL}$ e $\mathrm{T}=45^{\circ} \mathrm{C}$ nos instantes $\mathrm{t}=0(+), 600(\times)$ e $1200 \mathrm{~s}(*)$, utilizando \\
\hline
\end{tabular} \begin{tabular}{l|l|l|l|}
\hline os modelos de dímero da SEPT2G (Figura & $2.6)$ & e agregado do tipo Porod. . 84
\end{tabular}

4.16 Porcentagens de dímero, agregado do tipo cilindro e agregado do tipo Porod para $1 \mathrm{mg} / \mathrm{mL}$ em temperaturas de $(\mathrm{A}): 4^{\circ} \mathrm{C} ;(\mathrm{B}): 15^{\circ} \mathrm{C} ;(\mathrm{C}): 25^{\circ} \mathrm{C} ;(\mathrm{D}): 37^{\circ} \mathrm{C}$

\begin{tabular}{|c|c|}
\hline \hline e (E): $45^{\circ} \mathrm{C}$. Os cilindros representados estão em escala entre si, mas não com \\
\hline a representação do dímero. Em (C) temos a representação de dois cilindros, \\
\hline indicando a evolução desta estrutura no intervalo de medida. . . . . . . . . $\quad 89$ \\
\hline 4.17 Evolução temporal do volume do agregado do tipo cilindro. . . . . . . . . $\quad 90$
\end{tabular}




\section{Resumo}

Septinas fazem parte de uma família de proteínas de ligação ao nucleotídeo guanina que atuam no ciclo de divisão celular e também são amplamente encontradas em doenças neurodegenerativas tais como mal de Parkinson e Alzheimer e em alguns tipos de câncer como leucemia, linfoma e tumores sólidos. Neste trabalho investigamos como a temperatura e a concentração impactam na agregação do domínio GTPase da septina 2 (SEPT2G), podendo levar a formação de fibras amilóides, por espalhamento de luz (DLS) e Raios-X a baixos ângulos (SAXS).

Resultados de DLS revelaram que a cinética de agregação da proteína é da ordem de segundos para temperaturas maiores que $25^{\circ} \mathrm{C}$. Os dados de SAXS da proteina a $0,5 \mathrm{mg} / \mathrm{ml}$ mostraram que a SETP2G é um dímero em solução aquosa a $4^{\circ} \mathrm{C}$ e esta configuração se mantém estável por cerca de 1 hora de observação experimental. A $15^{\circ} \mathrm{C}$, os resultados de SAXS revelaram uma coexistência de três populações em solução compostas por $88 \%$ de dímeros, $10 \%$ de agregados pequenos tipo-cilindros (protofibrilas), e $2 \%$ de agregados grandes maiores que a resolução da técnica. Após cerca de 30 minutos existe um rearranjo preferencial de dímeros em favor de agregados muito grandes cuja contribuição à curva de espalhamento torna-se $8 \%$. A $25^{\circ} \mathrm{C}$, a porcentagem de dímeros decresce para $70 \%$ com uma contribuição de cerca de $30 \%$ de agregados grandes já no início das medidas experimentais. Nas temperaturas de $37^{\circ} \mathrm{C}$ e $45^{\circ} \mathrm{C}$, dímeros e agregados muito grandes coexistem em solução desde o início das medidas experimentais, cujo equilíbrio se desloca rapidamente tal que após 20 minutos de observação a solução é composta majoritariamente por agregados muito grandes, identificados como estruturas amilóides pela técnica de fluorescência da tioflavina, que se intercala em estruturas cross- $\beta$.

A $1 \mathrm{mg} / \mathrm{mL}$ e temperatura de $4^{\circ} \mathrm{C}$, a proteína permaneceu estável durante cerca de 1 hora de observação sendo que existe um equilíbrio de dímeros (93\%) com agregados alongados (contendo cerca de 80 monômeros) em solução. Com o aumento da temperatura para $15^{\circ} \mathrm{C}$, a maioria da população ainda é dimérica. Já a $25^{\circ} \mathrm{C}$, a presença de agregados muito grandes é bem significativa (da ordem de $30 \%$ coexistindo com dímeros e oligômeros). A $37^{\circ} \mathrm{C} \mathrm{e} 45^{\circ} \mathrm{C}$ existe a formação de grandes agregados similar ao observado para a SEPT2G a $0,5 \mathrm{mg} / \mathrm{mL}$.

Em suma, os resultados de SAXS demonstraram que a SEPT2G tem uma cinética muito rápida de agregação a temperatura fisiológica, acentuada com o aumento de concentração da proteína em solução. 



\section{Abstract}

Septins are proteins from the GTP-binding family and participate in cell division cycle performing functions such as secretion and cytoskeletal division. They can also be found in neurodegenerative conditions as Alzheimer's and Parkinson's diseases and some kinds of cancer as leukemia, lymphoma and solid tumors. In this work, we investigated the influence of temperature and concentration on the septin 2 GTPase domain (SEPT2G) aggregation using dynamic light scattering (DLS) and small angle x-ray scattering (SAXS).

DLS results revealed the protein aggregation kinetic is around seconds for temperatures above $25^{\circ} \mathrm{C}$. SAXS data of the protein at $0.5 \mathrm{mg} / \mathrm{mL}$ showed that SEPT2G is a dimer in aqueous solution at $4^{\circ} \mathrm{C}$ and this condition is kept stable for approximately one hour of experimental observation. At $15^{\circ} \mathrm{C}$, SAXS results revealed the coexistence of three populations in solution composed by $88 \%$ of dimers, $10 \%$ of cylinder-like smaller aggregates (protofibrils) and $2 \%$ of aggregates bigger than the technique detection. After 30 minutes there is a preferential rearrangement of dimers into very large aggregates which contribution on the scattering curve becomes $8 \%$. At $25^{\circ} \mathrm{C}$, the dimers percentage decreases to $70 \%$ with a contribution of circa $30 \%$ of bigger aggregates, even at the beginning of data acquisition. At temperatures of $37^{\circ} \mathrm{C}$ and $45^{\circ} \mathrm{C}$, dimers and very large aggregates coexist in solution since the beginning of data acquisition, which equilibrium quickly shifts in such a way that after 20 minutes of observation the solution is mostly composed by very large aggregates, indentified as amyloid structures by the thioflavine fluorescence technique, which intercalates in the cross- $\beta$ structures.

At $1 \mathrm{mg} / \mathrm{mL}$ and $4^{\circ} \mathrm{C}$, the protein was stable over 1 hour of observation where an equilibrium of dimers (93\%) and elongated structures (composed by approximately 80 monomers) in solution takes place. Increasing the temperature to $15^{\circ} \mathrm{C}$, most of the protein remains dimeric. On the other hand, at $25^{\circ} \mathrm{C}$ the very large aggregates contribution is around $30 \%$ coexisting with dimers and oligomers. At $37^{\circ} \mathrm{C}$ and $45^{\circ} \mathrm{C}$ there is the formation of large aggregates, similar to what was observed at $0.5 \mathrm{mg} / \mathrm{mL}$.

In conclusion, our SAXS results indicated that the aggregation process of SEPT2G in solution may follow different pathways depending on concentration and temperature. 



\section{Capítulo 1}

\section{Introdução}

\subsection{Proteínas Amilóides}

Proteínas e peptídeos considerados amilóides são aqueles que, sob determinadas condições, apresentam uma estrutura fibrilar insolúvel no meio biológico. Esta apresenta um grande número de ligações "cross- $\beta$ ", ou seja, ligações onde as folhas- $\beta$ são arranjadas perpendicularmente ao eixo das fibras (Figura 1.1) [1, 2].

O estudo de problemas de enovelamento de proteínas que formam fibras amilóides tem recebido muita atenção uma vez que estas são encontradas em mais de 40 doenças, particularmente em condições neurodegenerativas tais como Alzheimer e Parkinson [2]. A composição dos agregados encontrados nos pacientes que sofrem de qualquer doença amilóide tem em sua maior parte uma porção central formada pela proteína podendo também apresentar alguns outros componentes tais como íons metálicos, glicosaminoglicanas e colágeno [3, 4].

Além disso, a fibrilação de proteínas pode inibir sua atividade, como é o caso da insulina [5, 6]. Sendo assim, é crucial entender-se melhor os mecanismos de agregação, enovelamento e estabilidade de proteínas, visando inibir ou mesmo reverter a formação de fibras amilóides.

Apesar do processo de fibrilação ter sido extensamente estudado, a maior parte dos trabalhos tem como foco eventos de macro-escala, como mudanças no tempo de latência, taxa de crescimento, forma e tamanho de fibras longas. Entretanto, foi sugerido recentemente que os precursores oligoméricos das fibras amilóides são possivelmente os agentes tóxicos responsáveis pelas doenças [7, 8].

O processo típico de formação de fibrilas é caracterizado por uma fase de latência na 
qual nenhum filamento é formado. É então seguida por uma fase de alongamento na qual as fibras são formadas em um período que é em geral mais curto que a fase de latência. Eventualmente, o processo atinge o equilíbrio quando a maior parte das proteínas solúveis são convertidas em fibrilas [9]. Estudos in vitro mostraram que a duração do período de latência e a taxa de crescimento das fibrilas dependem de fatores como a concentração inicial, $\mathrm{pH}$, força iônica e a velocidade de agitação da amostra [10].

Esse fenômeno de agregação agora é conhecido como sendo uma propriedade universal das proteínas, contanto que existam condições apropriadas para que a proteína saia do estado nativo. Entre elas estão: pH baixo, altas temperaturas, alta pressão, presença de co-solventes [11]. Uma representação esquemática de algumas das várias conformações que podem ser adotadas pelas proteínas e como podem se converter em diferentes estruturas pode ser vista na Figura 1.1. Além dos agregados de proteínas formados a partir de estados desenovelados ou "mal"enovelados, podemos notar que também é possível a formação de fibras amilóides a partir da agregação de proteínas no estado nativo. 


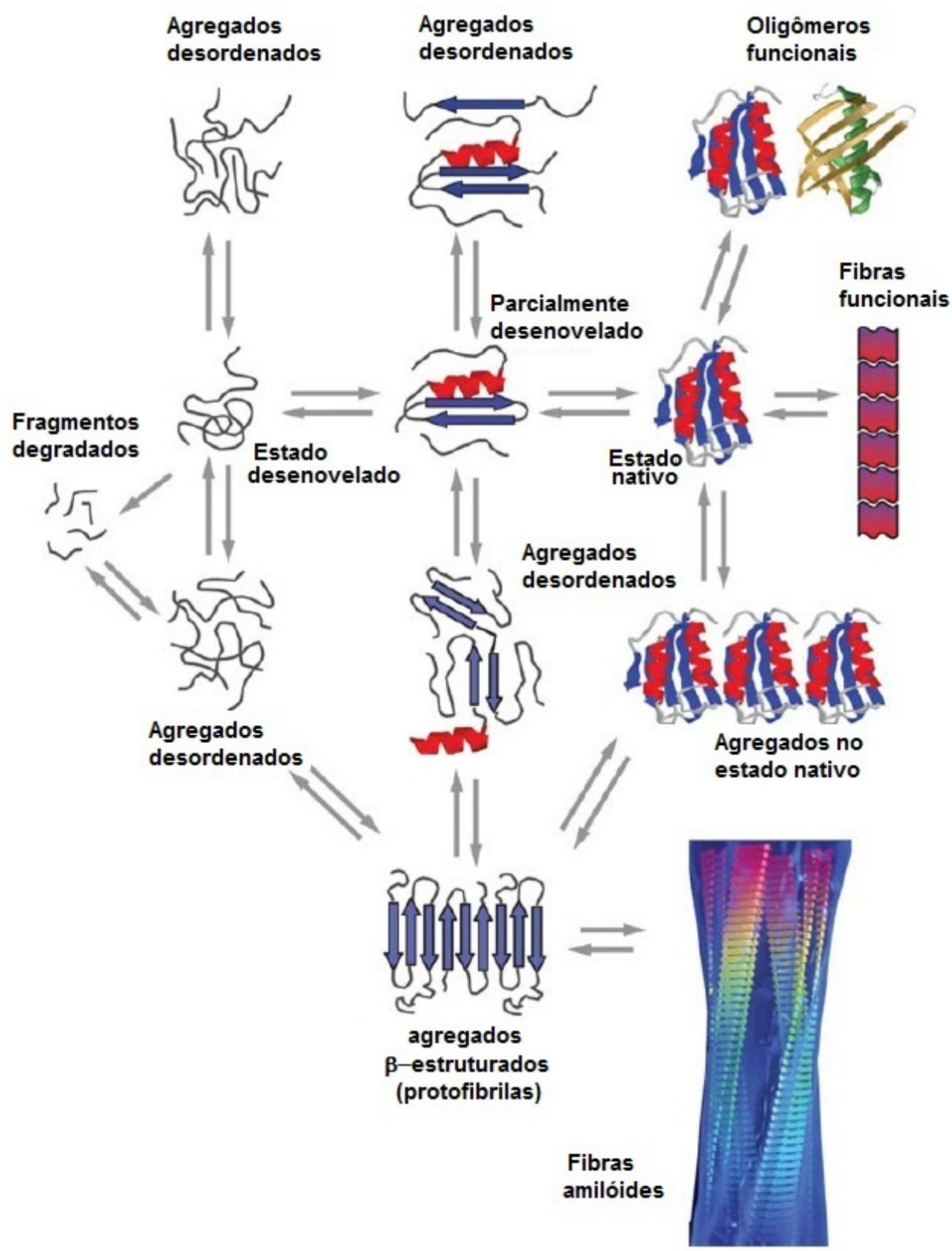

Figura 1.1: Representação esquemática de algumas de vias de formação de fibras amilóides. Figura extraída da referência [2]. 
A maior parte dos métodos aplicados para caracterização biofísica e estrutural da formação dessas fibras amilóides e seus precursores oligoméricos é problemática porque as medidas podem atrapalhar o equilíbrio do processo de fibrilação, uma vez que podem alterar ou interagir com a amostra (como é o caso da cristalografia de raio-x e ressonância magnética nuclear) ou então a amostra pode sofrer efeitos mediados pela superfície (como na microscopia de força atômica, microscopia de corrente de tunelamento, e crio microscopia eletrônica). Por outro lado, a técnica de espalhamento de raio-x a baixos ângulos (SAXS), indicada para o estudo em baixa resolução de estruturas macromoleculares, permite examinar o processo de fibrilação, dependente da cinética de evolução, diretamente em solução, de maneira que os componentes individuais presentes durante o equilibro envolvido podem ser estudados $[12$.

Entretanto, os estudos na literatura sobre fibras amilóides utilizando a técnica de SAXS são recentes, iniciando apenas em 1999 [13]. Entre as proteínas que formam agregados amilóides que já foram estudadas por SAXS estão: a insulina, que apresenta processo de fibrilação in vitro e in vivo no caso da infusão subcutânea [12, 14]; $\alpha$-sinucleína, relacionada à doença de Parkinson [15, 16]; proteína amilóide precursora (APP) [17, 18] e peptídeos da proteína $\beta$-amilóide [19], correlacionadas com a origem da doença de Alzheimer; glucagon, hormônio responsável por manter o nível de glicose no corpo humano [18, 20]; gliceraldeído-3-fosfato desidrogenase (GAPDH), uma enzima glicolítica tetramérica que pode formar filamentos na presença de heparina [21]; Ure2p, uma proteína dimérica envolvida na regulação do metabolismo de nitrogênio na levedura Saccharomyces cerevisiae [22]; septina 4 [23, 24] e uma mutação da apomioglobina [25].

É importante ressaltar que, no caso da maioria das proteínas citadas, a agregação foi induzida por algum fator externo. Algumas sofrem mutações, como é o caso da apomioglobina [25] e ure2p [22], outras tinham em solução a presença de outros compostos, como no estudo da $\alpha$-sinucleína com dopamina [15], da septina 4 com uréia [24], glucagon com heparina [18] e GAPDH também na presença de heparina [21. Temos ainda a agregação induzida pelo efeito de pH muito ácido, como é o caso da insulina (pH igual 2) [12] ou ainda o estudo de apenas um fragmento, como é o caso proteína amilóide precursora (APP) [18], que ainda assim utiliza a técnica de SAXS apenas para verificar a presença de dímeros.

Mesmo quando a macromolécula encontrava-se em condições fisiológicas, como foi o caso do estudo dos peptídeos $\beta$-amilóide [19], foram necessários períodos de incubação de mais de 4 horas e ainda assim a maior estrutura medida atingia dimensões de apenas $500 \AA$. 
Para o glucagon[20], não apenas foi necessário um período de incubação de 12 horas, como também concentrações altas (5 e $10 \mathrm{mg} / \mathrm{mL}$ ) para que fosse possível começar a verificar a presença de oligômeros de ate $400 \AA$ de tamanho. No caso da GAPDH, a presença de heparina a $\mathrm{T}=37^{\circ} \mathrm{C}$ e pH fisiológico, induz a formação de agregados com $200 \AA$ de dimensão após 2 minutos. Entretanto, após 180 minutos de medida, a dimensão máxima obtida não ultrapassou $250 \AA$ [21].

No caso da $\alpha$-sinucleína [16], o fator utilizado para induzir a agregação foi a temperatura, e ainda assim, mesmo após a amostra ter sido incubada a $50^{\circ} \mathrm{C}$, até $18 \mathrm{~h}$ de medida a proteína permaneceu monomérica. Estágios intermediários de agregação da proteína foram observados apenas após $120 \mathrm{~h}$ de incubação.

Esses dados são muito interessantes para efeito de comparação, uma vez que, conforme veremos adiante, a proteína estudada neste trabalho (septina 2) necessita de menos de 5 minutos para apresentar agregados com dimensões maiores que $1200 \AA$ em solução a pH próximo ao fisiológico, concentrações não tão altas $(0,5 \mathrm{mg} / \mathrm{mL})$ e temperatura fisiológica ou mais baixa que esta. 


\subsection{Septinas}

As septinas fazem parte de uma família de proteínas de ligação ao nucleotídeo guanina que atuam no ciclo de divisão celular e também são amplamente encontradas em doenças neurodegenerativas tais como mal de Parkinson e Alzheimer e em alguns tipos de câncer (assim como leucemia, linfoma e tumores sólidos)[26].

Em mamíferos, são conhecidos 13 tipos de septinas que apresentam estrutura composta por um domínio central GTPase, um domínio N-terminal e um C-terminal (Figura 1.2] [27], sendo os dois últimos variáveis. A estrutura primária dessas proteínas tem aproximadamente de 40 a 60 kDa e é bem conservada entre diferentes espécies. Para o domínio GTPase central, composto por três motivos de interação com o nucleotídeo guanina, G1, G3 e G4 [27], temos cerca de $35 \%$ de identidade sequencial entre septinas homólogas de levedura e mamíferos. Além disso, no domínio GTPase é encontrada uma sequência denominada de "septin unique element"(SUE) que é composta por 53 aminoácidos e caracteriza as proteínas da família das septinas (Figura 1.2] 28, 29].

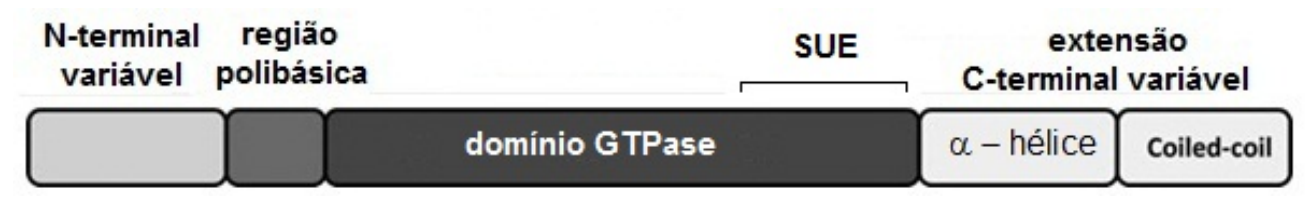

Figura 1.2: Esquema da estrutura das septinas. Figura adaptada da referência [27].

As septinas foram classificadas em quatro grupos de acordo com a similaridade de sequência na sua região C-terminal [30]. Uma representação esquemática dessa classificação pode ser vista na Figura 1.3 . 


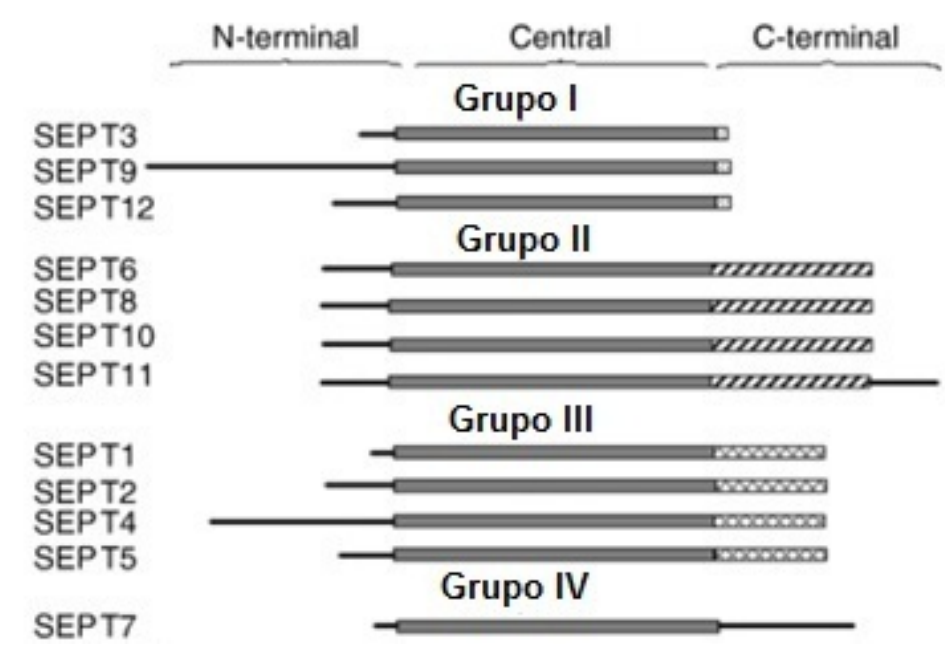

Figura 1.3: Classificação das septinas de mamíferos em grupos, considerando a homologia de suas seqüências primárias. Apesar de não estar representada, a SEPT14 pertence ao Grupo II. A SEPT13 é considerada um pseudogene, ou seja, a sequência tem homologia, mas não é funcional (comunicação pessoal da Profa. Dra. Ana Paula Araújo do IFSC-USP). Figura adaptada da referência [30].

As septinas formam filamentos que têm duas principais funções em células saudáveis [31]: criar uma estrutura temporária para interações entre outras proteínas e seus substratos e compartimentar o citosol e o retículo endoplasmático, servindo de localizador espacial para várias proteínas com funções fundamentais na polarização celular e na progressão do ciclo celular. Podem atuar também na organização de microtúbulos, podendo afetar de maneira crítica a mobilidade celular [32, 33] . Entretanto, o mecanismo dessa interação ainda não é bem compreendido. As septinas SEPT2, SEPT1 e SEPT4 foram encontradas em emaranhados neurofibrilares em cérebro de pacientes com mal de Alzheimer. Em especial, foi observada a associação da SEPT2 com tubulinas neuronais [34]. Na Figura 1.4 temos um fluxograma da atuação das septinas em casos de doenças e em funções celulares e moleculares normais. 


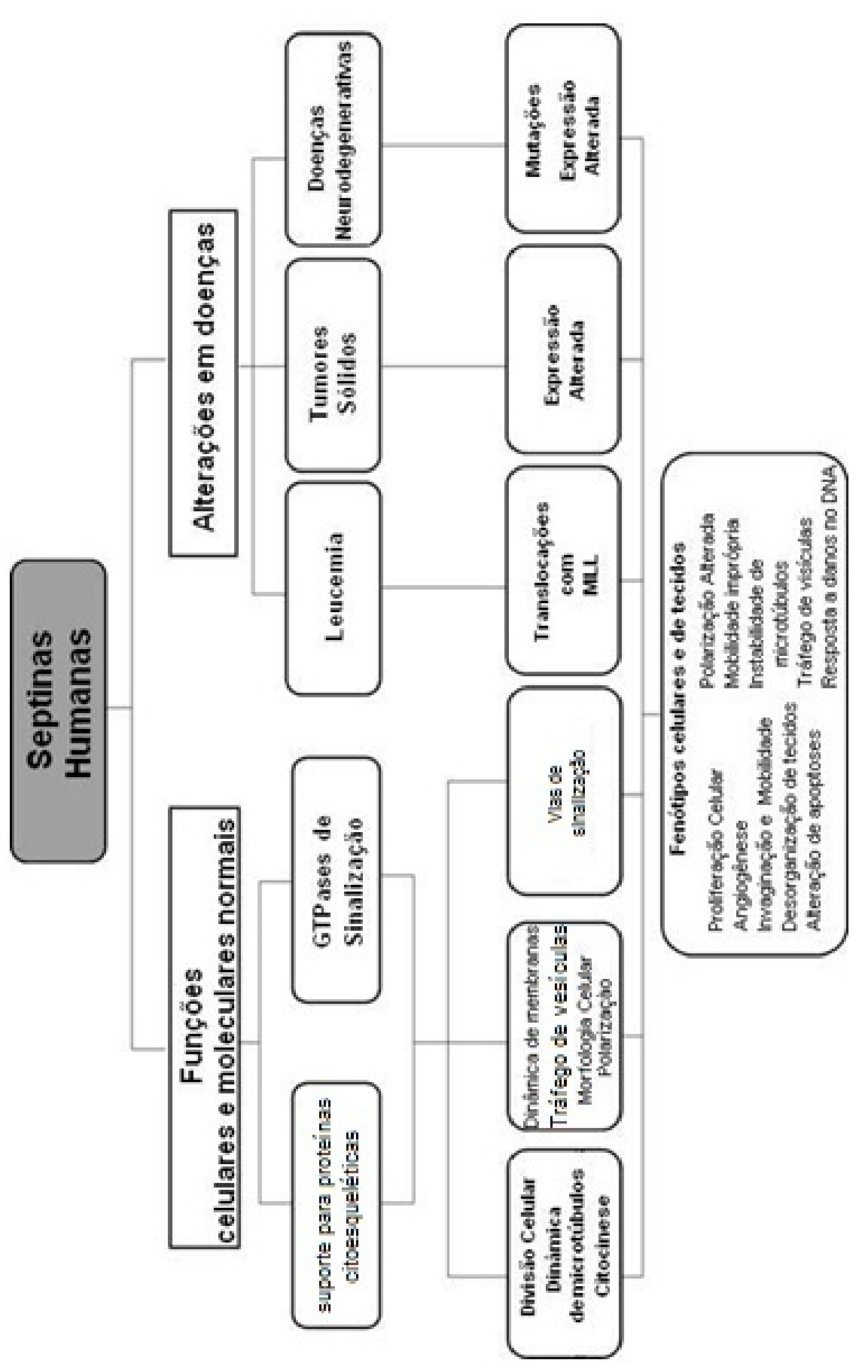

Figura 1.4: Funções das septinas humanas em situações de funcionamento celular e molecular normais e em casos de doenças e seu envolvimento em fenótipos celulares e tecidual. Figura extraída da referência [35]. 
Recentemente, Sirajuddin e colaboradores [26] publicaram a estrutura cristalográfica da SEPT2, de seu domínio GTPase (SEPT2G) e do complexo SEPT2-SEPT6-SEPT7. Na Figura 1.5 podemos ver as duas possíveis interfaces de formação do dímero da SEPT2. O primeiro tipo de interface ocorre ao longo do sítio de ligação de nucleotídeo e é chamado de dímero-G, enquanto o chamado dímero- $\mathrm{NC}$ é mediado pelas $\alpha$-hélices dos terminais $\mathrm{N}$ e C.

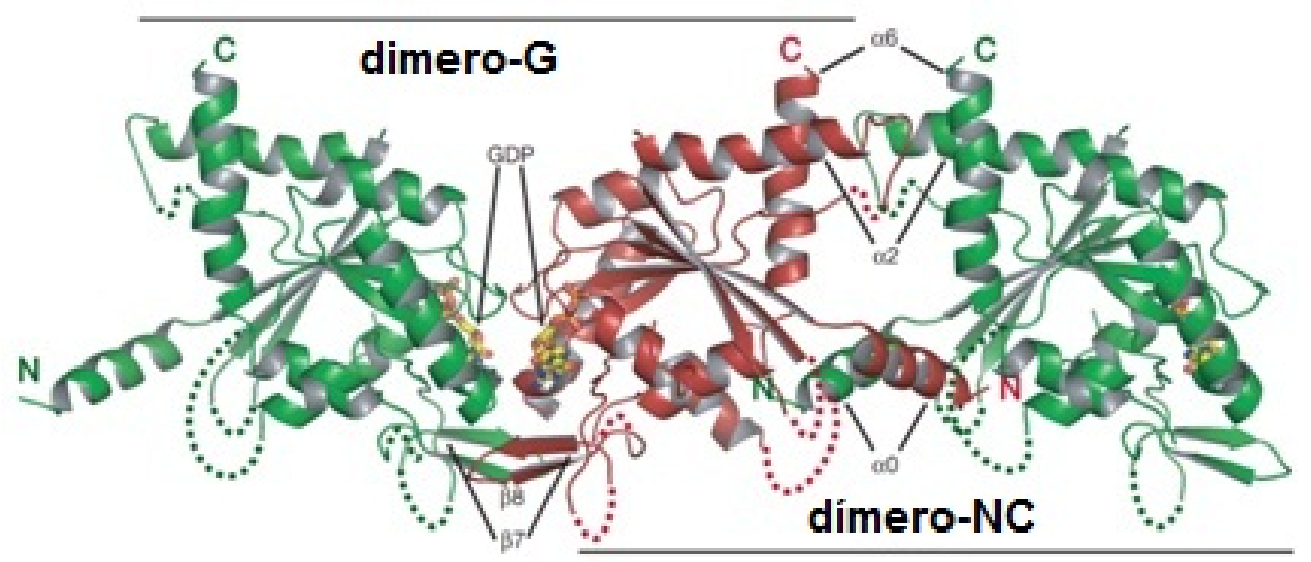

Figura 1.5: Representação de três monômeros da SEPT2, com as interfaces dímero-G e dímero-NC indicadas. As linhas tracejadas representam regiões desordenadas. Figura extraída da referência [26].

A estrutura encontrada para o complexo SEPT2-SEPT6-SEPT7 pode ser vista na Figura 1.6 e tem aproximadamente $5 \mathrm{~nm}$ de largura e $25 \mathrm{~nm}$ de comprimento (hexâmero). As setas na representação do complexo indicam a orientação dos C-terminais.

As regiões de interface são as mesmas observadas para a SEPT2 no cristal. Resultados de microscopia eletrônica indicaram que o filamento no cristal apresenta a mesma estrutura encontrada em solução com alta concentração de sal (sendo descrita pelos autores como uma solução de 20 mM HEPES pH 8.0, $800 \mathrm{mM} \mathrm{NaCl,} 5 \mathrm{mM} \mathrm{MgCl} 210 \mathrm{mM}$ ditiotreitol). No caso de baixas concentrações de sal, há apenas a formação de filamentos e anéis de várias dimensões, sem um padrão bem definido [26]. 


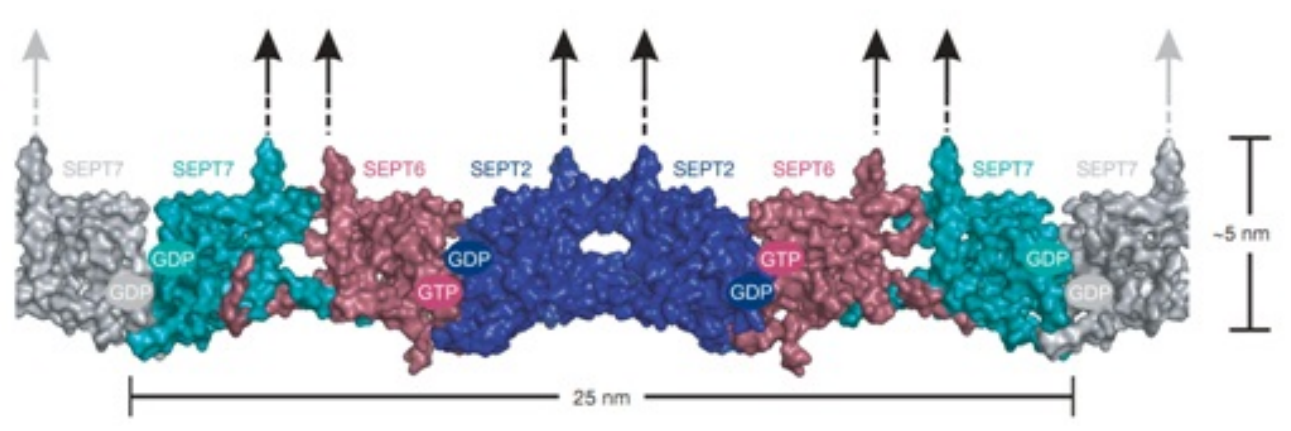

Figura 1.6: Representação de superfície do complexo SEPT2-SEPT6-SEPT7. Figura extraída da referência [26].

Análises anteriores realizadas pelo grupo da Profa. Dra. Ana Paula Araújo (IFSC-USP), utilizando a técnica de espectroscopia de fluorescência extrínseca com um marcador conhecido para fibras amilóides chamado Tioflavina-T (ThT), demonstraram que, a temperaturas maiores que $25^{\circ} \mathrm{C}$ e concentração de cerca de $0,44 \mathrm{mg} / \mathrm{mL}$, as estruturas formadas pela SEPT2 inteira e apenas seus domínios tratavam-se de fibras amilóides [36, 37], sendo que a SEPT2 começa a associar-se como oligômeros a $4^{\circ} \mathrm{C}$ após 48 horas de incubação.

Além disso, o mesmo grupo realizou estudos para determinar o espalhamento de luz a ângulos fixos para a SEPT2G, SEPT2GC e SEPT2 (Figura 1.2). Para a SEPT2G, a uma concentração de aproximadamente $0,34 \mathrm{mg} / \mathrm{mL}$, os resultados indicaram um espalhamento constante entre 15 e $30^{\circ} \mathrm{C}$ e um aumento da intensidade de espalhamento para temperaturas até $60^{\circ} \mathrm{C}$, ambos os casos considerando um intervalo de tempo de cerca de 5500s (90 minutos). Para a SEPT2 e SEPT2GC, a uma concentração de aproximadamente $0,44 \mathrm{mg} / \mathrm{mL}$, foi possível observar um aumento da intensidade de fluorescência para temperaturas acima de $15^{\circ} \mathrm{C}$, indicando, em todos os casos, um aumento de tamanho do agregado ao longo do tempo. A proteína e seus domínios, com concentrações da ordem de $0,2 \mathrm{mg} / \mathrm{mL}$, foram analisadas nas mesmas condições descritas anteriormente e, com isso, verificou-se que a concentração influencia no processo de agregação. No caso da SEPT2G a uma concentração igual a 0,2 $\mathrm{mg} / \mathrm{mL}$ só foi possível observar agregados a partir de $30^{\circ} \mathrm{C}$. Para a SEPT2 nessa mesma concentração, ainda é possível observar agregados a $15^{\circ} \mathrm{C}$, mas apenas após cerca de $1500 \mathrm{~s}$ (60 minutos) de medida. Entretanto, com as técnicas utilizadas até então não foi possível determinar o tamanho dos agregados nos estágios iniciais. 
Com o intuito de explorarmos os estágios iniciais e a formação de oligômeros das septinas, nosso grupo realizou estudos preliminares utilizando uma das linhas de SAXS do ESRF (Grenoble, França) da SEPT2 a $1,5 \mathrm{mg} / \mathrm{mL}$. Os resultados indicaram que, mesmo a $4^{\circ} \mathrm{C}$, a proteína se encontrava bastante agregada, evidenciando que a cinética de agregação da proteína é concentração-dependente. Nossos estudos preliminares revelaram também uma grande auto-associação em função da temperatura, uma vez que a $38^{\circ} \mathrm{C}$ a proteína já se encontrava completamente agregada.

Em função destes resultados, decidimos explorar os possíveis estágios intermediários de agregação por SAXS utilizando apenas o domínio GTPase, que apresenta uma evolução temporal um pouco mais lenta que a proteína inteira (comunicação pessoal da Profa. Dra. Ana Paula Araújo), e é objeto desta dissertação.

\subsection{Objetivos}

\section{Geral:}

Investigar de maneira comparativa a evolução temporal dos possíveis estágios de agregação da SEPT2G a concentração de $0,5 \mathrm{mg} / \mathrm{mL}$ e $1,0 \mathrm{mg} / \mathrm{mL}$ por SAXS em função da temperatura.

\section{Específicos:}

- Investigar por SAXS a evolução temporal da SEPT2G com concentração igual a 0,5 $\mathrm{mg} / \mathrm{mL}$ a $\mathrm{T}=4,15,25,37$ e $45^{\circ} \mathrm{C}$;

- Investigar por SAXS a evolução temporal da SEPT2G com concentração igual a 1 $\mathrm{mg} / \mathrm{mL}$ a $\mathrm{T}=4,15,25,37$ e $45^{\circ} \mathrm{C}$;

- Correlacionar os resultados com os processos de agregação que levam a formação de fibras amilóides. 


\subsection{Estrutura da dissertação}

No Capítulo 1, apresentamos a definição, assim como uma breve discussão da importância da investigação de proteínas amilóides. Destacamos, ainda, as proteínas amilóides estudadas por espalhamento de raios-x, principal técnica utilizada nesse trabalho. Em seguida, focamos em um grupo específico de proteínas, as septinas, uma vez que a SEPT2G será o objeto de estudo desta dissertação. Encontram-se também nesse capítulo os objetivos e motivações do trabalho.

No Capítulo 2, estão descritas as amostras e arranjos experimentais utilizados. Apresentamos também a teoria de espalhamento de raio-x a baixos ângulos (SAXS) e de luz (DLS), conforme foram necessárias para o desenvolvimento da metodologia de análise.

No Capítulo 3, serão mostradas as curvas de SAXS e suas análises modelo-independentes e os resultados de DLS. No que diz respeito às curvas de SAXS, apresentamos os resultados da análise da região de Guinier, onde obtivemos informações da massa molecular e raio de giro. Além disso mostramos também a evolução da função distribuição de distâncias $p(r)$ com o tempo.

No Capítulo 4, fazemos uma análise quantitativa das populações presentes em solução. Os modelos utilizados foram escolhidos com base nos resultados da análise modelo-independente. Primeiramente mostramos um exemplo de como procedemos com essa análise e em seguida separamos as análises e discussões em dois grupos, levando em consideração a concentração das amostras.

Por fim, no Capítulo 5 resumimos as conclusões do trabalho apresentado nessa dissertação. 


\section{Capítulo 2}

\section{Materiais e Métodos}

\subsection{Amostras de Septinas}

Nesse trabalho investigamos o domínio GTPase da septina 2 (SEPT2G) em tampão Tris 25mM, Glicerol $10 \%$ a pH 7,8. A expressão e a purificação da proteína foi feita pelo Dr. Julio Cesar Pissuti Damalio sob orientação da Prof. ${ }^{a}$ Ana Paula U. Araujo (IFSC-USP). Para evitar efeitos de agregação, as amostras $(0,5$ e $1 \mathrm{mg} / \mathrm{mL})$ foram preparadas na mesma semana em que foram realizadas as aquisições de dados. Várias alíquotas acondicionadas em tubos eppendorf foram mantidas congeladas em nitrogênio líquido em um "dewar".

\subsection{Espalhamento de Raios-X a Baixos Ângulos}

\subsubsection{SAXS no Laboratório Nacional de Luz Sincroton (LNLS)}

O conjunto de resultados apresentado foi obtido utilizando a linha de SAXS1 do Laboratório Nacional de Luz Síncroton (LNLS). As amostras eram compostas pelo domínio GTPase da septina 2 (SEPT 2G), com concentração de 0,5 e $1 \mathrm{mg} / \mathrm{mL}$, a temperaturas de $4,15,25,37$ e $45^{\circ} \mathrm{C}$.

Para cada temperatura citada anteriormente, investigamos o comportamento da SEPT2G em ambas concentrações com o passar do tempo até $\mathrm{t}=2100$ s (35 minutos). Para tanto, para cada concentração e temperatura, um eppendorf era retirado do nitrogênio líquido e a amostra era deixada descongelar lentamente em um banho de gelo $\left(T \approx 4^{\circ} \mathrm{C}\right)$, antes de ser 
colocada no porta-amostra. A temperatura do porta-amostra foi controlada por um sistema de aquecimento/resfriamento por banho térmico. Cada amostra era deixada à temperatura desejada por cerca de cinco minutos antes do início da medida experimental.

Cada uma das curvas experimentais com concentração igual a $0,5 \mathrm{mg} / \mathrm{mL}$ é o resultado de uma única tomada de dados com tempo de aquisição de 180 segundos. Para a medida experimental seguinte na mesma temperatura e concentração, houve uma espera de 120 segundos (2 minutos) para evitar efeitos da radiação na amostra. De maneira similar, para as amostras com uma concentração de $1 \mathrm{mg} / \mathrm{mL}$ os tempos de medida e de espera foram de 60 e 240 segundos, respectivamente. As curvas foram corrigidas pelo espalhamento do tampão utilizado, levando-se em conta a absorção da amostra e do tampão e o decréscimo da intensidade do feixe de Raios-X ao longo da medida.

Na Figura 2.1. podemos observar um esquema da linha de SAXS, que é composta por um monocromador do feixe de raios-X $(\lambda=1,55 \AA)$, um sistema de colimação, porta amostra acoplado a um banho térmico e um detector bidimensional Pilatus (marca Dectris).

Sendo $2 \theta$ o ângulo formado entre a amostra e o detector, como indicado na Figura 2.1 , o módulo do vetor de espalhamento $q$ é dado por:

$$
q=\frac{4 \pi}{\lambda} \operatorname{sen} \theta
$$

A distância entre a amostra e o detector neste arranjo foi de $160,7 \mathrm{~cm}$, resultando em um intervalo de $0,00519 \leq q \leq 0,2541 \AA^{-1}$.

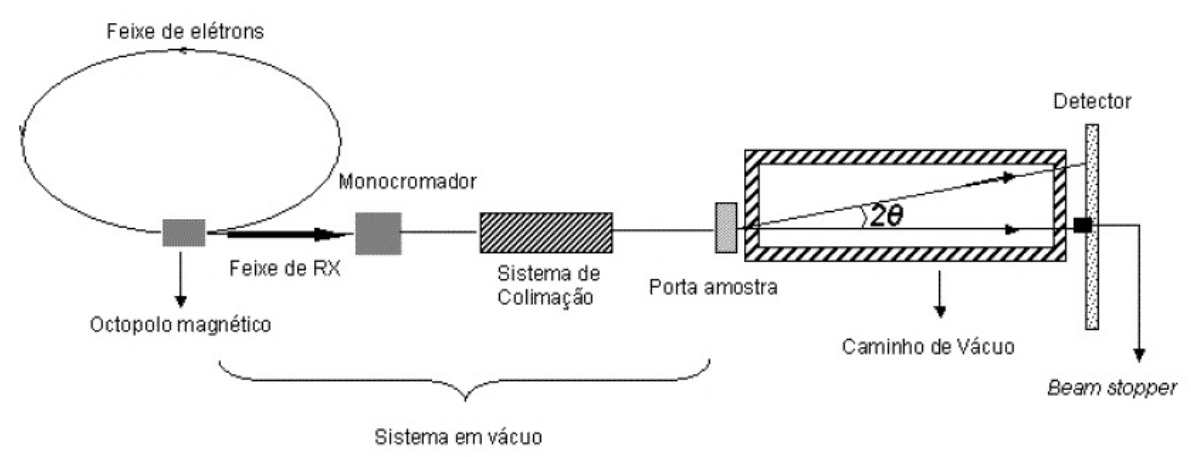

Figura 2.1: Representação esquemática da linha de SAXS do LNLS. Figura extraída da referência [38].

A dimensão máxima medida pela técnica é então dada por [39]: 


$$
D_{\operatorname{máx}}=\frac{2 \pi}{q_{\min }}
$$

Da mesma maneira, a dimensão mínima é dada por:

$$
D_{\min }=\frac{2 \pi}{q_{\operatorname{máx}}}
$$

A partir das Eqs. 2.2 e 2.3 temos que as dimensões observadas com este arranjo experimental estão no intervalo de $25 \AA \lesssim D_{L N L S} \lesssim 1210 \AA$.

\subsubsection{Teoria}

Considerando um sistema de partículas não interagentes, podemos escrever a intensidade de espalhamento como sendo proporcional à forma da partícula espalhadora $P(q)$ tal que [39, 40],

$$
I(q)=K n_{p} P(q)
$$

onde $K$ é uma constante experimental relacionada ao arranjo experimental utilizado e $n_{p}$ é a densidade numérica das partículas. As curvas experimentais serão analisadas em escala absoluta, tal que $K=1$.

É bem conhecido que a função de forma $P(q)$, e assim, $I(q)$, para sistemas esfericamente simétricos, pode ser aproximada por uma função exponencial para $q \rightarrow 0$, tal que [41]:

$$
I(q \rightarrow 0)=I(0) e^{-\frac{q^{2} R_{g}^{2}}{3}}
$$

onde $I(0)$ é a intensidade de espalhamento em $q=0$ e $R_{g}$ é o raio de giro da partícula espalhadora, conhecida como Lei de Guinier.

Fazendo um ajuste linear do gráfico de $\ln (I) \times q^{2}$ (gráfico de Guinier [41]) podemos obter $I(0)$ e $R_{g}$ tal que:

$$
\begin{gathered}
I(0)=e^{A} \\
R_{g}=\sqrt{3 B}
\end{gathered}
$$

Lembrando que $A$ e $B$ são os coeficientes do ajuste $y=A-B q^{2}$. 
A aproximação de Guinier vale para a condição que [42, 43]

$$
q R_{g} \leq 1,3
$$

onde $q$ é o último vetor de espalhamento utilizado no ajuste aos pontos experimentais.

\subsubsection{Determinação da massa molecular}

Sabendo-se que a massa molecular, MM, pode ser definida a partir dos dados de espalhamento por [44]:

$$
M M=\frac{I(0)_{a b s}}{c} \frac{N_{A}}{\Delta \rho^{2} r_{e}^{2} v_{e s p}^{2}}
$$

onde $I(0)_{a b s}$ é a intensidade em escala absoluta, $c$ a concentração da proteína, $N_{A}$ o número de Avogadro, $\Delta \rho$ o contraste de densidade eletrônica entre a proteína e o solvente, $r_{e}=0,28 \times 10^{-12} \mathrm{~cm}$ o raio do elétron e $v_{e s p}$ o volume específico da proteína.

Portanto, percebemos diretamente da Eq. 2.9 que a massa molecular é diretamente proporcional ao valor de $I(0)$. Assim, podemos observar a formação de agregados proteicos pelas variações no valor de $I(0)$ em diferentes condições experimentais.

Para o cálculo da massa molecular utilizando a Eq. 2.9, consideramos em primeira aproximação a septina como uma proteína globular densa. Assim sendo, o valor do volume específico da proteína utilizado foi $v_{e s p}=0,72 \frac{\mathrm{cm}^{3}}{\mathrm{~g}}$ [44]. O contraste de densidade eletrônica entre a proteína e a água é escrito como sendo $\Delta \rho=\rho_{\text {proteina }}-\rho_{0}$, onde a densidade eletrônica da água é dada por $\rho_{0}=0,334 \frac{e}{\AA^{3}}$ [44] e a da proteína $\rho_{\text {proteina }}=0,4235 \frac{e}{\AA^{3}}$ [45], utilizando novamente a aproximação de proteína globular.

Uma vez que as medidas experimentais não foram feitas diretamente em escala absoluta, usamos um padrão para efetuar a conversão. Assim sendo, para obter as intensidades em escala absoluta consideramos:

$$
I(q)_{a b s}=\frac{I(q)_{u \cdot a .}}{k}
$$

onde $I(q)_{u . a .}$ é a intensidade medida em unidades arbitrárias e $k$ é o fator experimental dado por:

$$
k=\frac{I(0)_{\mathrm{H}_{2} \mathrm{O}}}{I(0)_{s t}}
$$


onde $I(0)_{s t}$ é um valor padrão tabelado para a água [44] $\operatorname{com} I(0)_{s t}=0,01632 \mathrm{~cm}^{-1} \mathrm{e}$ $I(0)_{\mathrm{H}_{2} \mathrm{O}}$ é a intensidade medida experimentalmente da água avaliada em $q \rightarrow 0$, nas mesmas condições que as amostras de septina.

No nosso caso, para obtermos $I(0)_{\mathrm{H}_{2} \mathrm{O}}$, foi feito um ajuste linear da intensidade experimental do espalhamento da água normalizada pelo tempo de aquisição (100s), como mostrado na Figura 2.2.

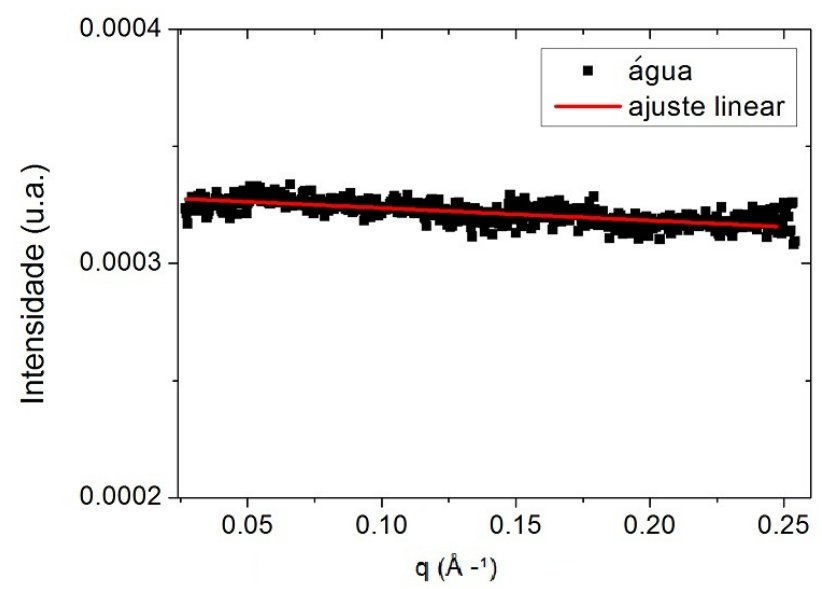

Figura 2.2: Curva de SAXS da água.

Assim sendo, o valor da intensidade experimental da água em $q \rightarrow 0$ obtido foi $I(0)_{H_{2} O}=$ 3, 298(4) $\times 10^{-4}$ u.a.. Utilizando a Eq. 2.11, temos:

$$
k=0,02021(3) \frac{u \cdot a .}{c m^{-1}}
$$

Os valores em parênteses representam as incertezas associadas às medidas experimentais. Tal notação será utilizada ao longo dessa dissertação. 


\subsubsection{Porod}

No caso de partículas muito grandes, ou agregados muito grandes, cuja $D_{\text {máx }}$ ultrapasse o limite de detecção da técnica, podemos observar, às vezes, apenas um comportamento do tipo $I(q) \propto q^{-4}$ na região de $q$ analisada, indicando que a partícula espalhadora tem interfaces bem definidas em relação ao solvente.

A intensidade espalhada está diretamente correlacionada com o contraste de densidade eletrônica $(\Delta \rho)$ e a razão entre a superfície $(S)$ e o volume $(V)$ da partícula espalhadora. Sendo assim, a função que descreve a intensidade na região de $q$ estudada é dada por [39]:

$$
I_{\text {porod }}(q)=\frac{2 \pi(\Delta \rho)^{2}}{q^{4}} \frac{S}{V}
$$

\subsubsection{Função distribuição de distâncias}

A função $p(r)$ corresponde à distribuição de distâncias entre elementos espalhadores dentro de uma partícula. Essa função de distribuição de distâncias pode ser obtida calculando-se a transformada inversa da intensidade de espalhamento dada por [39]

$$
p(r)=\frac{1}{2 \pi^{2}} \int_{0}^{\infty} I(q) q r \operatorname{sen}(q r) \mathrm{d} q
$$

A Figura 2.3 mostra padrões de espalhamento típicos e funções distribuição de distâncias correspondentes para corpos geométricos de mesma dimensão máxima. Partículas globulares (curva vermelha), apresentam uma função $p(r)$ no formato de um sino com um máximo de frequências de distâncias internas à partícula em $D_{\text {máx }} / 2$. Partículas alongadas tem distribuições com máximo correspondente ao raio da secção transversal (curva verde). Partículas achatadas apresentam uma função $p(r)$ com um máximo mais alargado (curva amarela), também deslocada para distâncias menores que $D_{m a ́ x} / 2$. Uma função $p(r)$ com máximo deslocado para distâncias maiores que $D_{m a ́ x} / 2$ é geralmente um indicativo de uma partícula oca (curva azul). Partículas que são compostas por unidades bem separadas apresentam mais de um ponto de máximo na função $p(r)$, sendo o primeiro correspondente às distâncias entre elementos na mesma subunidade e o seguinte indica a separação entre as subunidades (curva rosa) [42].

As funções $p(r)$ mostradas aqui foram obtidas utilizando o programa GNOM, desenvolvido por Svergun e colaboradores [46]. 

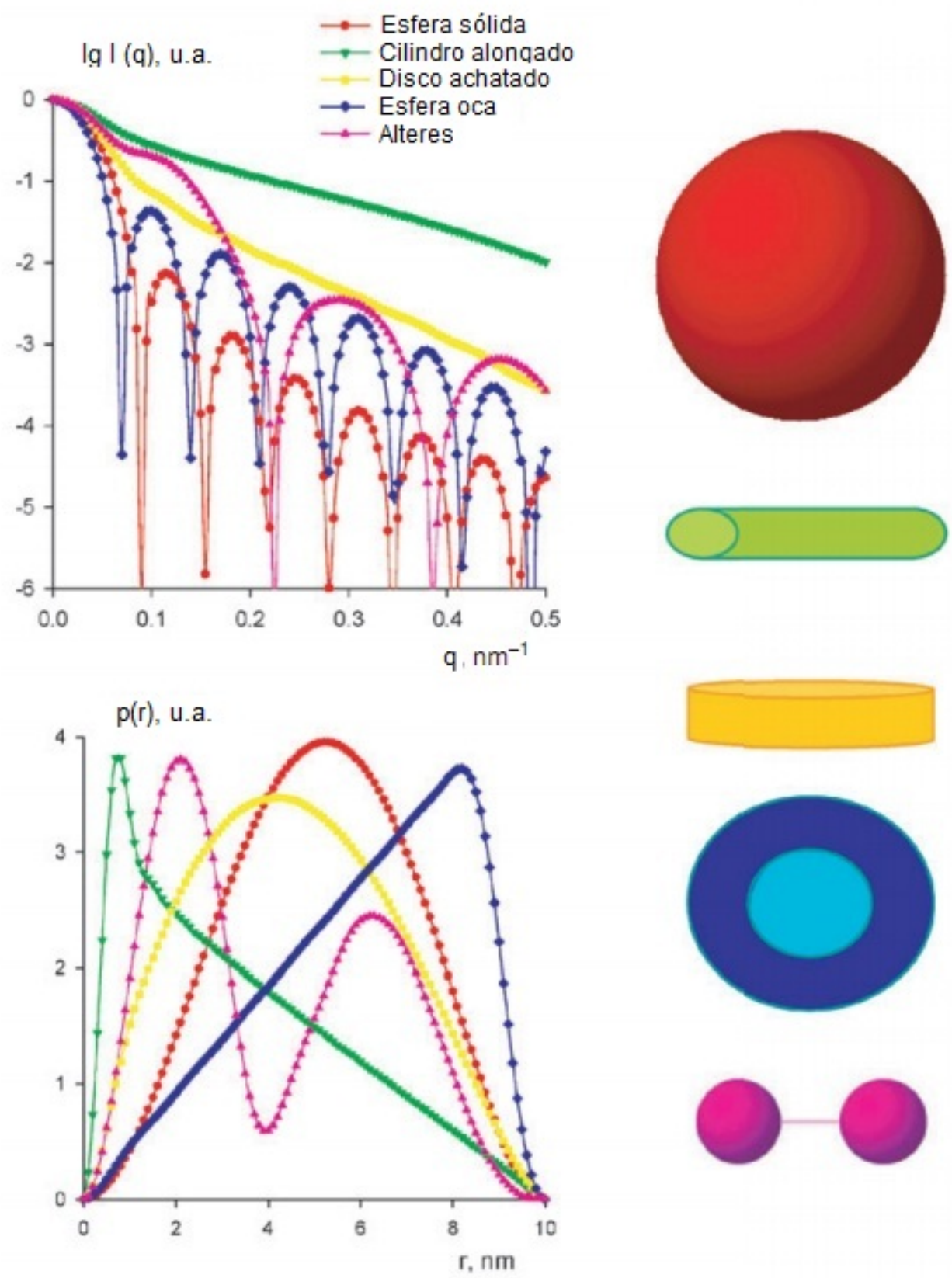

Figura 2.3: Intensidades de espalhamento e funções distribuição de distâncias $p(r)$ de diferentes corpos geométricos. Figura extraída da referência [42]. 


\subsubsection{Modelos para análise das curvas de SAXS}

As curvas experimentais foram ajustadas pelo programa GENFIT [47] utilizando-se a combinação linear de três modelos: proteína dimérica, cilindro (representando os oligômeros) e Porod (representando os agregados com dimensão maior que o limite de detecção da técnica experimental). Vale a pena ressaltar que, consideramos inicialmente um modelo de monômero, mas os ajustes às curvas experimentais não foram satisfatórios.

Para o dímero temos que a intensidade é dada por:

$$
I_{\text {dímero }}(q)=n_{\text {dímero }} P_{\text {dímero }}(q)
$$

onde o fator de forma $P(q)$ é calculado pelo programa a partir da estrutura cristalográfica da proteína (ver abaixo) e a densidade numérica de dímeros $n_{\text {dímero }}$ é escrita como:

$$
n_{\text {dimero }}=x_{\text {dimero }} 6,022 \times 10^{-4} \frac{c}{2 w_{\text {molec }}}
$$

onde $x_{\text {dímero }}$ é a fração numérica de dímeros (parâmetro de ajuste), $c$ é a concentração em $g / L$ de proteína, $w_{\text {molec }}=34 k D a$ a massa molecular do monômero da SEPT2G com a cauda de histidina (ver abaixo) e $6,022 \times 10^{-4}$ é o fator de conversão de $\mathrm{mol} / L$ para partículas $/ \AA^{3}$.

Na Figura 2.4 vemos a sequência primária da SEPT2G de nossas amostras[37]. Os primeiros 20 aminoácidos marcados em verde referem-se à cauda de histidina. Assim, a SEPT2G somada a cauda de histidina é composta por 294 aminoácidos e tem massa molecular igual a $34 \mathrm{kDa}$ (valor fornecido pelo Dr. Julio C. P. Damalio) [37. 


MGSSHHHHHHSS GLVPRGSH---------------GFEFTLMVVGESGLG
KSTLINS LFLTDLYPERVIPGAAEKIERTVQIEASTVEIEERGVKLRLTV
VDTPGYGDAINCRDCFKTI ISYIDEQFERYLHDESGLNRRH I IDNRVHCC
FYFISPFGHGLKPLDVAFMKA IHNKVNIVPVIAKADTLTLKERERLKKRI
LDEIEEHNIKIYHLPDAESDE DEDFKEQTRLLKASI PFSVVGSNQLIEAK
GKKVRGRLYPWGVVEVENPEHNDFLKLRTMLITHMQDLQEVTQDLHYENF
RSERLKRGG

Figura 2.4: Sequência primária das amostras de SEPT2G utilizadas. Os 20 primeiros aminoácidos marcados em verde representam a cauda de histidina ligada a cada monômero da proteína (sequência fornecida pelo grupo da Profa. Ana Paula Araújo).

\begin{tabular}{|r|}
\hline FANLPNQVHRKSVKKGFEFTLMVVGESGLG \\
KSTLINSLFLTDLYPERVIPGAAEKIER-------------VKLRLTV \\
VDTPGYGDAINCRDCFKTIISYIDEQFERYLHDESG-NRRH I IDNRVHCC \\
FYFISPFGHGLKPLDVAFMK-IHNKVNIVPVIAKADTLTLKERERLKKRI \\
LDEIEEHNIKIYHLPDAESDEDEDFKEQTRLLKASI PFSVVGSNLIEAK \\
GKKVRGRLYPWGVVEVENPEHNDFLKLRTMLITHMQDLQEVTQDLHYENF \\
RSERLK--- \\
\hline
\end{tabular}

Figura 2.5: Sequência primária referente ao arquivo pdb da SEPT2G (código 2QA5). A sequência inicia-se deslocada para uma melhor comparação com a sequência da Figura 2.4 . O símbolo - representa aminoácidos que estão faltando nesta sequência primária.

Entretanto, a definição do domínio GTPase utilizada pelo grupo da Prof. Ana Paula Araújo (Figura 2.4) é diferente da definição do Sirajuddin e colaboradores [26], responsáveis pelo arquivo depositado no Protein Data Bank (arquivo pdb) da SEPT2, código 2QA5 (Figura 2.5). Para que a sequência primária da estrutura cristalográfica utilizada nas simulações fosse a mais próxima possível da sequência primária das amostras utilizadas nesse trabalho, selecionamos apenas a região do arquivo pdb que corresponde à sequência mostrada na Figura 2.4. Verificamos ainda que na estrutura pdb (Figura 2.5 faltam os aminoácidos de 59 a 73, 136, 151 e 287 a 289, além dos 20 aminoácidos correspondentes a cauda de histidina ligada a cada monômero. Tendo em vista tais diferenças, para o cálculo do fator de forma da proteína no programa GENFIT, utilizamos a sequência primária da SEPT2G 
(2QA5) subtraíndo-se os 15 primeiros aminoácidos (ressaltados em vermelho na Figura 2.5), resultando em um total de 254 aminoácidos. A correspondente estrutura cristalográfica da forma dimérica está representada na Figura 2.6.

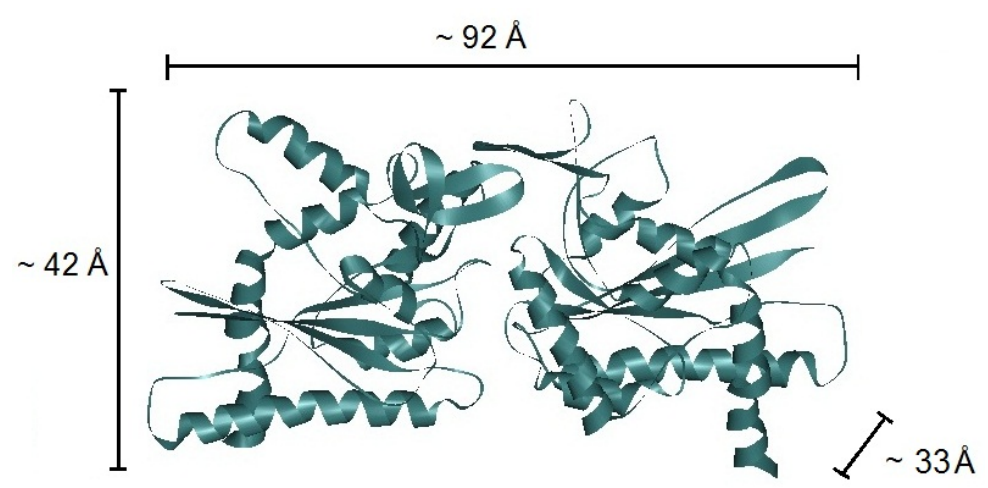

Figura 2.6: Estrutura cristalográfica da SEPT2G adaptada do arquivo pdb 2QA5 (ver Figura 2.5], sem os 15 primeiros aminoácidos.

Ao calcularmos o volume da SEPT2G medida experimentalmente a partir da soma dos volumes individuais de cada aminoácido da sua sequência primária (Figura 2.4), considerando também as caudas de histidina (total de 294 aminoácidos), temos um volume igual a $40625 \AA^{3}$. Enquanto isso, o volume calculado da mesma maneira para a estrutura adaptada do arquivo pdb 2QA5 (Figura 2.5) é de $36824 \AA^{3}$, ou seja, o volume calculado a partir do arquivo pdb é $10 \%$ menor que o calculado a partir da sequência primária da proteína purificada, devido a falta de 40 aminoácidos. Para compensar tal diferença no envelope da proteína, utilizamos um parâmetro de ajuste $\gamma$ que aumenta o volume calculado da estrutura pdb por este fator $\gamma$ durante o procedimento do ajuste do modelo em relação aos dados experimentais pelo GENFIT. Como veremos a seguir, o melhor valor encontrado para esse parâmetro foi $\gamma=1,09$, indicando um aumento de $9 \%$ no volume, resultado que se encontra de acordo com as considerações feitas.

Outro parâmetro utilizado nos ajustes foi a densidade eletrônica da camada de hidratação da proteína, cuja espessura foi fixada em $3 \AA$. Na realidade, o parâmetro de ajuste, denominado $d_{c o r}$, corresponde a uma porcentagem relativa de aumento de densidade eletrônica da camada de hidratação em relação à densidade eletrônica do solvente.

Na Figura 2.7 vemos a curva de SAXS simulada pelo GENFIT a partir do dímero da SEPT2G (Figura 2.6), considerando as adaptações descritas anteriormente $(\gamma=1,09$ ). 
Em detalhe temos a função $p(r)$ calculada com o programa GNOM utilizando essa mesma curva. O raio de giro de Guinier obtido a partir dessa curva de espalhamento, calculado como descrito na Secção 2.2 .2 é de $R_{g}=28,6 \AA$.

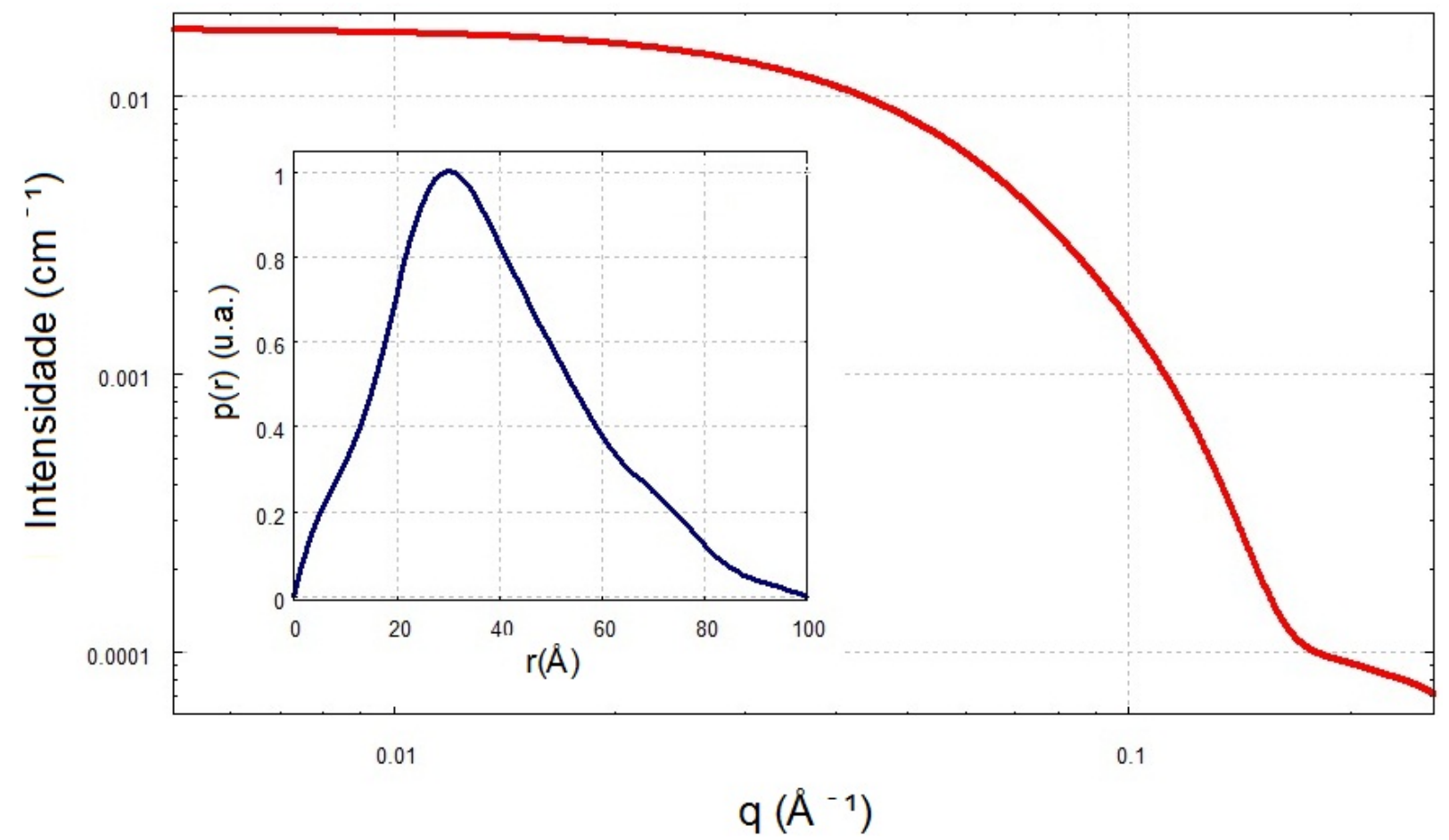

Figura 2.7: Curva de SAXS simulada a partir da estrutura cristalográfica do dímero (Figura 2.6). Em detalhe, vemos a função $p(r)$ referente a essa curva simulada. 
A intensidade espalhada referente aos cilindros é descrita pela equação abaixo [41, 48]:

$$
I_{\text {cilindro }}(q)=n_{\text {cilindro }}\left(2 \pi R^{2} L \Delta \rho_{\text {cilindro }}\right)^{2} \int_{0}^{1}\left(\frac{J_{1}\left(q R \sqrt{1-x^{2}}\right) \operatorname{sen}(q L x / 2)}{q^{2} R \sqrt{1-x^{2}} L x / 2}\right)^{2} \mathrm{~d} x
$$

Onde $R$ é o raio do cilindro, $L$ o comprimento e $\Delta \rho_{\text {cilindro }}$ o contraste de densidade eletrônica entre o cilindro e o solvente e $n_{\text {cilindro }}$ a densidade numérica de cilindros. Para vincular a porcentagem de proteína na forma de dímero, cilindro e Porod reescrevemos $n_{\text {cilindro }}$ como:

$$
n_{\text {cilindro }}=x_{\text {cilindro }}\left(1-x_{\text {dimero }}\right) 6,022 \times 10^{-4} \times 0,28^{2} \frac{c}{w_{\text {molec }} N_{\text {agreg }}}
$$

onde $x_{\text {cilindro }}\left(1-x_{\text {dímero }}\right)$ é a fração numérica de proteínas agregadas formando um envelope cilíndrico e $N_{\text {agreg }}$ representa o número de monômeros de proteína que compõem o cilindro. Sendo o raio do elétron dado por $r_{e}=0,28 \times 10^{-12} \mathrm{~cm}$, o fator 0,28 encontrado na expressão é o valor de conversão da densidade eletrônica proporcional à $\frac{10^{-12} \mathrm{~cm}}{\AA^{3}}$, que é a unidade utilizada no código do programa GENFIT, para a unidade de entrada de $\Delta \rho$ em $\frac{e}{\AA^{3}}$ [25]. Uma vez que a densidade eletrônica encontra-se elevada ao quadrado, o fator de conversão também leva a mesma potência.

Para o modelo de Porod a função que descreve a intensidade de espalhamento é dada por:

$$
I_{\text {porod }}=\left(1-x_{\text {cilindro }}\right)\left(1-x_{\text {dimero }}\right) 6,022 \times 10^{-4} \times 0,28^{2} \frac{c}{w_{\text {molec }}} V_{\text {monômero }}\left(\Delta \rho_{\text {Porod }}\right)^{2} \sigma
$$

onde $\left(1-x_{\text {cilindro }}\right)\left(1-x_{\text {dímero }}\right)$ é a fração numérica de proteínas no agregado tipo Porod, $\Delta \rho_{\text {Porod }}$ é o contraste de densidade eletrônica entre o agregado tipo Porod e o solvente e $\sigma=S / V$, sendo $S$ a superfície e $V$ o volume do agregado tipo Porod. 
Na Tabela 2.1 estão listados, separados pelo modelo, os parâmetros obtidos a partir do ajuste experimental das curvas. As constantes inseridas no programa são mostradas na Tabela 2.2 e por fim a Tabela 2.3 mostra os parâmetros calculados a partir dos dois grupos anteriores.

Tabela 2.1: Parâmetros calculados a partir dos ajustes das curvas de espalhamento.

\begin{tabular}{c|c|c}
\hline dímero & cilindro & porod \\
\hline$x_{\text {dimero }}, d_{\text {cor }}, \gamma$ & $x_{\text {cilindro }}, \mathrm{R}, \rho_{\text {cilindro }}, \mathrm{L}$ & $\rho_{\text {porod }}, \sigma$ \\
\hline
\end{tabular}

Tabela 2.2: Constantes inseridas no programa.

\begin{tabular}{c|c}
\hline$\rho_{0}=0,334 \frac{e}{\AA^{3}}$ & $c=0.5$ ou $c=1 \mathrm{mg} / \mathrm{mL}$ \\
\hline$w_{\text {molec }}=34 k D a$ & $V_{\text {monomero }}=40625 \AA^{3}$ \\
\hline
\end{tabular}

Tabela 2.3: Parâmetros calculados a partir das constantes e dos parâmetros ajustados pelo GENFIT.

\begin{tabular}{c|c|c}
\hline dímero & cilindro & Porod \\
\hline$\%_{\text {dimero }}$ & $\%_{\text {cilindro }}, \phi, N_{\text {agreg }}, V_{H_{2} O}$ & $\%_{\text {porod }}$ \\
\hline
\end{tabular}

Um fator $\gamma>1$ indica que a proteína estudada por SAXS está expandida com relação à estrutura cristalográfica. Temos ainda que $\phi$ é a fração volume de proteína dentro do envelope cilíndrico, $N_{\text {agreg }}$ o número de monômeros e $V_{\mathrm{H}_{2} \mathrm{O}}$ volume de água nos cilindros. Além disso, segue que:

$$
\begin{array}{r}
\%_{\text {dímero }}=100 \times x_{\text {dímero }} \\
\%_{\text {cilindro }}=100 \times x_{\text {cilindro }}\left(1-x_{\text {dímero }}\right) \\
\%_{\text {porod }}=100 \times\left(1-x_{\text {cilindro }}\right)\left(1-x_{\text {dimero }}\right)
\end{array}
$$

Para calcular as variáveis $\phi, N_{\text {agreg }}$ e $V_{\mathrm{H}_{2} \mathrm{O}}$, partimos das Equações 2.23 e 2.24.

$$
V=\pi R^{2} L=N_{\text {agreg }} V_{\text {monômero }}+V_{\mathrm{H}_{2} \mathrm{O}}
$$




$$
\rho_{\text {cilindro }}=\frac{\rho_{\text {proteina }} N_{\text {agreg }} V_{\text {monômero }}+\rho_{0} V_{\mathrm{H}_{2} \mathrm{O}}}{N_{\text {agreg }} V_{\text {monômero }}+V_{\mathrm{H}_{2} \mathrm{O}}}
$$

Reordenando a Equação 2.23 .

$$
N_{\text {agreg }}=\frac{\pi R^{2} L-V_{\mathrm{H}_{2} \mathrm{O}}}{V_{\text {monômero }}}
$$

e a Equação 2.24

$$
\begin{gathered}
\rho_{\text {cilindro }} N_{\text {agreg }} V_{\text {monômero }}+\rho_{\text {cilindro }} V_{\mathrm{H}_{2} \mathrm{O}}=\rho_{\text {proteina }} N_{\text {agreg }} V_{\text {monômero }}+\rho_{0} V_{\mathrm{H}_{2} \mathrm{O}} \\
V_{\mathrm{H}_{2} \mathrm{O}}=\frac{\rho_{\text {proteina }} N_{\text {agreg }} V_{\text {monômero }}-\rho_{\text {cilindro }} N_{\text {agreg }} V_{\text {monômero }}}{\rho_{\text {cilindro }}-\rho_{0}} \\
V_{\mathrm{H}_{2} \mathrm{O}}=\frac{\left(\rho_{\text {proteina }}-\rho_{\text {cilindro }}\right) N_{\text {agreg }} V_{\text {monômero }}}{\rho_{\text {cilindro }}-\rho_{0}}
\end{gathered}
$$

Sendo $\rho_{\text {proteina }}=0,4235 \frac{e}{\AA^{3}}$ e $\rho_{0}=0,334 \frac{e}{\AA^{3}}$, temos:

$$
V_{\mathrm{H}_{2} \mathrm{O}}=\frac{0,4235-\rho_{\text {cilindro }}}{\rho_{\text {cilindro }}-0,334} N_{\text {agreg }} V_{\text {monômero }}=a N_{\text {agreg }} V_{\text {monômero }}
$$

com

$$
a=\frac{0,4235-\rho_{\text {cilindro }}}{\rho_{\text {cilindro }}-0,334}
$$

Substituindo a Eq. 2.29 na Eq. 2.25.

$$
\begin{gathered}
N_{\text {agreg }}=\frac{\pi R^{2} L}{V_{\text {monômero }}}-a N_{\text {agreg }} \\
N_{\text {agreg }}(1+a)=\frac{\pi R^{2} L}{V_{\text {monômero }}} \\
N_{\text {agreg }}=\frac{\pi R^{2} L}{V_{\text {monômero }}} \frac{1}{1+a}
\end{gathered}
$$

Substituindo a Eq. 2.33 na Eq. 2.29 para achar o volume de água 


$$
V_{\mathrm{H}_{2} \mathrm{O}}=\pi R^{2} L \frac{a}{1+a}
$$

Considerando que o volume de uma molécula de água é dado por $30 \AA^{3}$ [49], o número de moléculas de água dentro do cilindro espalhador é então dado por:

$$
N_{\mathrm{H}_{2} \mathrm{O}}=\frac{V_{\mathrm{H}_{2} \mathrm{O}}}{30}
$$

Sendo a fração volume de proteina no cilindro dada por:

$$
\phi=\frac{N_{\text {agreg }} V_{\text {monômero }}}{N_{\text {agreg }} V_{\text {monômero }}+V_{H_{2} O}}
$$

Ao substituir as Eq. 2.33 e 2.34 na Eq. 2.36, temos a porcentagem de proteína contida no envelope cilíndrico ajustado. 


\subsection{Espalhamento de Luz Dinâmico}

\subsubsection{DLS no Laboratório de Cristalografia do Instituto de Física da USP (LCr)}

As medidas de espalhamento de luz dinâmico (DLS) foram realizadas no Laboratório de Cristalografia do Instituto de Física da USP (LCr). As amostras eram de SEPT2G com concentração de $1 \mathrm{mg} / \mathrm{mL}$ e nas temperaturas de 15,30 e $44^{\circ} \mathrm{C}$. O processo de descongelamento foi o mesmo descrito para as medidas de SAXS.

Assim como o espalhamento de raios-X a baixos ângulos, a técnica de espalhamento de luz dinâmico mede a flutuação da intensidade de luz espalhada por moléculas em solução para obtermos informações sobre as partículas espalhadoras. Entretanto, a resolução da técnica nos permite medir partículas de até poucos micrômetros de comprimento. A partir de medidas sucessivas de intensidade da luz espalhada, é possível analisar a flutuação decorrente do espalhamento da luz, considerando uma aproximação onde as partículas espalhadoras são consideradas esféricas e se movimentam devido ao movimento Browniano.

Utilizou-se o equipamento da Brookhaven Instruments e respectivo programa de aquisição e análise de dados de espalhamento de luz dinâmico. As medidas experimentais foram realizadas a $90^{\circ}$, com tempo de aquisição de aproximadamente 50 segundos. Na Figura 2.8 podemos observar um esquema do equipamento de DLS. 


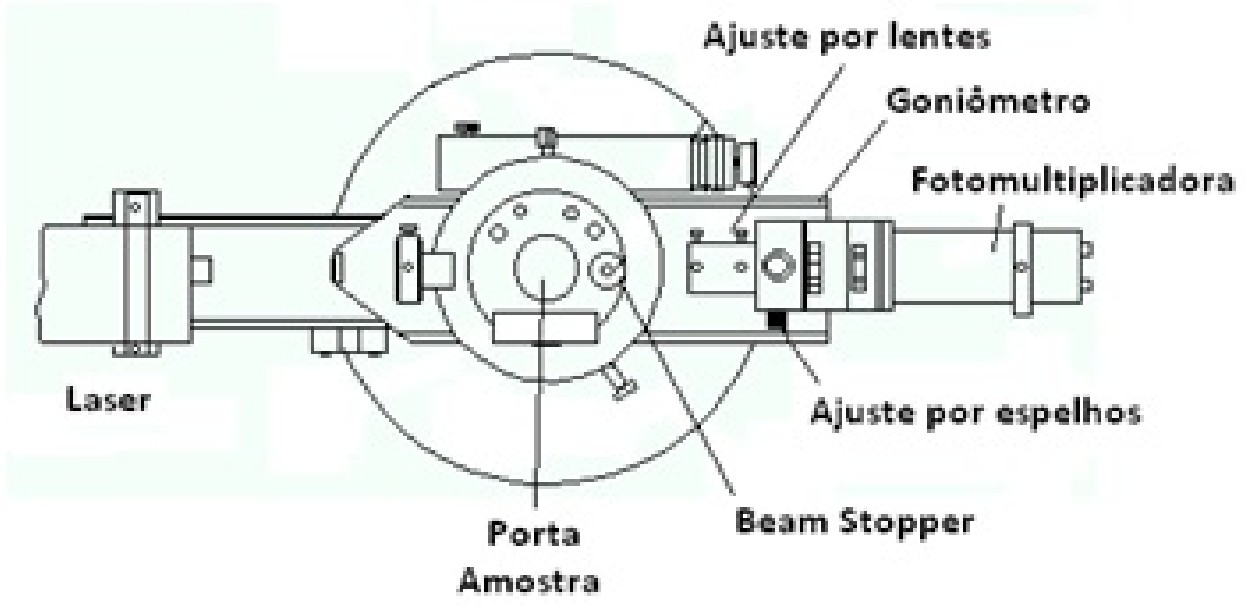

Figura 2.8: Representação esquemática do equipamento de espalhamento de luz. No nosso caso, o detector encontrava-se a $90^{\circ}$ em relação ao feixe incidente. Figura extraída da referência [50]. 


\subsubsection{Cálculo do diâmetro hidrodinâmico}

Em experimentos de espalhamento de luz, o campo de luz incidente é suficientemente fraco de modo que podemos considerar que o sistema responde linearmente a ele. O problema consiste em descrever a resposta de um sistema em equilíbrio a esse campo, ou mais precisamente, às mudanças do campo de luz devido a interações com o sistema [51].

Se duas propriedades dinâmicas são correlacionadas em um período, a função que descreve tal correlação é chamada de função de correlação. Por sua vez, a intensidade de espalhamento pode ser escrita em termos de funções de correlação como sendo[52]:

$$
I(\omega)=N \frac{1}{2 \pi} \int_{-\infty}^{\infty} e^{i\left(w-w_{0}\right) t}\left[G_{A}(\tau)\right]\left[G_{\phi}(\tau)\right] \mathrm{d} \tau
$$

onde $N$ é o número de espalhadores no sistema, $\omega_{0}$ é a frequência natural do sistema, $\tau$ é o tempo de relaxação, $G_{A}(\tau)$ é a função de correlação de orientação do sistema e $G_{\phi}(\tau)$ é a função de correlação de posição do sistema.

Tais funções são dadas por:

$$
G_{A}(\tau)=\left\langle A^{*}(t) A(t-\tau)\right\rangle
$$

onde $A$ é a amplitude da onda eletromagnética. Usando a aproximação de que os espalhadores são esféricos, podemos simplificar a função para:

$$
G_{A}(\tau)=|A|^{2}
$$

Temos ainda que:

$$
G_{\phi}(\tau)=e^{-D q^{2} t}
$$

onde $D$ é o coeficiente de difusão.

Assim sendo, podemos escrever a intensidade de espalhamento como sendo:

$$
I(\omega)=N|A|^{2} \frac{1}{2 \pi} \int_{-\infty}^{\infty} e^{i\left(w-w_{0}\right) t} e^{-D q^{2} t} \mathrm{~d} t
$$

Ou ainda:

$$
I(\omega)=N|A|^{2} \frac{D q^{2} / \pi}{\left(w-w_{0}\right)^{2}+\left(D q^{2}\right)^{2}}
$$


Para obter o diâmetro hidrodinâmico, utilizamos o coeficiente de difusão[52]:

$$
D=\frac{k_{b} T}{6 \pi \eta \xi}
$$

Reordenando temos:

$$
\xi=\frac{k_{b} T}{6 \pi \eta D}
$$

onde $k_{b}=1,38 \times 10^{-23} \mathrm{JK}^{-1}$ é a constante de Boltzmann, $T$ é a temperatura absoluta, $\eta$ é a viscosidade do solvente dada por $1,139 \mathrm{cP}, 0,798 \mathrm{cP}$ e $0,607 \mathrm{cP}$ para 15,30 e $44^{\circ} \mathrm{C}$, respectivamente e $\xi$ é o diâmetro hidrodinâmico da partícula. 



\section{Capítulo 3}

\section{Resultados e Análise Modelo-Independente}

\subsection{Resultados: amostras a $0,5 \mathrm{mg} / \mathrm{mL}$}

As Figuras 3.1 a 3.5 mostram as curvas de SAXS em escala absoluta da SEPT2G a 0,5 $\mathrm{mg} / \mathrm{mL}$ medidas no LNLS .

Podemos observar na Figura 3.1 que os dados de espalhamento não apresentam alterações até 3300s (55 minutos) para uma temperatura igual a $4^{\circ} \mathrm{C}$. Portanto, para sua análise será feita uma média de todos os dados para uma melhor estatística dos dados. Como veremos no próximo Capítulo, os dados de espalhamento serão bem representados pelo espalhamento de dímeros em solução. 


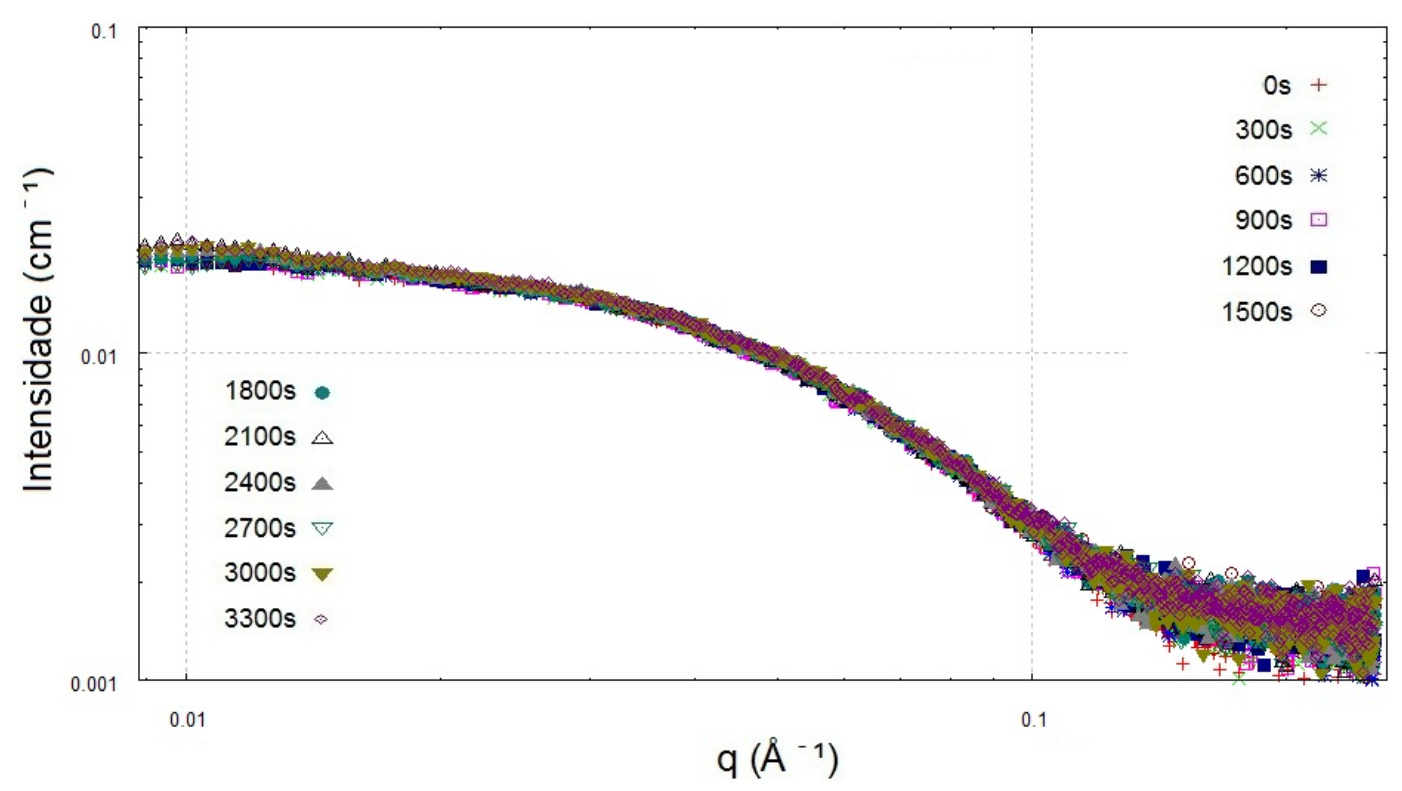

Figura 3.1: Evolução temporal das curvas de SAXS para a proteína SEPT2G a uma concentração de $0,5 \mathrm{mg} / \mathrm{mL}$ e $\mathrm{T}=4^{\circ} \mathrm{C}: \mathrm{t}=0 \mathrm{~s}$ corresponde à primeira medida experimental com acúmulo de intensidade de espalhamento durante 3 minutos; $\mathrm{t}=300 \mathrm{~s}$ corresponde à medida iniciada após 5 minutos do início da aquisição de dados, ou seja, após uma espera de 2 minutos da medida iniciada com $\mathrm{t}=0 \mathrm{~s}$ e assim sucessivamente para as medidas seguintes.

Ao aumentarmos a temperatura para $15^{\circ} \mathrm{C}$ (Figura 3.2), vemos uma mudança na inclinação da curva de espalhamento para valores pequenos de $q$ (região indicada pela seta no gráfico) a partir de 600s (10 minutos). Tal aumento de intensidade nesta região indica a formação de oligômeros [53].

O aumento no tamanho das partículas espalhadoras se mostra ainda mais acentuado conforme aumentamos a temperatura para $\mathrm{T}=25^{\circ} \mathrm{C}$ (Figura 3.3 ). Entretanto, percebemos que o comportamento da curva a partir de aproximadamente $q \geq 0,03 \AA$ é o mesmo para todas as curvas a 4,15 e $25^{\circ} \mathrm{C}$, indicando que ainda temos a presença da estrutura dimérica. 


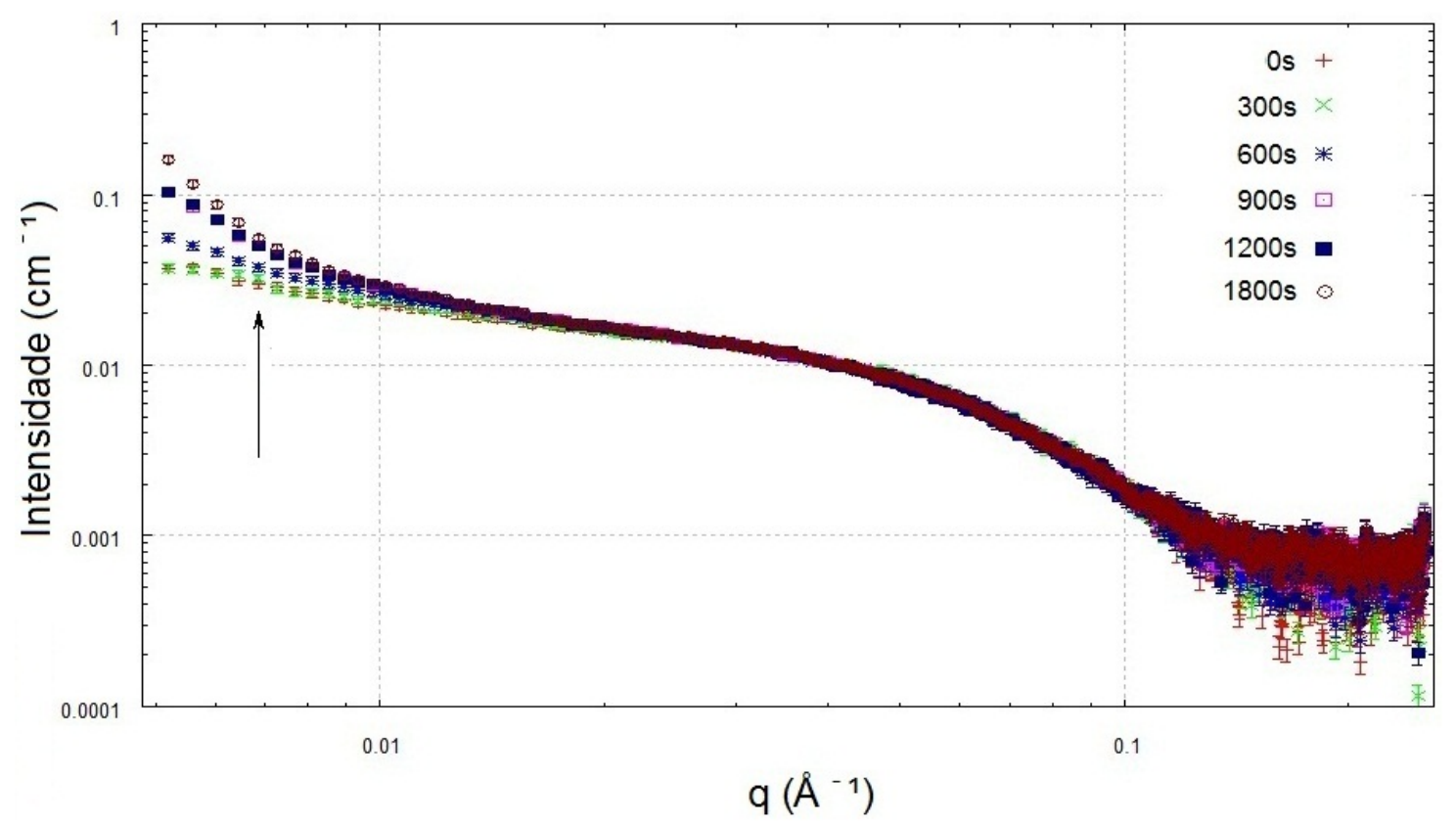

Figura 3.2: Evolução temporal das curvas de SAXS para a proteína SEPT2G a uma concentração de $0,5 \mathrm{mg} / \mathrm{mL}$ e $\mathrm{T}=15^{\circ} \mathrm{C}$. Para a indicação de tempo de medida, verificar legenda da Figura 3.1 


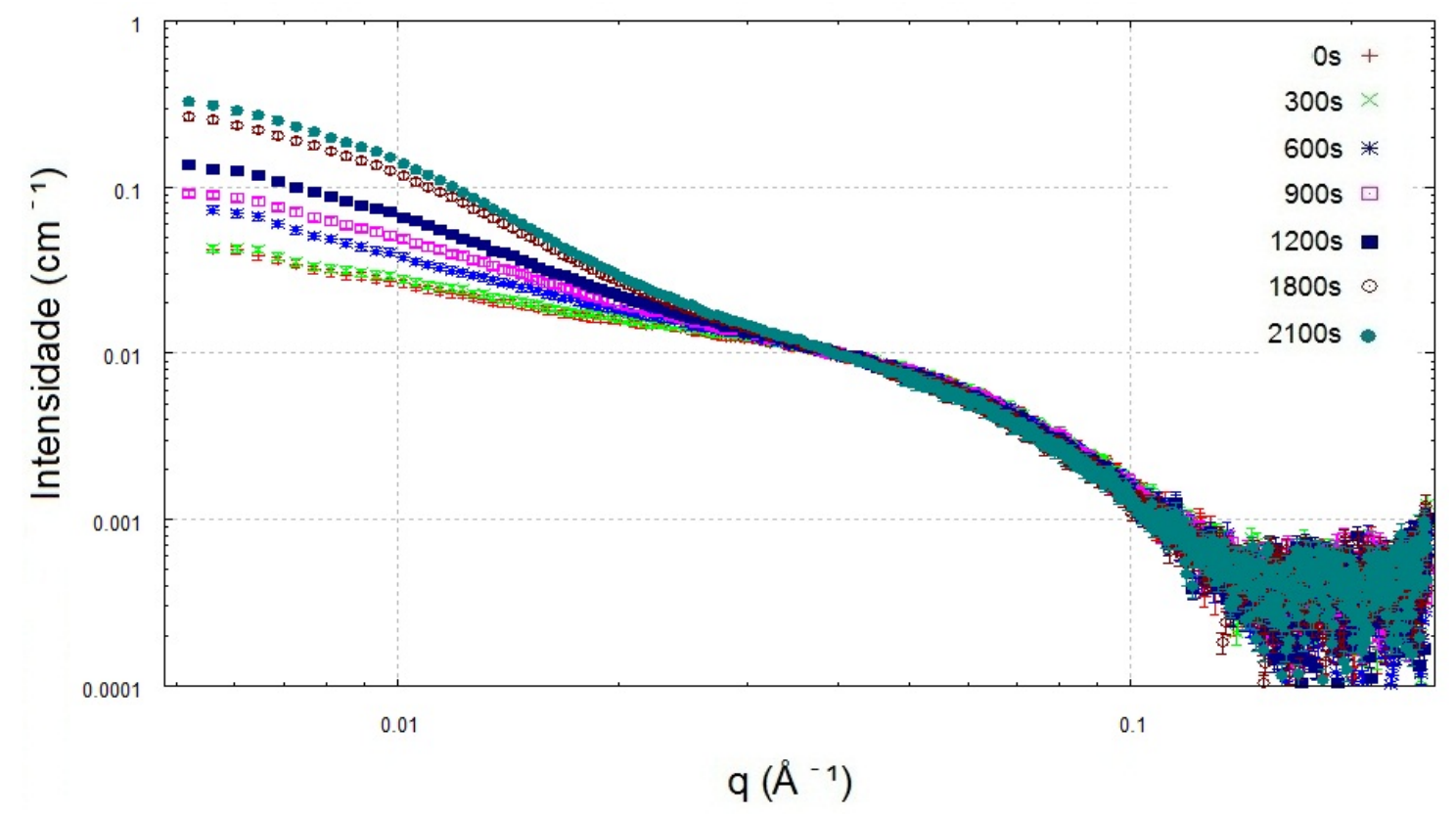

Figura 3.3: Evolução temporal das curvas de SAXS para a proteína SEPT2G a uma concentração de $0,5 \mathrm{mg} / \mathrm{mL}$ e $\mathrm{T}=25^{\circ} \mathrm{C}$. Para a indicação de tempo de medida, verificar legenda da Figura 3.1 . 
Diferentemente das temperaturas analisadas até então, para $37^{\circ} \mathrm{C}$ (Figura 3.4), logo no instante inicial de medida a inclinação das curvas de SAXS para $q$ pequenos já é acentuada, denotando a presença de grandes agregados de proteína. Ao mesmo tempo, ocorre alteração da curva experimental em $q \geq 0,03 \AA$ ), provavelmente relacionado a diminuição da quantidade de dímeros da SEPT2G na solução.

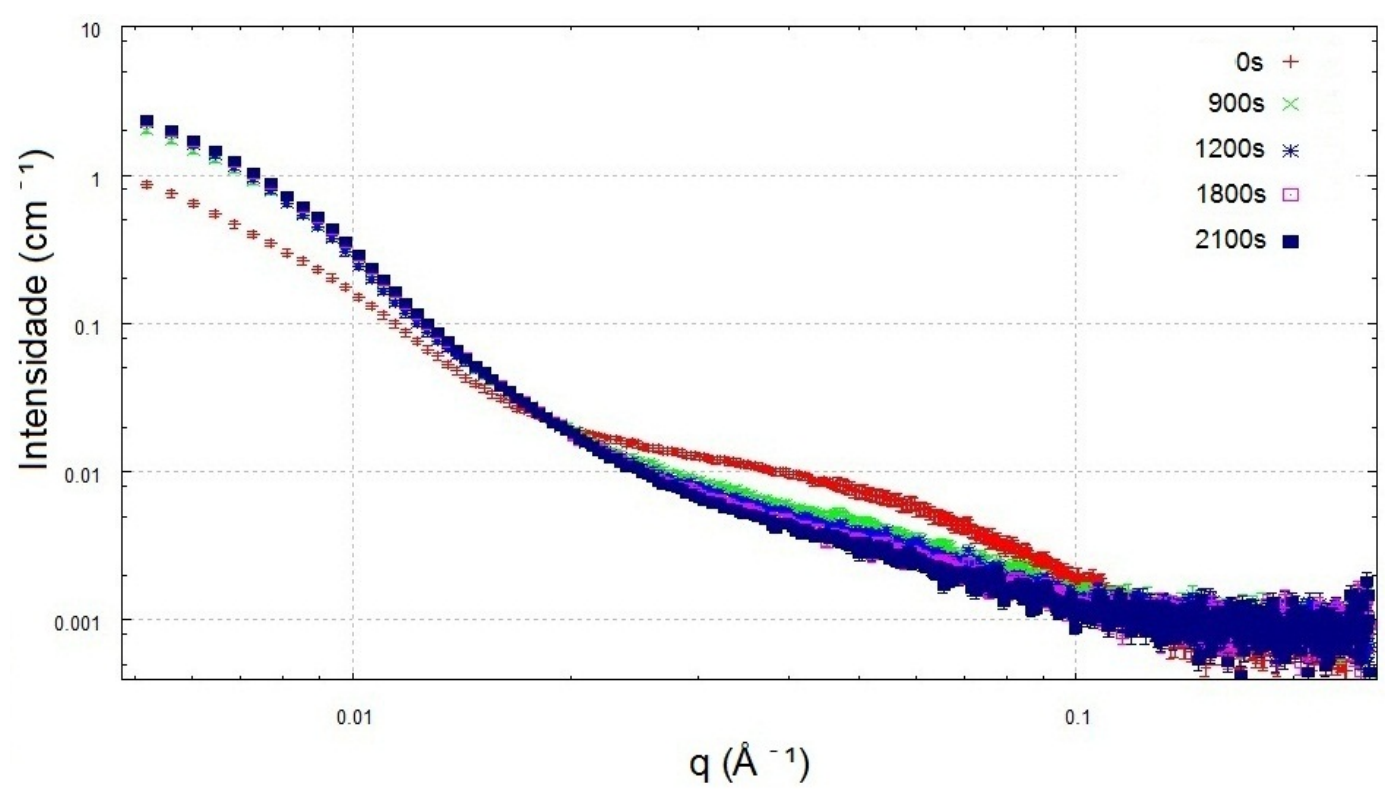

Figura 3.4: Evolução temporal das curvas de SAXS para a proteína SEPT2G a uma concentração de $0,5 \mathrm{mg} / \mathrm{mL}$ e $\mathrm{T}=37^{\circ} \mathrm{C}$. Para a indicação de tempo de medida, verificar legenda da Figura 3.1 .

Para as amostras a $45^{\circ} \mathrm{C}$ (Figura 3.5), observamos que a inclinação do trecho para $q \leq$ $0,03 \AA^{-1}$ é aproximadamente de $q^{-4}$, indicando a presença de agregados muito grandes. $\mathrm{O}$ fato da curva não ser exatamente proporcional à $q^{-4}$ indica que ainda temos a contribuição de partículas menores, apesar do espalhamento devido aos agregados ser predominante. Como descrevemos na Seção 2.2 .3 , poderemos estudar esses agregados maiores a partir da Lei de Porod (próximo capítulo). 


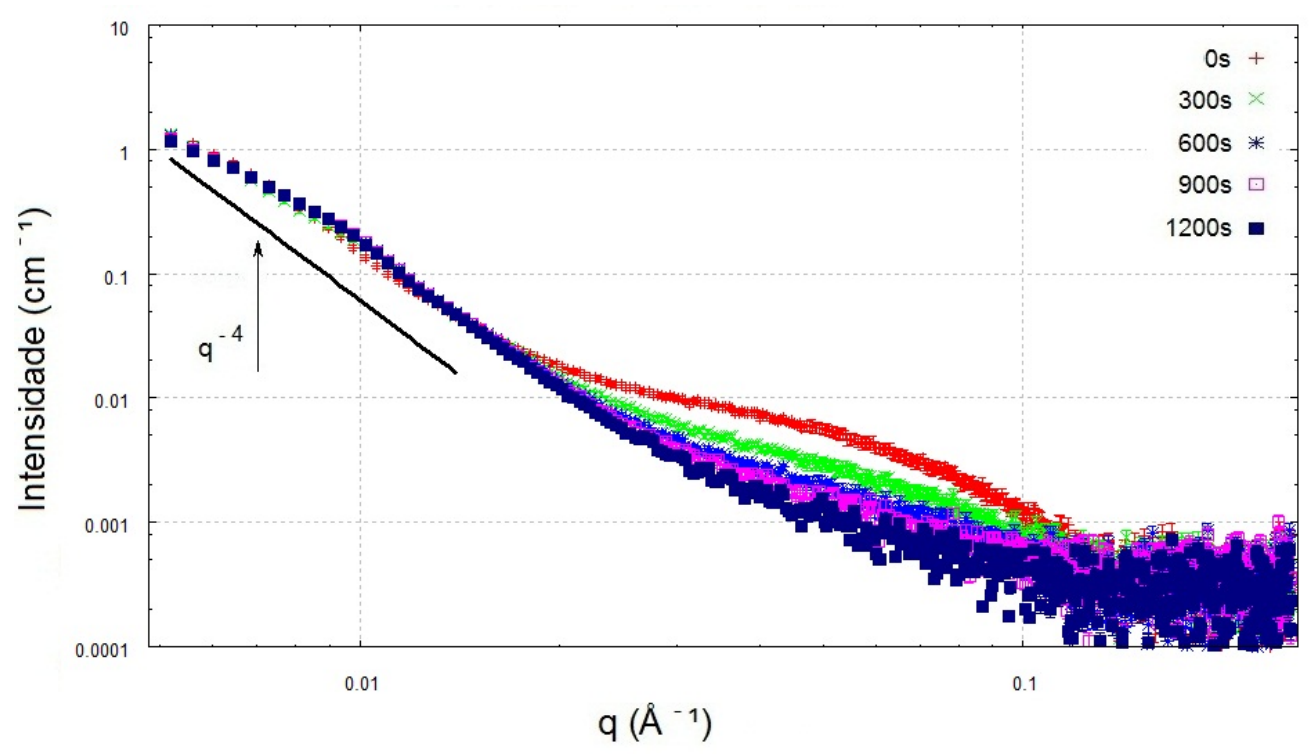

Figura 3.5: Evolução temporal das curvas de SAXS para a proteína SEPT2G a uma concentração de $0,5 \mathrm{mg} / \mathrm{mL}$ e $\mathrm{T}=45^{\circ} \mathrm{C}$. A linha preta indicada pela flecha representa a função $I(q) \propto q^{-4}$. Para a indicação de tempo de medida, verificar legenda da Figura 3.1 . 


\subsection{Resultados: Amostras a $1 \mathrm{mg} / \mathrm{mL}$}

Da mesma maneira que para a concentração menor, a $1 \mathrm{mg} / \mathrm{mL}$ a proteína não apresenta mudanças na curva de espalhamento com o passar do tempo até 3300 s a $4^{\circ} \mathrm{C}$ (Figura 3.6).

Apesar da proteína se manter estável com o passar do tempo, podemos observar que diferente do que ocorre a $0,5 \mathrm{mg} / \mathrm{mL}$, já a $4^{\circ} \mathrm{C}$ a proteína apresenta uma estrutura maior, evidenciada pela inclinação da curva na região de $q$ pequenos.

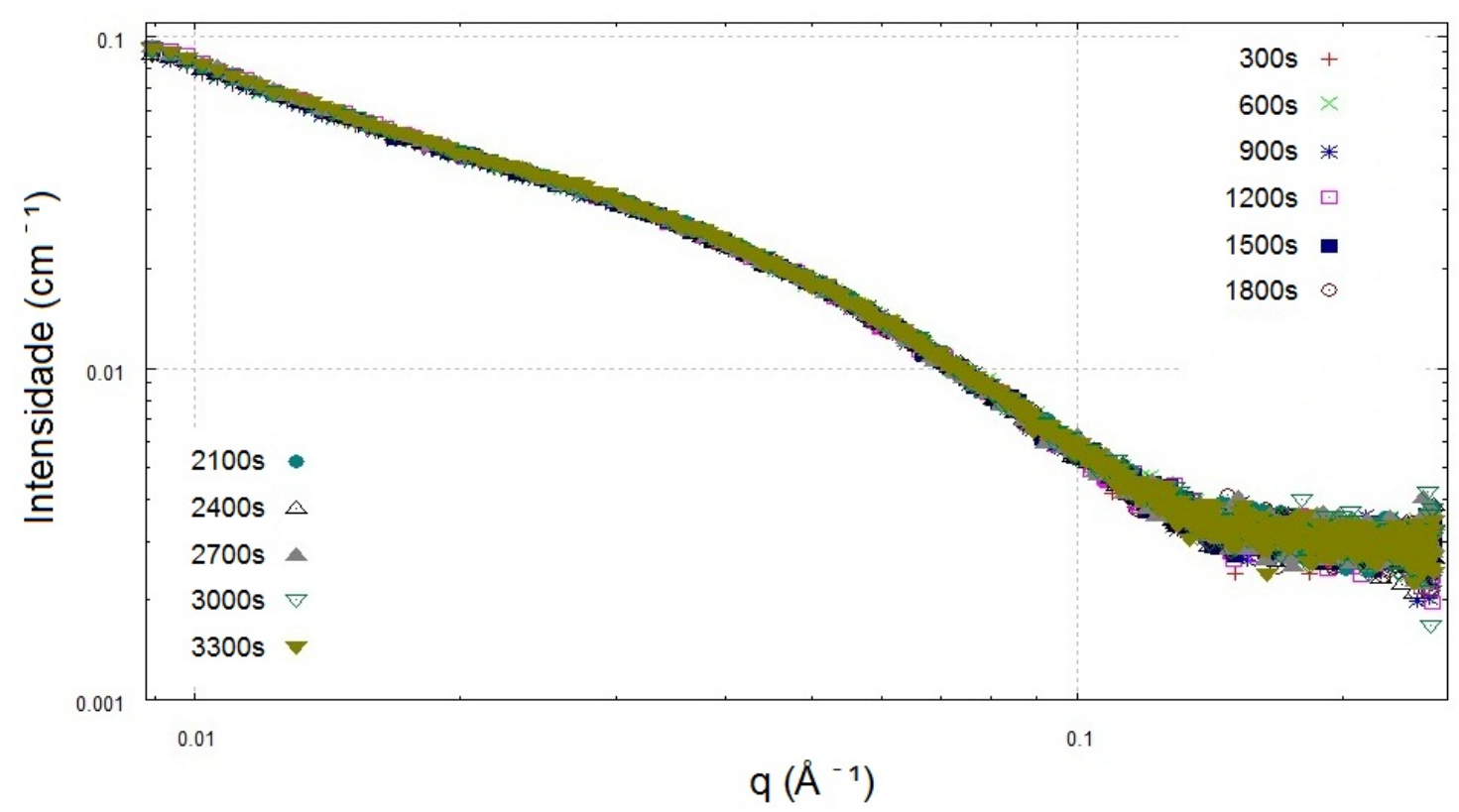

Figura 3.6: Evolução temporal das curvas de SAXS para a proteína SEPT2G a uma concentração de $1 \mathrm{mg} / \mathrm{mL}$ e $\mathrm{T}=4^{\circ} \mathrm{C}:$ : $\mathrm{t}=0 \mathrm{~s}$ corresponde à primeira medida experimental com acúmulo de intensidade de espalhamento durante 2 minutos; $\mathrm{t}=300$ s corresponde à medida iniciada após 5 minutos do início da aquisição de dados, ou seja, após uma espera de 3 minutos da medida iniciada com $\mathrm{t}=0 \mathrm{~s}$ e assim sucessivamente para as medidas seguintes.

Nas amostras de SEPT2G a $0,5 \mathrm{mg} / \mathrm{mL}$ e $15^{\circ} \mathrm{C}$, o início da curva de espalhamento modificou-se significativamente com o passar do tempo, indicando um aumento no tamanho dos agregados. Por sua vez, para $1 \mathrm{mg} / \mathrm{mL}$ podemos identificar que a proteína já se encontra mais agregada em relação à concentração menor (Figura 3.7). Entretanto, a variação observada com o passar do tempo não é tão acentuada quanto no caso anterior (Figura 3.2). 


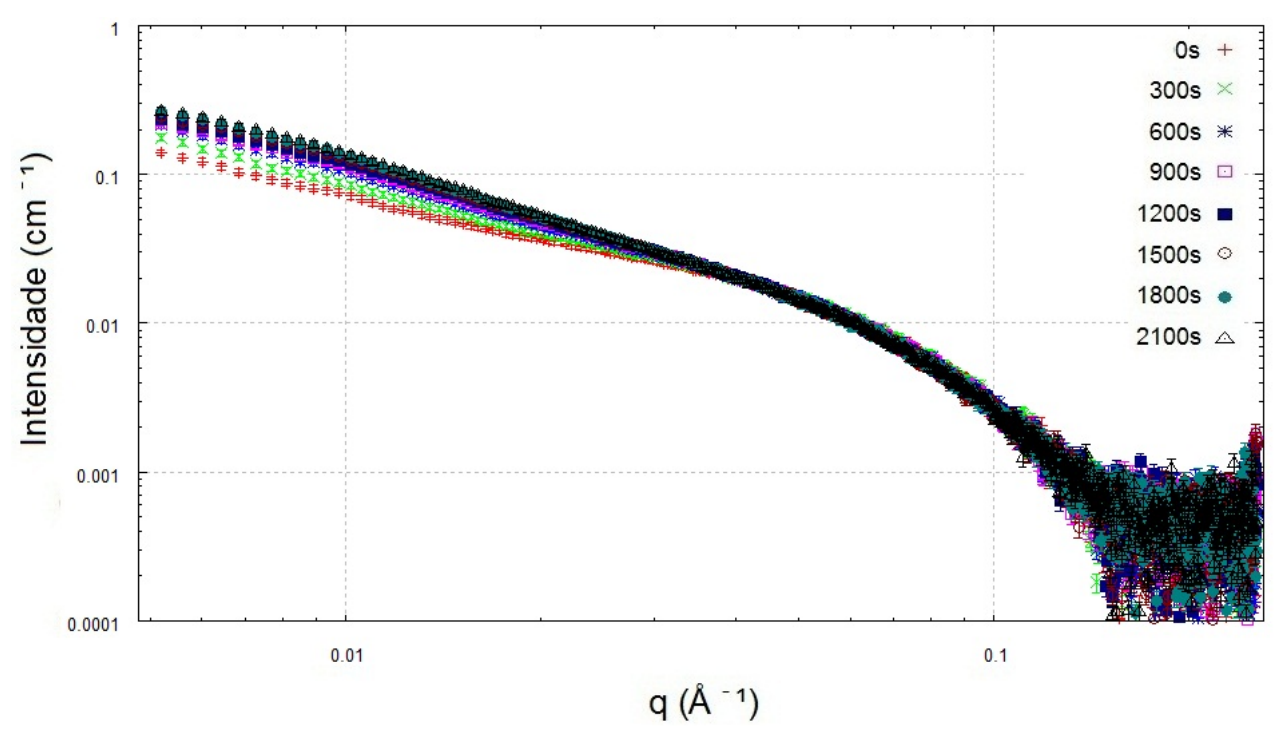

Figura 3.7: Evolução temporal das curvas de SAXS para a proteína SEPT2G a uma concentração de $1 \mathrm{mg} / \mathrm{mL}$ e $\mathrm{T}=15^{\circ} \mathrm{C}$. Para a indicação de tempo de medida, verificar legenda da Figura 3.6 .

A Figura 3.8 mostra a evolução temporal das curvas de espalhamento para a amostra a $25^{\circ} \mathrm{C}$. Podemos observar uma mudança significativa na região de $q \leq 0,02 \AA^{-1}$, indicando um aumento de tamanho nas partículas espalhadoras. 


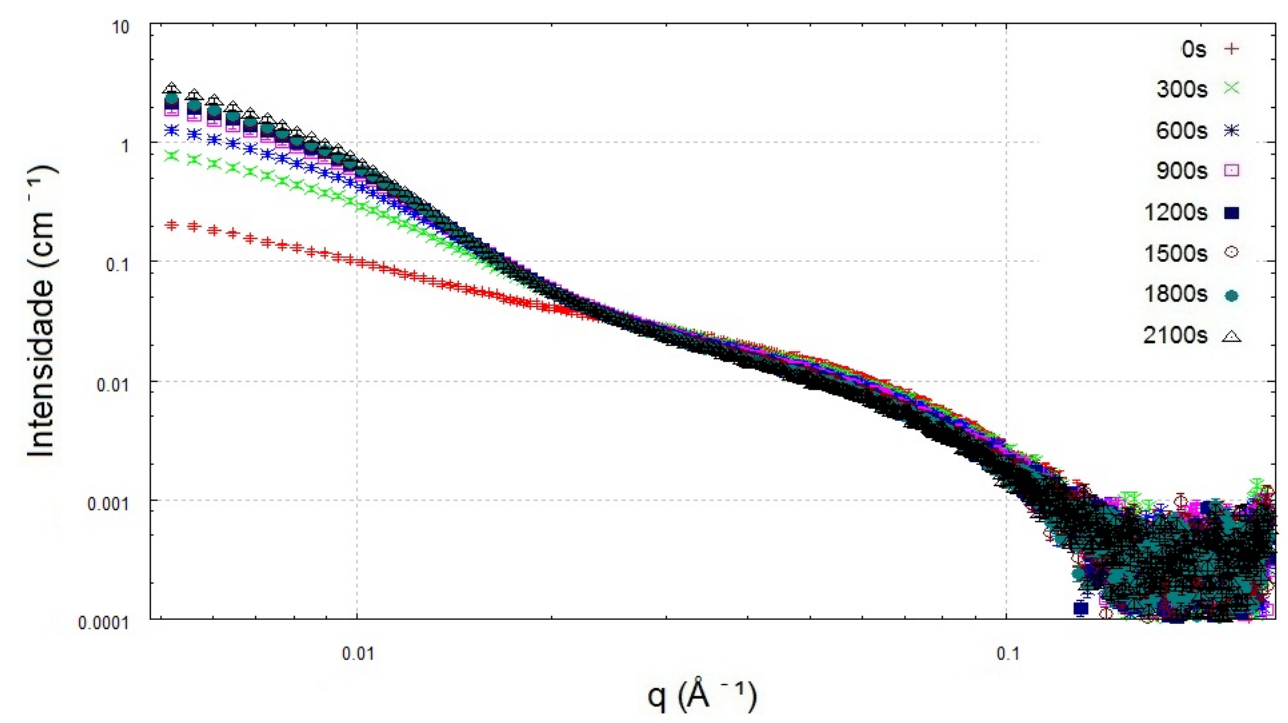

Figura 3.8: Evolução temporal das curvas de SAXS para a proteína SEPT2G a uma concentração de $1 \mathrm{mg} / \mathrm{mL}$ e $\mathrm{T}=25^{\circ} \mathrm{C}$. Para a indicação de tempo de medida, verificar legenda da Figura 3.6 . 
Ao aumentarmos a temperatura para $37^{\circ} \mathrm{C}$, observamos na região de $q \geq 0,02 \AA^{-1}$ das curvas de espalhamento, que durante todo o intervalo de medida ainda temos a presença de uma estrutura menor (Figura 3.9.

Da mesma maneira que para a proteína a $45^{\circ} \mathrm{C}$ e $0,5 \mathrm{mg} / \mathrm{mL}$ (Figura 3.5), a inclinação da região de $q \leq 0,02 \AA^{-1}$ para a amostra a 37 e $45^{\circ} \mathrm{C}$ e $1 \mathrm{mg} / \mathrm{mL}$ (Figuras 3.9 e 3.10 também é proporcional à $q^{-4}$, podendo ser descrita por um agregado do tipo Porod.

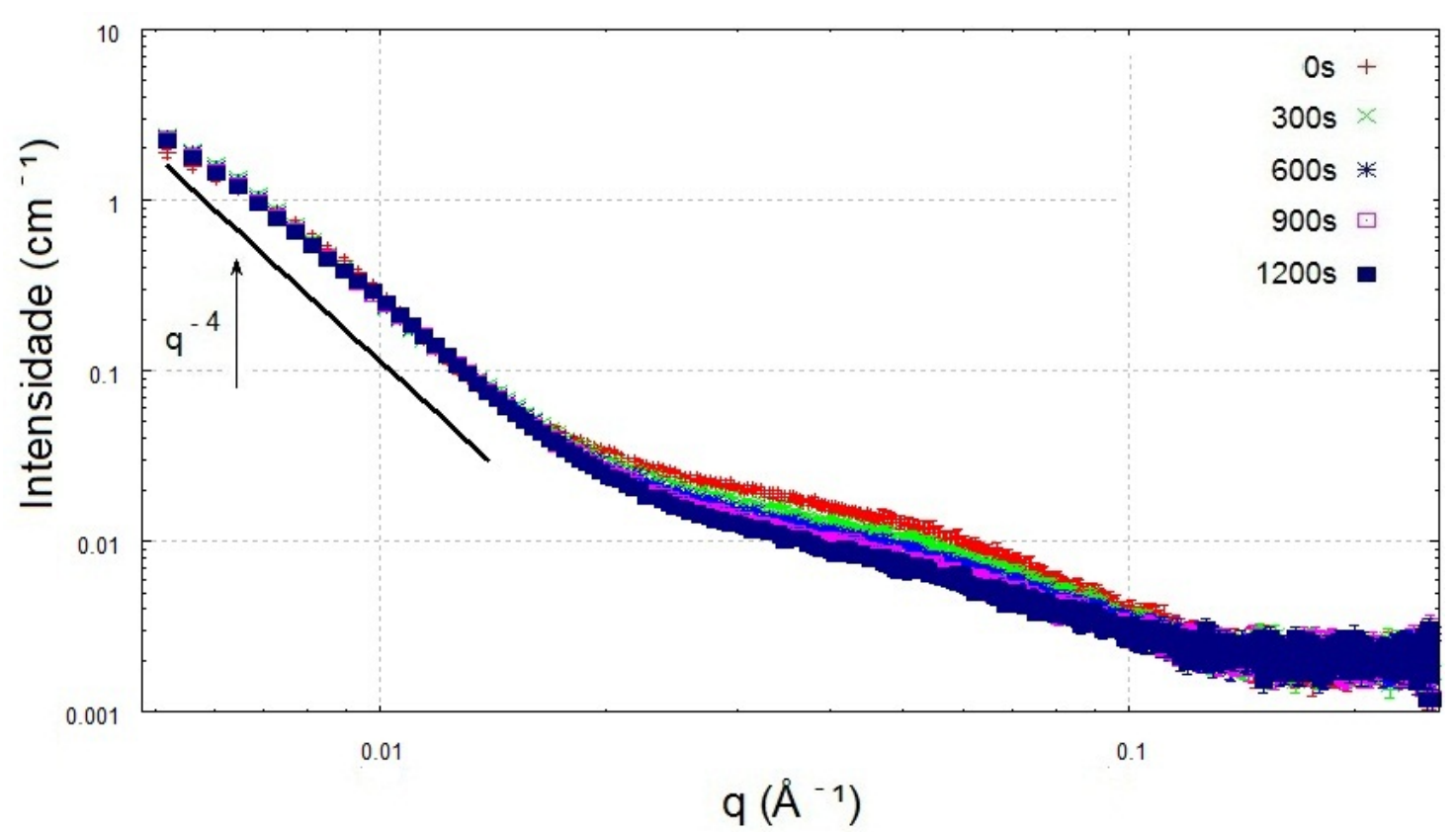

Figura 3.9: Evolução temporal das curvas de SAXS para a proteína SEPT2G a uma concentração de $1 \mathrm{mg} / \mathrm{mL}$ e $\mathrm{T}=37^{\circ} \mathrm{C}$. A linha preta indicada pela flecha representa a função $I(q) \propto q^{-4}$. Para a indicação de tempo de medida, verificar legenda da Figura 3.6 . 


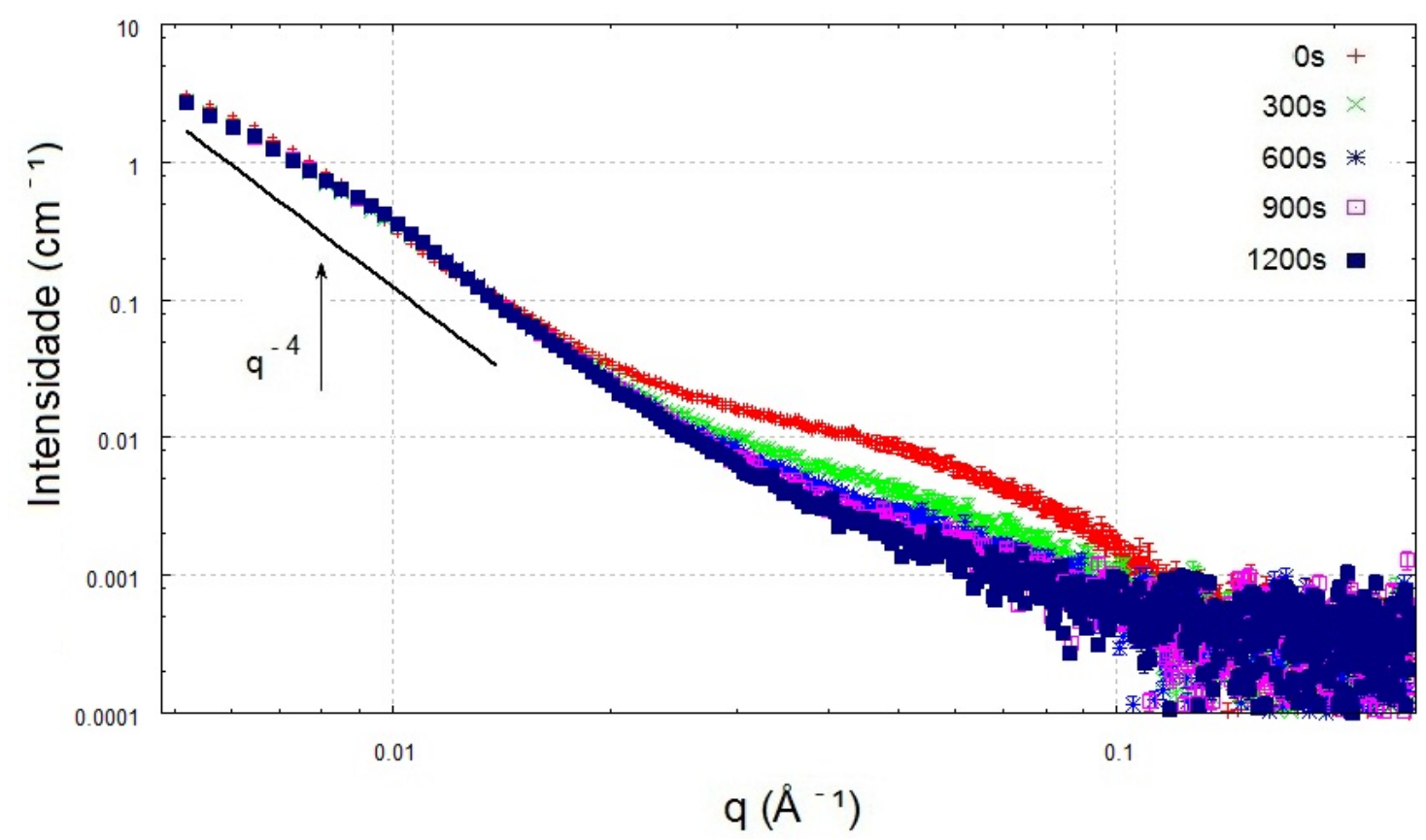

Figura 3.10: Evolução temporal das curvas de SAXS para a proteína SEPT2G a uma concentração de $1 \mathrm{mg} / \mathrm{mL}$ e $\mathrm{T}=45^{\circ} \mathrm{C}$. A linha preta indicada pela flecha representa a função $I(q) \propto q^{-4}$. Para a indicação de tempo de medida, verificar legenda da Figura 3.6 . 


\subsection{Raio de giro}

O raio de giro foi calculado como descrito na Seção 2.2.2. Na Figura 3.11 vemos como exemplo o ajuste da região de Guinier para a amostra a $15^{\circ} \mathrm{C}$ com $0,5 \mathrm{mg} / \mathrm{mL}$ de SEPT2G para $\mathrm{t}=0,300$ e $600 \mathrm{~s}$.

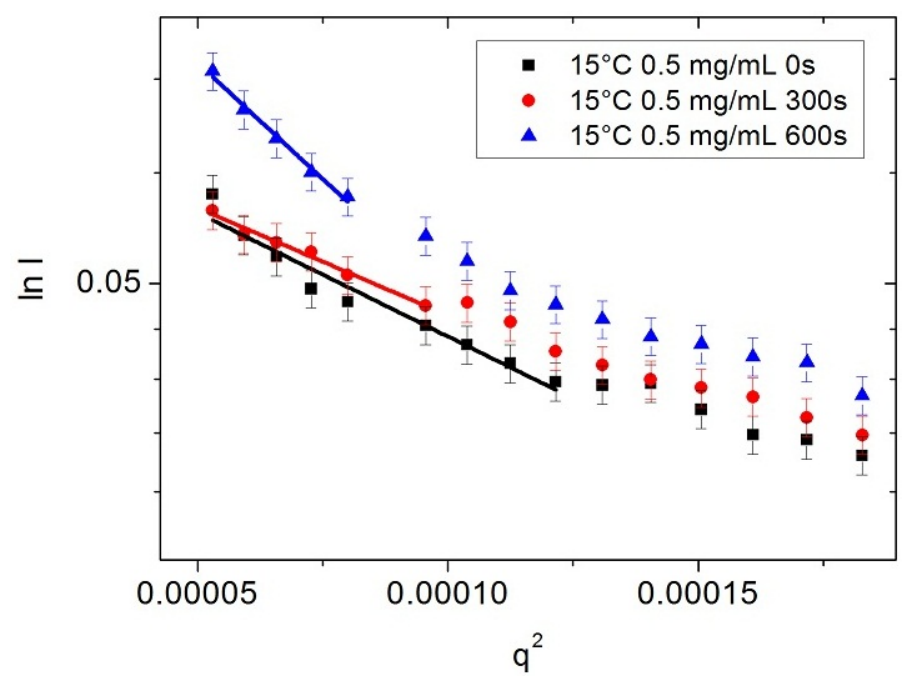

Figura 3.11: Alguns exemplos do ajuste linear da região de Guinier.

Na Figura 3.12 podemos observar os casos onde a relação $2.8\left(q R_{g} \leq 1,3\right)$ foi satisfeita. Podemos observar que não houve alterações com o passar do tempo para as amostras a $4^{\circ} \mathrm{C}$ em ambas concentrações estudadas. Em especial, verificamos que o raio de giro da amostra a $0,5 \mathrm{mg} / \mathrm{mL}$ é compatível com o valor do raio de giro do dímero calculado através da curva de SAXS simulada, utilizando a metodologia descrita na Secção $2.2 .2\left(R_{g}=28,6 \AA\right.$, indicado pela linha tracejada em vermelho na Figura 3.12). Além disso, o gráfico indica que a concentração influencia no processo de agregação, uma vez que o raio de giro para a amostra a $1 \mathrm{mg} / \mathrm{mL}$ e $4^{\circ} \mathrm{C}$ se mostra aproximadamente 3 vezes maior que para a amostra a $0,5 \mathrm{mg} / \mathrm{mL}$.

Para as amostras com mesma concentração de $0,5 \mathrm{mg} / \mathrm{mL}$ e diferentes temperaturas, é possível determinar o raio de giro apenas no início da tomada de dados para 15 e $25^{\circ} \mathrm{C}$ até aproximadamente $900 \mathrm{~s}$, respeitando a condição que $q R_{g} \leq 1,3$. Além disso, para temperaturas maiores que $25^{\circ} \mathrm{C}$, todos os resultados obtidos para o raio de giro não satisfazem a relação 2.8 . 
Ao analisarmos as amostras de septina a $1 \mathrm{mg} / \mathrm{mL}$, verificamos que os agregados já são maiores que a $0,5 \mathrm{mg} / \mathrm{mL}$ mesmo na temperatura de $4^{\circ} \mathrm{C}$. Para temperaturas maiores, já não foi possível obter valores de raio de giro pois a relação $q R_{g} \leq 1,3$ não foi satisfeita.

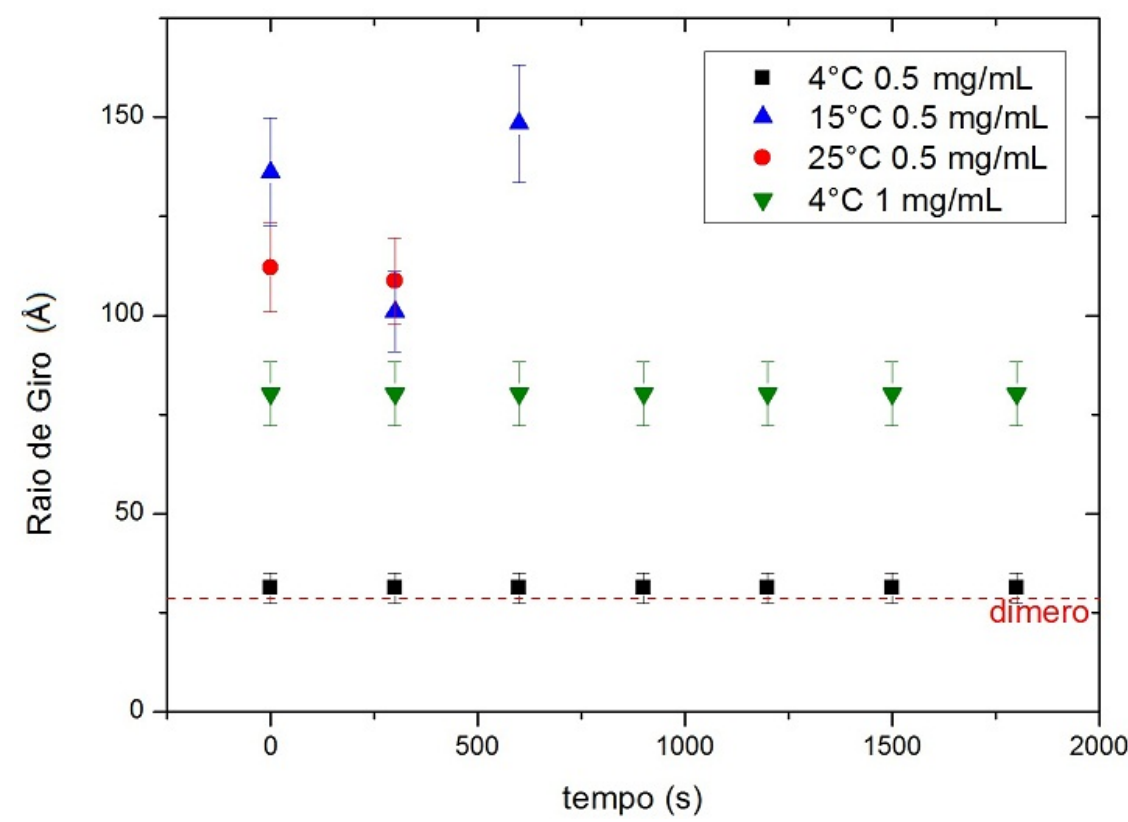

Figura 3.12: Gráfico do raio de giro em função do tempo para a SEPT2G.

\subsection{Massa molecular}

Muito embora a maioria de nossos dados indiquem a formação de grandes agregados logo no início das curvas de espalhamento, fizemos uma avaliação, em primeira aproximação, das massas moleculares obtidos a partir dos valores de $I(0)$ avaliados através de uma extrapolação de um ajuste linear dos primeiros pontos da curva de espalhamento.

Na Figura 3.13 estão representados as evoluções temporais dos valores da massa molecular calculadas a partir da Eq. 2.9 para a SEPT2G a $0,5 \mathrm{mg} / \mathrm{mL}$. Para efeito de comparação, a linha pontilhada em vermelho indica a massa molecular do dímero da SEPT2G $\left(M M_{\text {dimero }_{S E P T 2 G}}=68 \mathrm{kDa}\right)$ e a linha pontilhada em verde indica a massa molecular do tetrâmero da SEPT2G $\left(M M_{\text {tetrâmero }_{S E P T 2 G}}=136 k D a\right)$ [Seção 2.2.2.1]. Assim como os resultados de raio de giro, a massa molecular da SEPT2G a $4^{\circ} \mathrm{C}$ também é compatível com o 
valor para o dímero da proteína, o que confirma que nessas condições a proteína se encontra na forma dimérica.

Para $15^{\circ} \mathrm{C}$, mesmo no instante inicial, a amostra já apresenta massa molecular maior que para $4^{\circ} \mathrm{C}$. Apesar do valor encontrado nessa condição ser da ordem de grandeza de um tetrâmero, não podemos descartar a possibilidade de se tratar de uma média de populações com massa molecular resultante similar a de um tetrâmero. Ao contrário do que foi observado na temperatura inferior, temos um aumento nos valores obtidos com o passar do tempo. Essa evolução é ainda mais evidente para $25^{\circ} \mathrm{C}$. No instante inicial a $25^{\circ} \mathrm{C}$, a massa molecular é compatível com a obtida para $15^{\circ} \mathrm{C}$ (aproximadamente $130 \mathrm{kDa}$ ), entretanto, em 1800s tal valor atinge $1000 \mathrm{kDa}$. Para $15^{\circ} \mathrm{C}$, nesse mesmo intervalo, a massa molecular obtida é de apenas $330 \mathrm{kDa}$.

Ao aumentarmos a temperatura para $37^{\circ} \mathrm{C}$, a massa molecular no instante inicial é da ordem de $5600 \mathrm{kDa}$, aumentando para cerca de $18000 \mathrm{kDa}$ no intervalo de $2100 \mathrm{~s}$. Para $45^{\circ} \mathrm{C}$, verificamos que a amostra apresenta massa molecular constante por volta de $11000 \mathrm{kDa}$ em um intervalo de 1200s. Vale a pena lembrar, entretanto, que nestas condições, estamos trabalhando no limite de detecção da técnica. Portanto, tais valores devem ser bem maiores que os calculados.

Na Figura 3.14 estão representados os valores da massa molecular em função do tempo para a SEPT2G a $1 \mathrm{mg} / \mathrm{mL}$. Para $4^{\circ} \mathrm{C}$, assim como visto na concentração anterior, a massa molecular manteve-se constante. Seu valor, entretanto, não é mais o correspondente ao dímero de SEPT2G, mas tem ordem de grandeza de um tetrâmero (indicado pela linha pontilhada em verde). Como discutido anteriormente, apesar do valor ser compatível com o de um tetrâmero, não podemos afirmar que a solução é composta unicamente por este tipo de partícula espalhadora. Este fato será melhor avaliado no próximo Capítulo.

Para $15^{\circ} \mathrm{C}$, observamos um aumento de cerca de $280 \mathrm{kDa}$ para $542 \mathrm{kDa}$ em um intervalo de 2100s. A maior evolução na massa molecular se dá, entretanto, na temperatura de $25^{\circ} \mathrm{C}$. Podemos observar que em 2100s o valor obtido passa de aproximadamente $450 \mathrm{kDa}$ para cerca de $7000 \mathrm{kDa}$. Se compararmos com a concentração 0,5 mg/mL (Figura 3.13), a medida final na temperatura de $25^{\circ} \mathrm{C}$ é cerca de 5 vezes menor do que a $1 \mathrm{mg} / \mathrm{mL}$. A $37^{\circ} \mathrm{C}$ a massa molecular passa de cerca de $5300 \mathrm{kDa}$ para aproximadamente $8200 \mathrm{kDa}$ ou seja, o comportamento das amostras a $37^{\circ} \mathrm{C}$ se mostrou similar para as duas concentrações estudadas. Para $45^{\circ} \mathrm{C}$ verificamos que o valor permance por volta de $11000 \mathrm{kDa}$ em todo o intervalo de medida. É importante ressaltar que nessas condições estamos no limite de deteç̧ão da técnica de SAXS. 


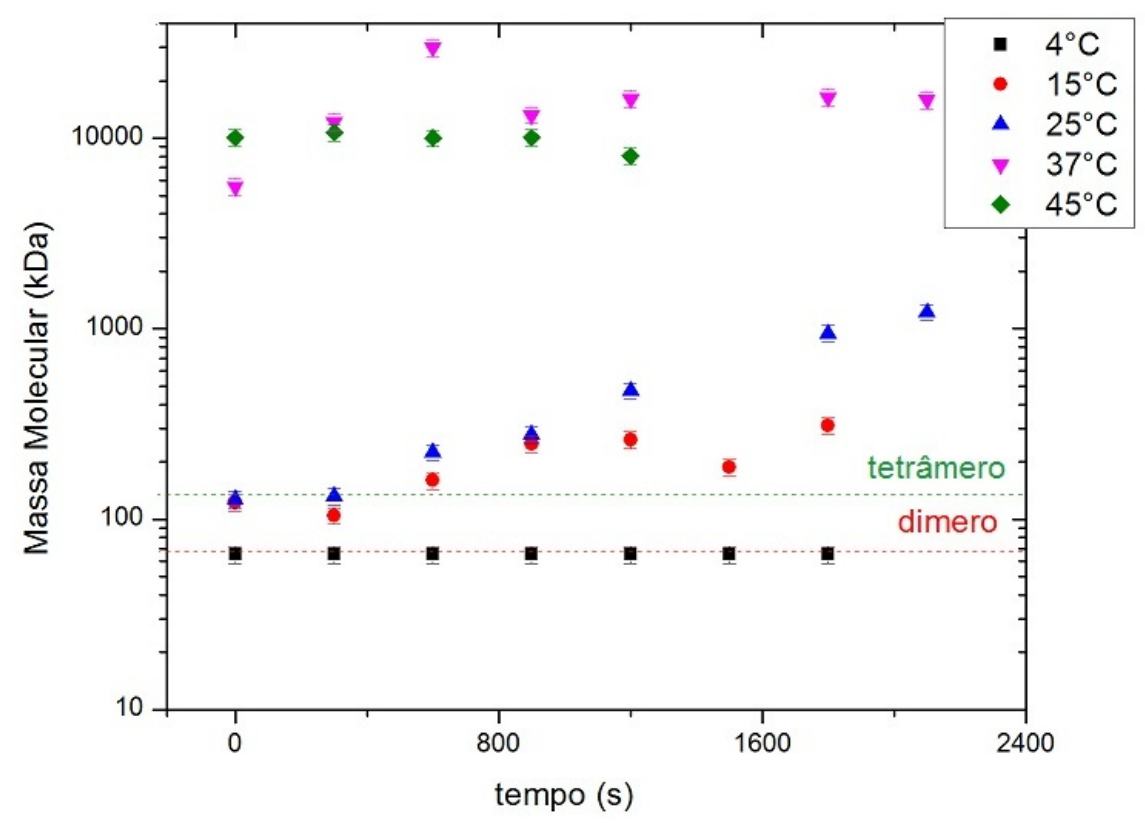

Figura 3.13: Evolução temporal da massa molecular para a SEPT2G a $0,5 \mathrm{mg} / \mathrm{mL}$.

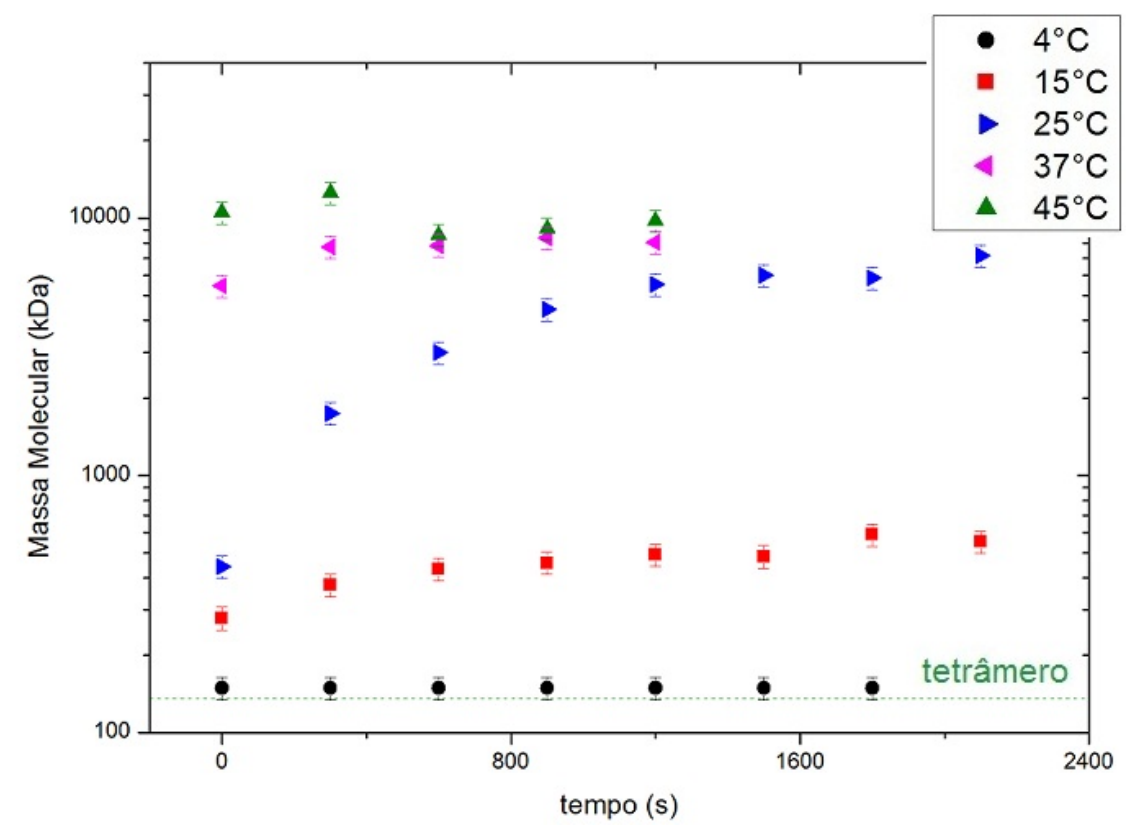

Figura 3.14: Evolução temporal da massa molecular para a SEPT2G a $1 \mathrm{mg} / \mathrm{mL}$. 


\subsection{Função distribuição de distâncias}

\subsubsection{Amostras a $0,5 \mathrm{mg} / \mathrm{mL}$}

As Figuras 3.15 a 3.19 mostram as funções $p(r)$ das curvas de SAXS da SEPT2G a 0,5 $\mathrm{mg} / \mathrm{mL}$ medidas no LNLS.

Como visto anteriormente, a SEPT2G a $0,5 \mathrm{mg} / \mathrm{L}$ e $4^{\circ} \mathrm{C}$ se mantém estável com o passar do tempo. Assim sendo, na Figura 3.15 temos uma média das curvas em todo o intervalo de medida para uma melhor estatística dos dados. Juntamente com a média dos dados experimentais temos, como exemplo, a melhor curva ajustada correspondente a função $p(r)$ calculada pelo programa GNOM (à esquerda em detalhe nessa mesma figura).

A função $p(r)$ apresenta uma forma de sino, porém seu máximo está deslocado para valores menores que $D_{m a ́ x} / 2$, indicando uma estrutura alongada. Comparando a $p(r)$ da média das curvas experimentais com a simulada a partir do dímero da estrutura cristalográfica da proteína utilizando o programa GNOM, vemos que as duas são compatíveis. Assim sendo, a função $p(r)$ reforça as análises de Guinier e massa molecular revelando que a $4^{\circ} \mathrm{C}$ e 0,5 $\mathrm{mg} / \mathrm{mL}$ de SEPT2G a proteína apresenta-se na forma dimérica em solução aquosa. 


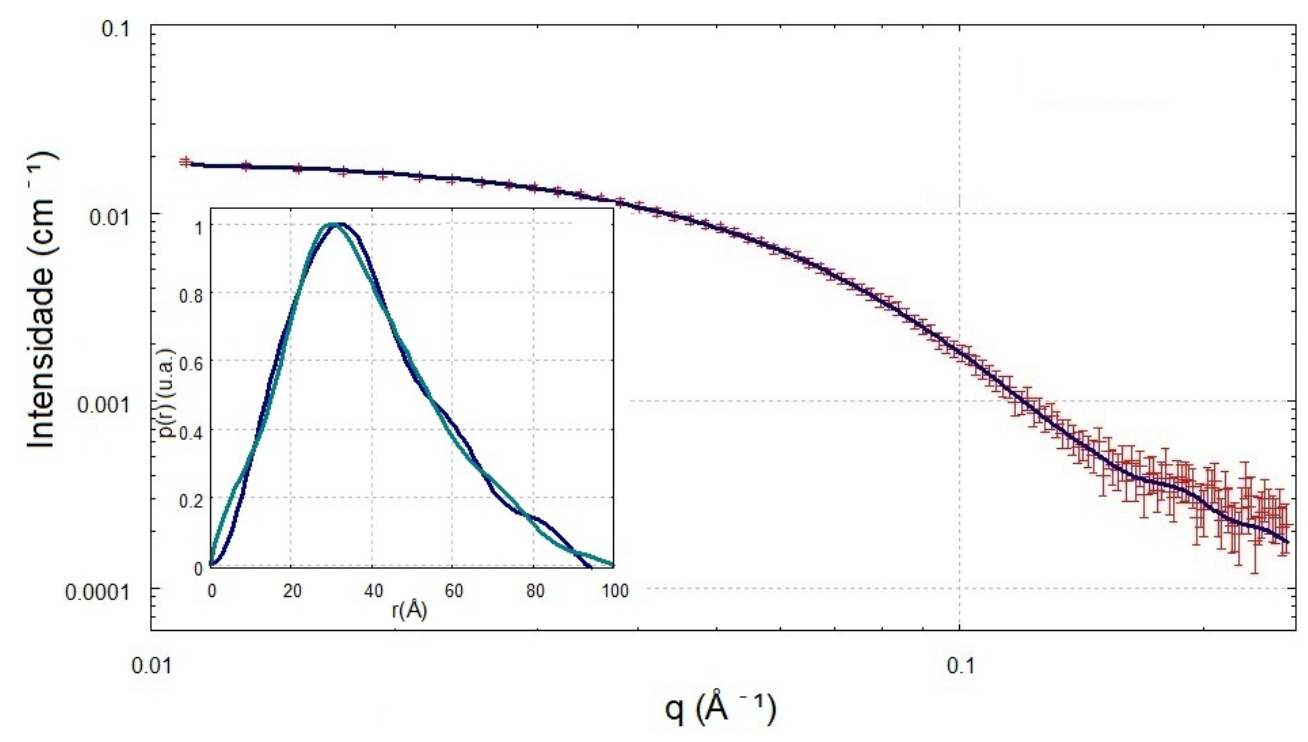

Figura 3.15: Média das curvas de SAXS para a proteína SEPT2G a uma concentração de $0,5 \mathrm{mg} / \mathrm{mL}$ e $\mathrm{T}=4^{\circ} \mathrm{C}(+)$ e o melhor ajuste aos dados experimentais obtido pelo programa GNOM (linha contínua em azul). No inserto temos a função $p(r)$ correspondente à curva de SAXS obtida pelo programa GNOM (em azul) e, para efeito de comparação, a função $p(r)$ calculada a partir da curva simulada obtida através da estrutura cristalográfica do dímero, como mostrado na Figura 2.6 (em verde). 
Por sua vez, a função distribuição de distâncias da proteína a $15^{\circ} \mathrm{C}$ (Figura 3.16) indica a presença de mais de uma população. Ao compararmos as funções $p(r)$ das curvas experimentais com a $p(r)$ do dímero (linha contínua em vermelho), vemos que o primeiro pico representa o dímero na solução, coexistindo com uma estrutura maior, indicado pelo segundo máximo da função. Com o passar do tempo, a contribuição da estrutura maior aumenta (região indicada pela seta vermelha), com consequente diminuição da população de dímeros (indicada pela seta azul) evidenciando uma evolução no processo de agregação.

A função $p(r)$ tem $p\left(D_{m a ́ x}\right)=0$, entretanto, como analisaremos adiante, $D_{\text {máx deve }}$ estar associado ao limite da técnica experimental e não à dimensão máxima "verdadeira"do agregado.

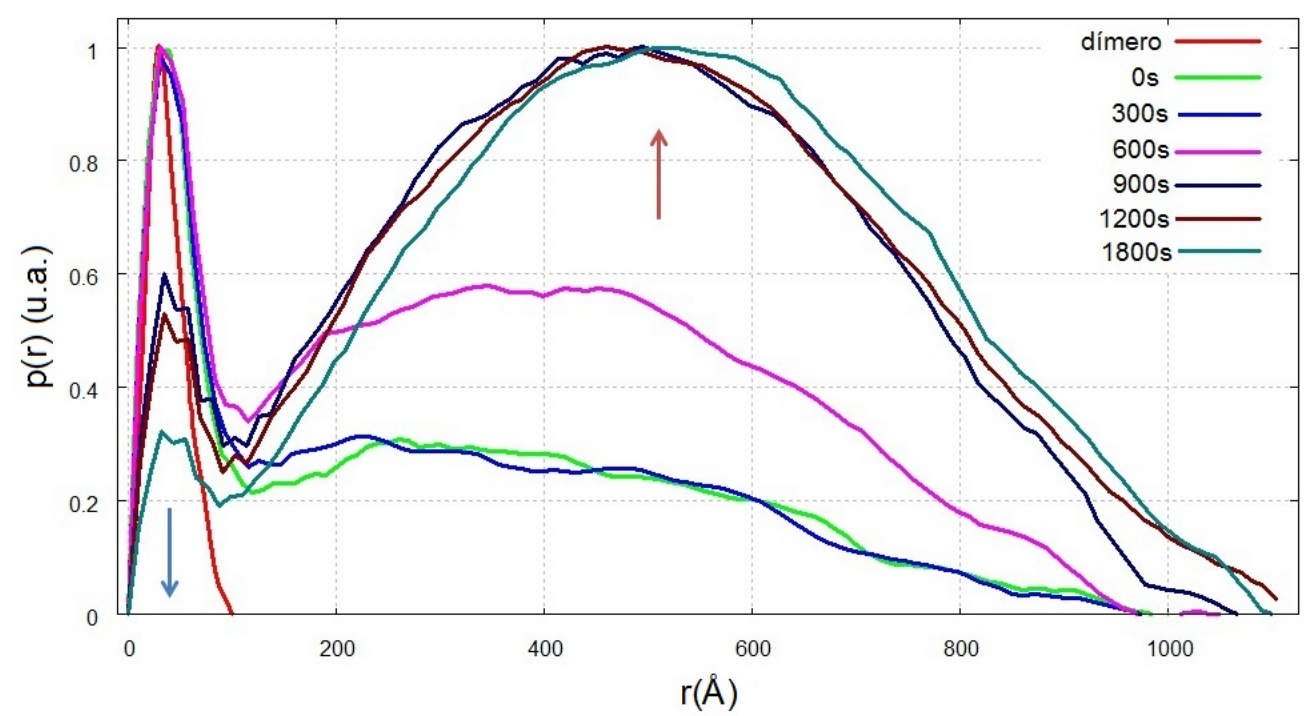

Figura 3.16: Evolução da função $p(r)$ com o tempo para a proteína SEPT2G a uma concentração de $0,5 \mathrm{mg} / \mathrm{mL}$ e $\mathrm{T}=15^{\circ} \mathrm{C}$. 
A $25^{\circ} \mathrm{C}$, podemos observar na Figura 3.17 que, a partir de 900 s o máximo correspondente ao dímero começa a ser englobado pela parte referente a estruturas maiores (região indicada pela seta vermelha) e em 1800s já não é mais possível distinguir o dímero (região indicada pela seta azul) na função $p(r)$. Um outro ponto a observar é que a característica da função $p(r)$ para o segundo pico de frequência de distâncias tem máximo em torno de $200 \AA$ e $D_{\text {máx }} \approx 1200 \AA$. Ao mesmo tempo, o comportamento da função $p(r)$ para $r \geq 200 \AA$ sugere a presença de partículas alongadas (tipo cilindro) em solução.

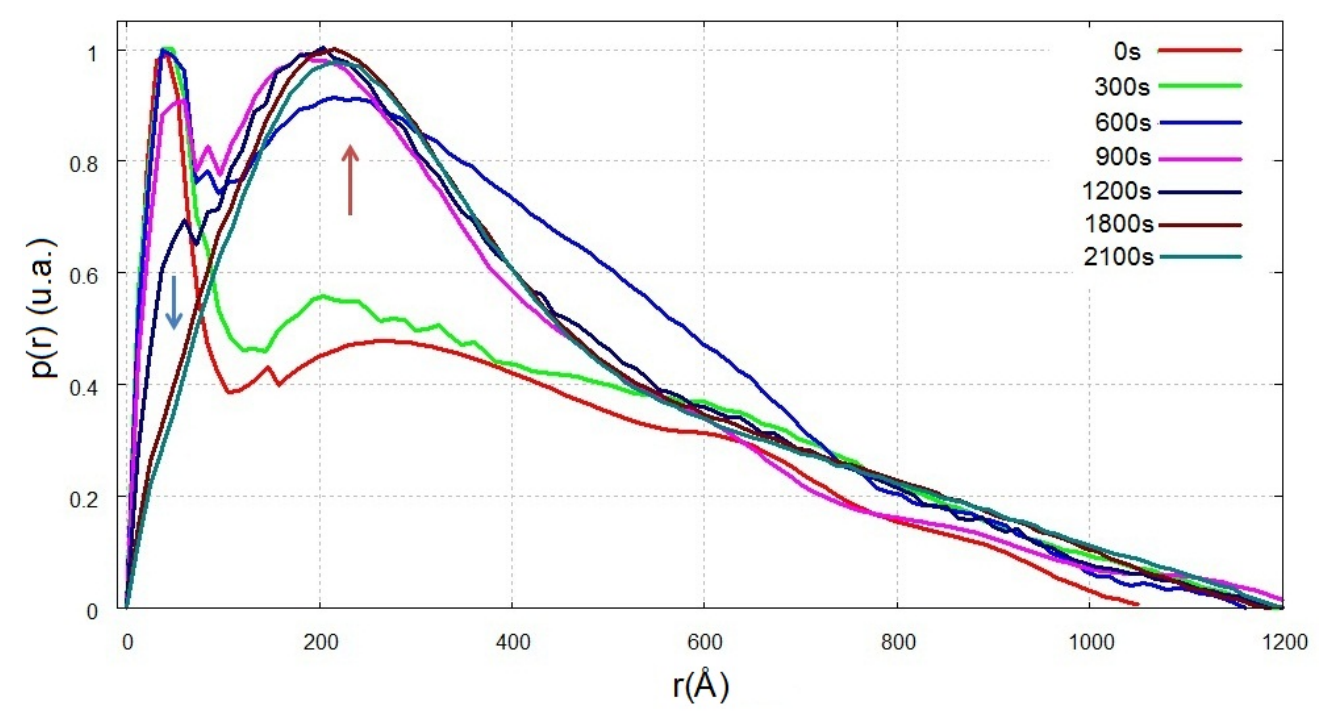

Figura 3.17: Evolução da função $p(r)$ com o tempo para a proteína SEPT2G a uma concentração de $0,5 \mathrm{mg} / \mathrm{mL}$ e $\mathrm{T}=25^{\circ} \mathrm{C}$.

Diferentemente das temperaturas analisadas até então, para 37 e $45^{\circ} \mathrm{C}$ (Figuras $3.18 \mathrm{e}$ 3.19 , respectivamente, logo no instante inicial de medida já não é mais possível observar a estrutura dimérica na $p(r)$, indicando que a amostra já se encontra bastante agregada.

Temos agora um único pico, denotando um aumento na secção transversal para $\approx 350 \AA$. Vale a pena ressaltar que, como vimos anteriormente com os resultados de massa molecular, não é possível perceber diferença entre as funções $p(r)$ em 37 e $45^{\circ} \mathrm{C}$. Novamente, podemos ter mistura de agregados proteicos de dimensões diferentes em solução, que serão melhor avaliadas no próximo Capítulo. 


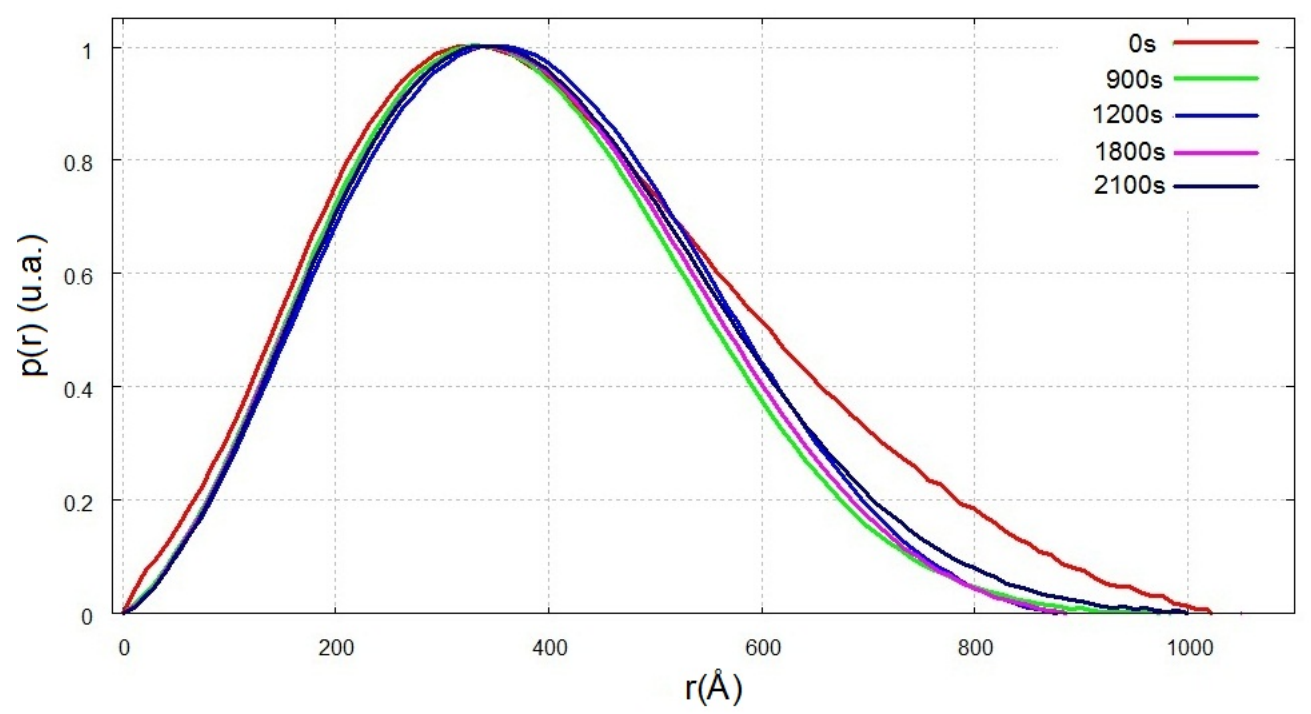

Figura 3.18: Evolução da função $p(r)$ com o tempo para a proteína SEPT2G a uma concentração de $0,5 \mathrm{mg} / \mathrm{mL}$ e $\mathrm{T}=37^{\circ} \mathrm{C}$.

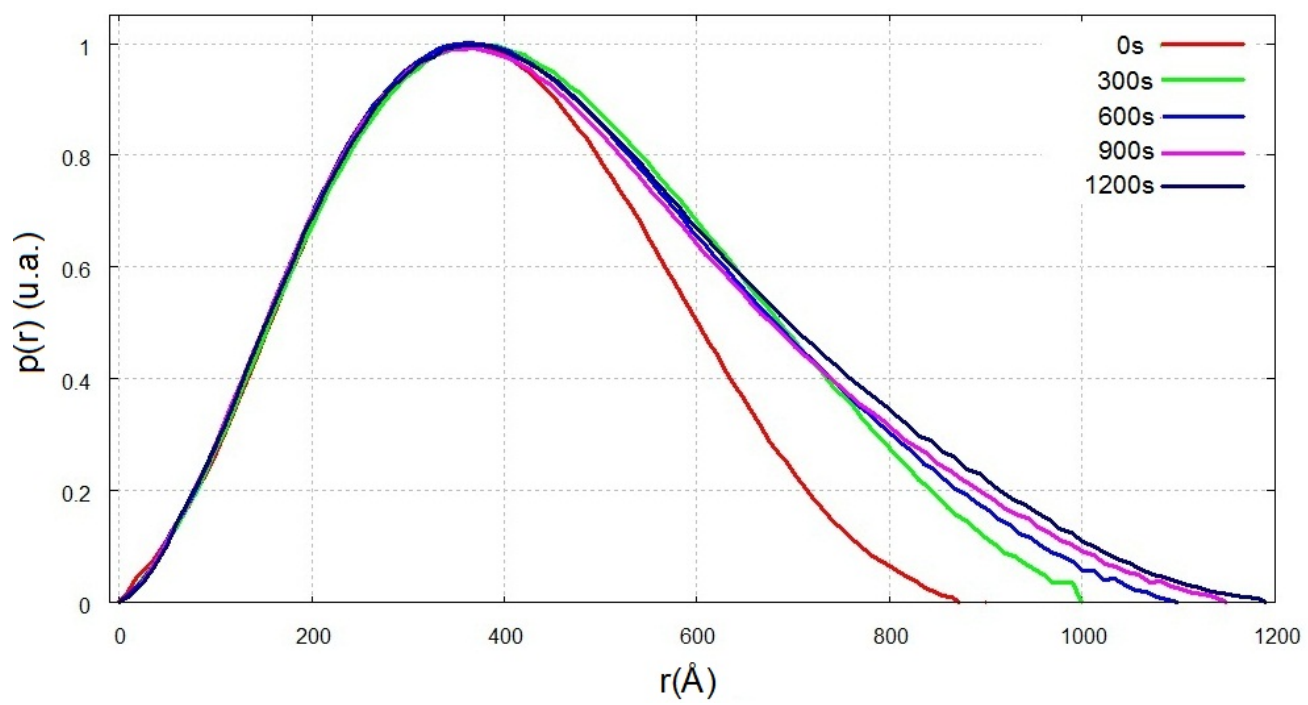

Figura 3.19: Evolução da função $p(r)$ com o tempo para a proteína SEPT2G a uma concentração de $0,5 \mathrm{mg} / \mathrm{mL}$ e $\mathrm{T}=45^{\circ} \mathrm{C}$. 


\subsubsection{Amostras a $1 \mathrm{mg} / \mathrm{mL}$}

Como observado para a concentração menor, a $1 \mathrm{mg} / \mathrm{mL}$ a proteína não apresenta mudanças na curva de espalhamento com o passar do tempo até $3300 \mathrm{~s}$ a $4^{\circ} \mathrm{C}$. A Figura 3.20 mostra a média das curvas experimentais e em detalhe temos a respectiva função $p(r)$ comparada à função $p(r)$ do dimero da SEPT2G. Os resultados da função $p(r)$ indicam a contribuição do dímero coexistindo com uma partícula espalhadora mais alongada tipo cilindro, cuja secção transversal é da ordem da menor dimensão do dímero (em torno de 40Å, Figura 2.6) e dimensão máxima $D_{\operatorname{máx}} \approx 400 \AA$.

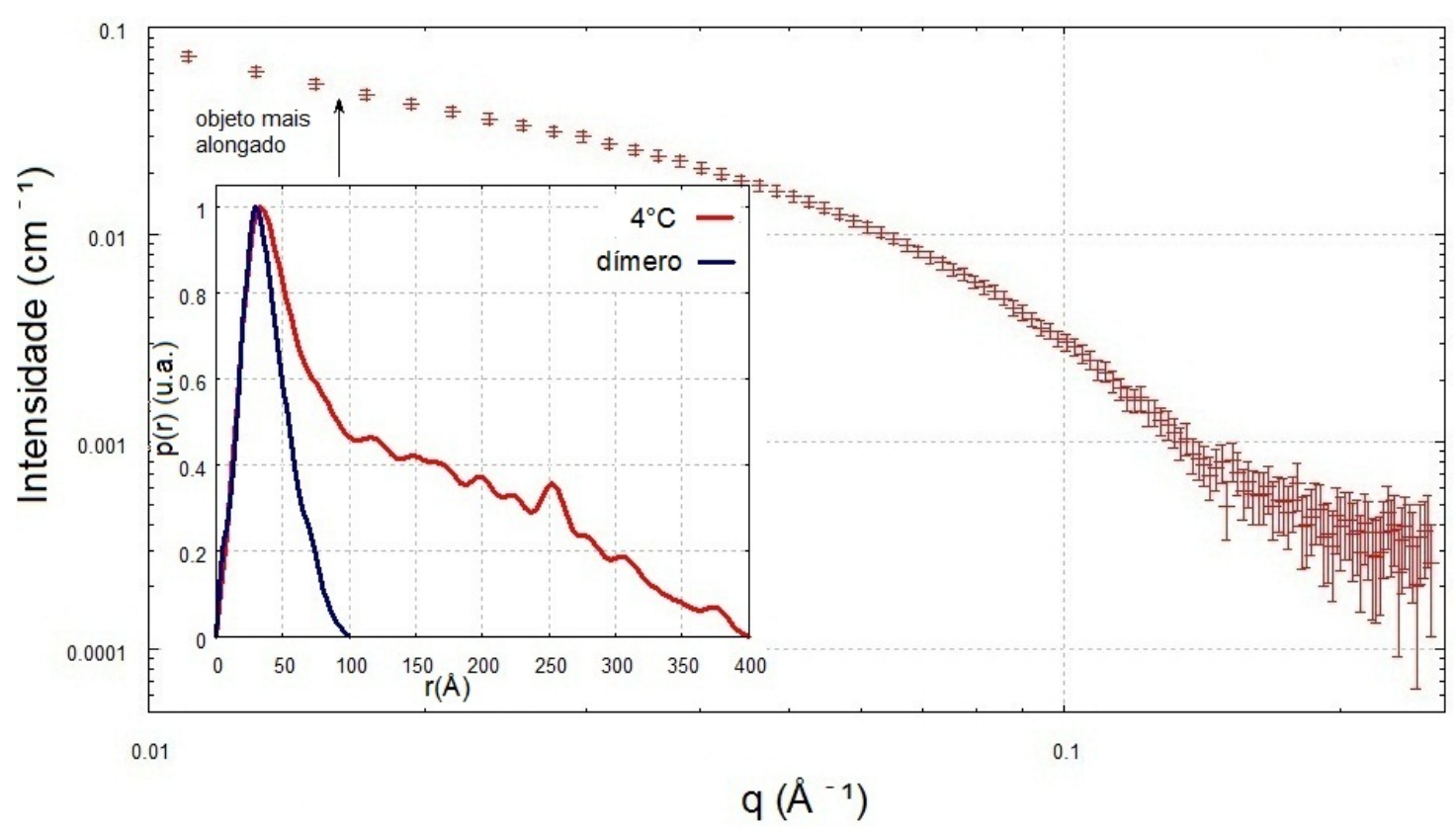

Figura 3.20: Média das curvas de SAXS para a proteína SEPT2G a uma concentração de $1 \mathrm{mg} / \mathrm{mL}$ e $\mathrm{T}=4^{\circ} \mathrm{C}$. No inserto temos a função $p(r)$ correspondente à curva de SAXS obtida pelo programa GNOM (em vermelho) e, para efeito de comparação, a função $p(r)$ calculada a partir da curva simulada obtida através da estrutura cristalográfica do dímero, como mostrado na Figura 2.6 (em azul).

Nas amostras de SEPT2G a $0,5 \mathrm{mg} / \mathrm{mL}$ e $15^{\circ} \mathrm{C}$ (Figura 3.16), apesar da função $p(r$ ) revelar a presença de agregados maiores, a estrutura dimérica está presente em todo o intervalo de medida. No entanto, para $1 \mathrm{mg} / \mathrm{mL}$ (Figura 3.21), verificamos que a partir de 1200s, já não vemos o pico inicial que representa essa estrutura menor. 


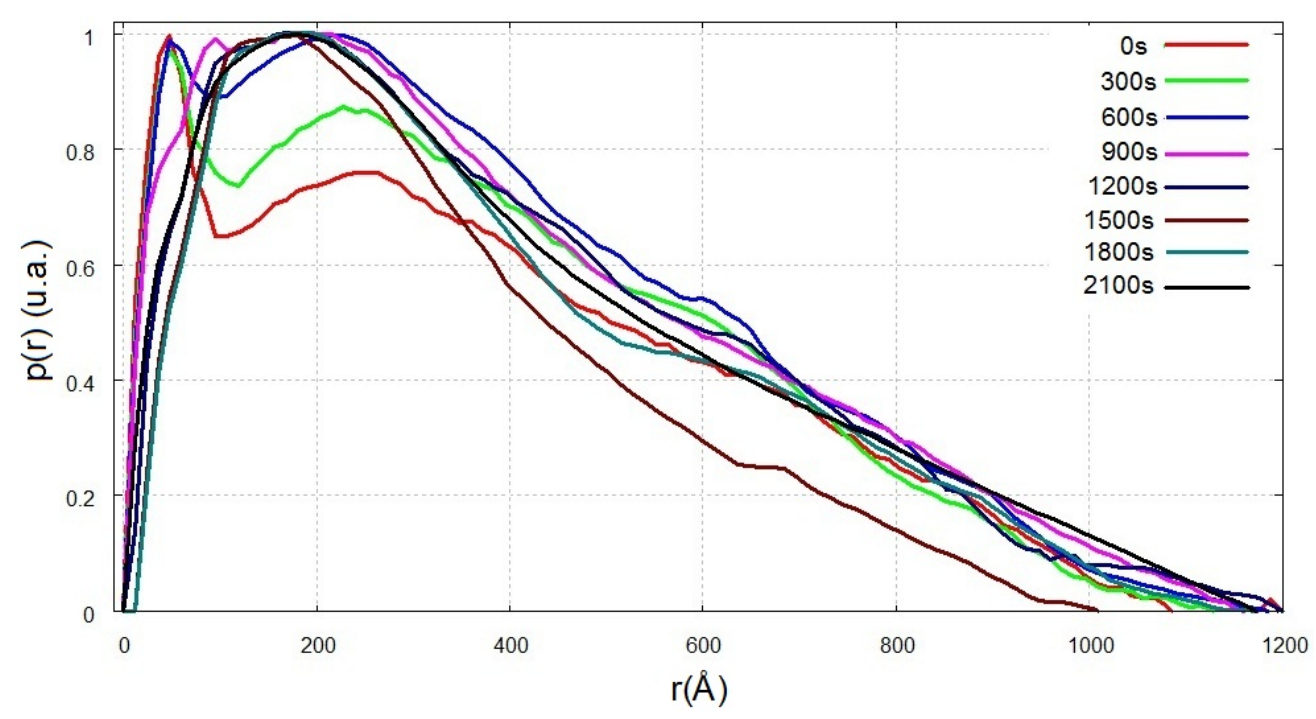

Figura 3.21: Evolução temporal da função $p(r)$ para a proteína SEPT2G a uma concentração de $1 \mathrm{mg} / \mathrm{mL}$ e $\mathrm{T}=15^{\circ} \mathrm{C}$.

Assim como para $0,5 \mathrm{mg} / \mathrm{mL}$ (Figura 3.17), a função $p(r)$ da amostra a $25^{\circ} \mathrm{C}$ (Figura 3.22 apresenta dois máximos: o primeiro indica a contribuição do dímero e o segundo, a presença de um oligômero de secção transversal de aproximadamente $200 \AA ̊ a$ a $300 \AA$. Ao contrário do caso a $25^{\circ} \mathrm{C}$ e $0,5 \mathrm{mg} / \mathrm{mL}$ onde essas duas contribuições são vistas ao longo de todo o intervalo de medida, para $1 \mathrm{mg} / \mathrm{mL}$ verificamos que a partir de 300 s a função apresenta apenas a parte referente a agregados maiores. A $p(r)$ na forma de sino foi vista anteriormente para a amostra com uma concentração de $0,5 \mathrm{mg} / \mathrm{mL}$ a 37 e $45^{\circ} \mathrm{C}$. Isso indica, como descrito anteriormente, que podemos ter a contribuição de agregados alongados de diversas dimensões em solução. 


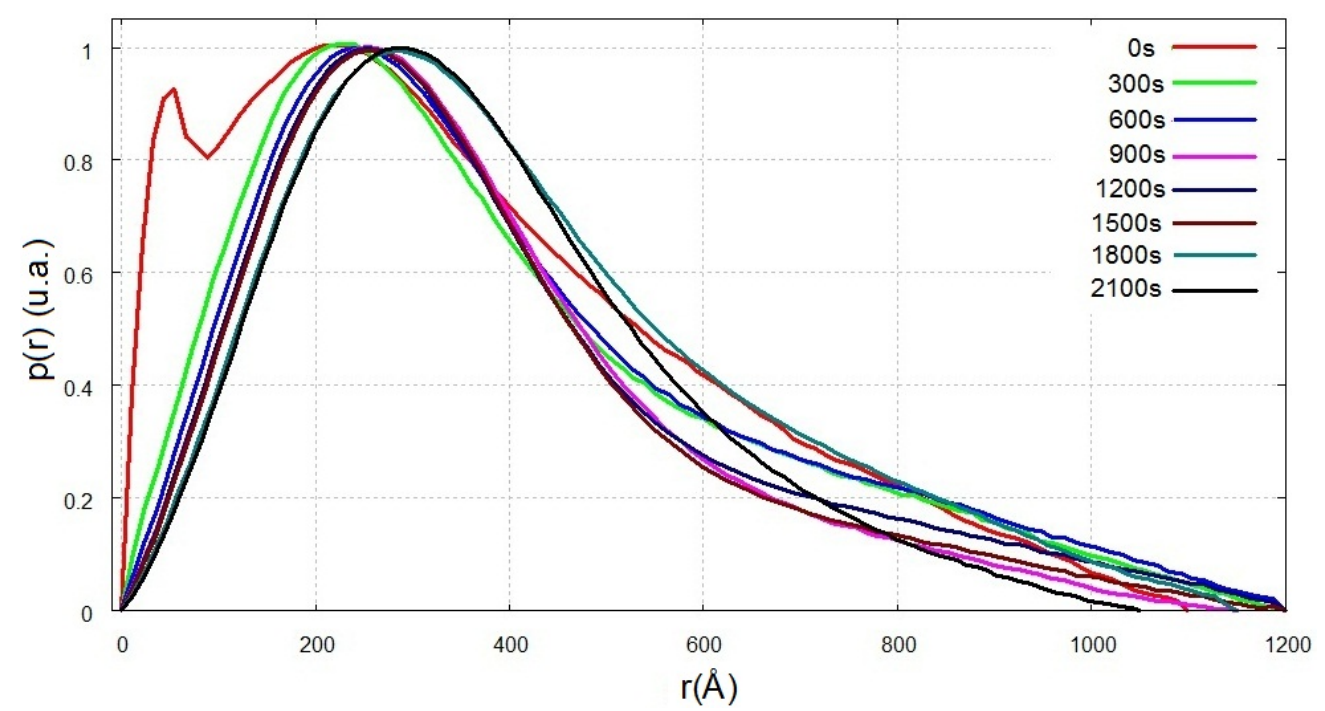

Figura 3.22: Evolução temporal da função $p(r)$ para a proteína SEPT2G a uma concentração de $1 \mathrm{mg} / \mathrm{mL}$ e $\mathrm{T}=25^{\circ} \mathrm{C}$. 
Ao aumentarmos a temperatura para $37^{\circ} \mathrm{C}$, o comportamento da função $p(r)$ é o mesmo que o observado para $0,5 \mathrm{mg} / \mathrm{mL}$, ou seja, desde o instante inicial já não vemos a componente do dimero (Figura 3.23). Podemos observar ainda um deslocamento no ponto máximo de 300 para $400 \AA$ ao longo do intervalo de 1200 s. O comportamento para $45^{\circ} \mathrm{C}$ (Figura 3.24 é similar ao que vemos a $37^{\circ} \mathrm{C}$ : a $p(r)$ já tem forma de sino logo no instante inicial e tem seu máximo deslocado para $400 \AA$, sem deixar evidente através da função a presença do dímero. Entretanto, não podemos descartar a sua contribuição sem a utilização de modelos para uma análise mais quantitativa.

Nossos resultados da análise modelo-independente das curvas de SAXS indicam que as curvas de espalhamento poderão ser ajustadas pela composição de dímeros, uma estrutura maior que representa um estágio intermediário de agregação, o que associamos a um agregado tipo-cilindro, e um agregado com dimensões maiores que o limite da técnica de SAXS. 


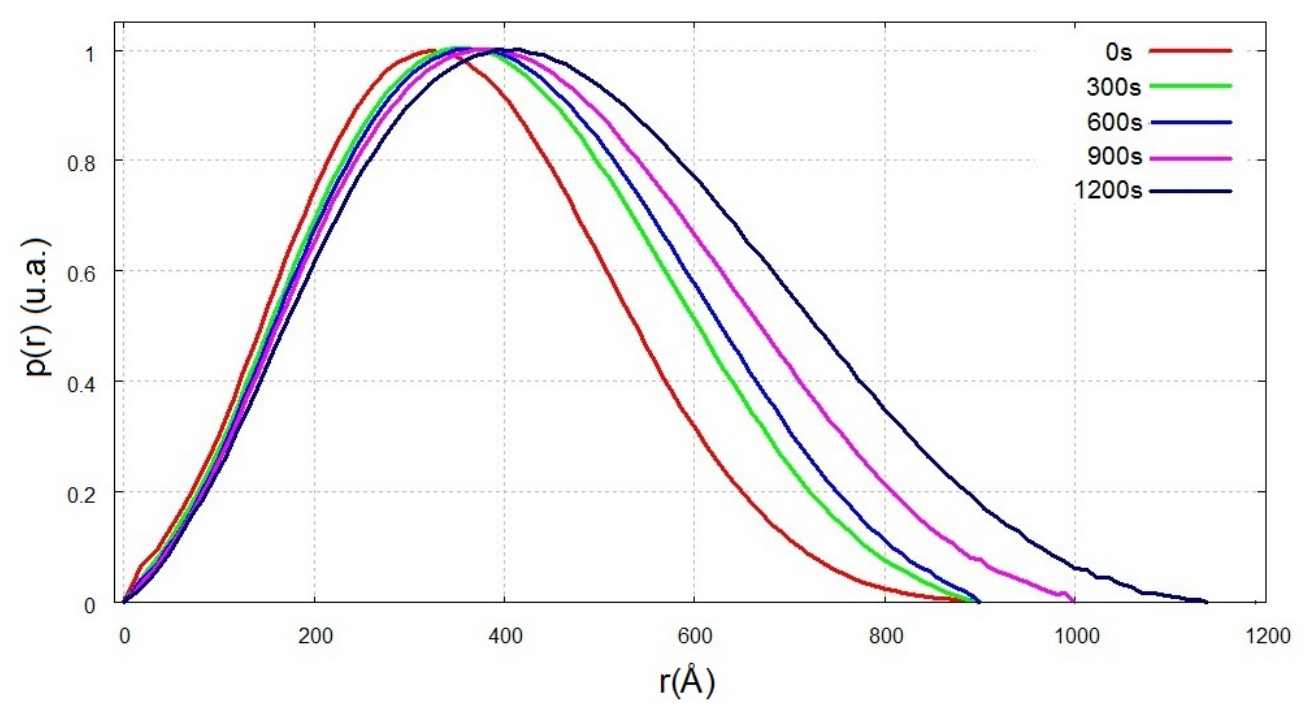

Figura 3.23: Evolução temporal da função $p(r)$ para a proteína SEPT2G a uma concentração de $1 \mathrm{mg} / \mathrm{mL}$ e $\mathrm{T}=37^{\circ} \mathrm{C}$.

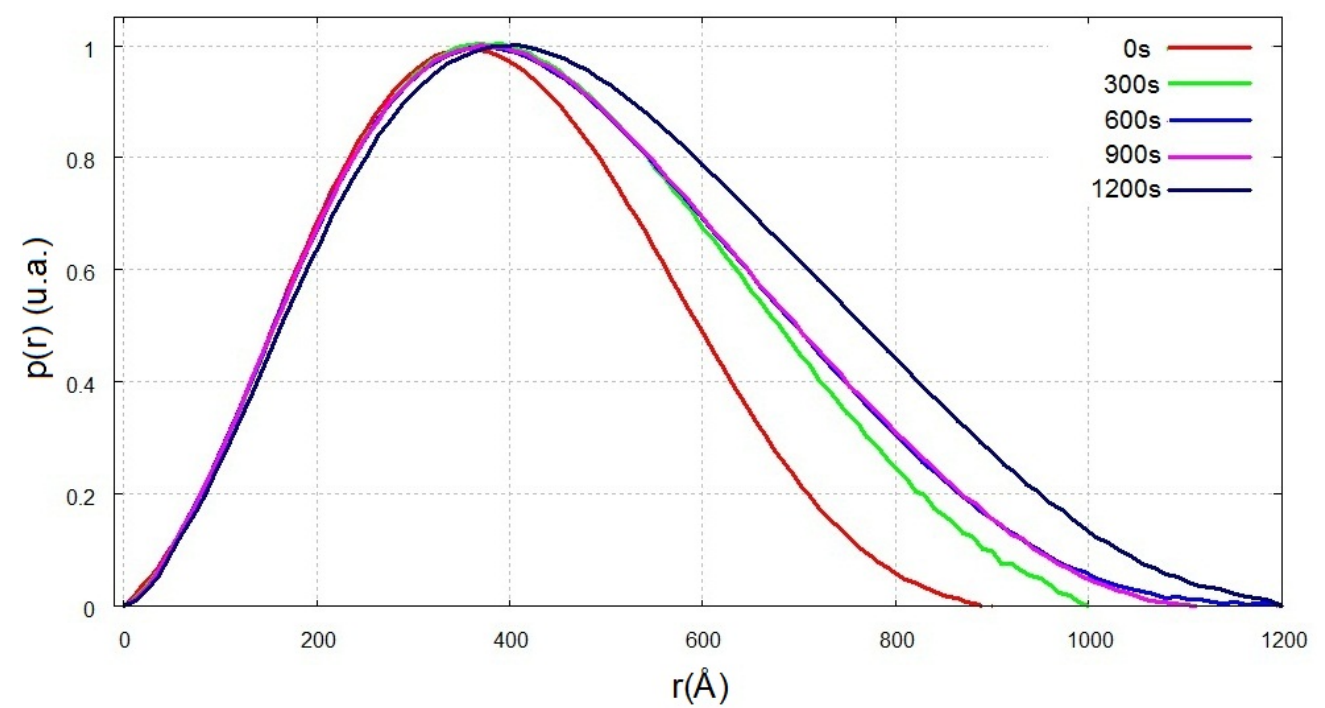

Figura 3.24: Evolução temporal da função $p(r)$ para a proteína SEPT2G a uma concentração de $1 \mathrm{mg} / \mathrm{mL}$ e $\mathrm{T}=45^{\circ} \mathrm{C}$. 


\subsection{Resultados de DLS}

Tendo em vista a grande variação de tamanho nos agregados de septina em função do tempo para uma temperatura fixa, foram realizadas medidas de espalhamento de luz dinâmico, uma vez que esta técnica nos permite observar dimensões maiores que a técnica de espalhamento de Raios-x.

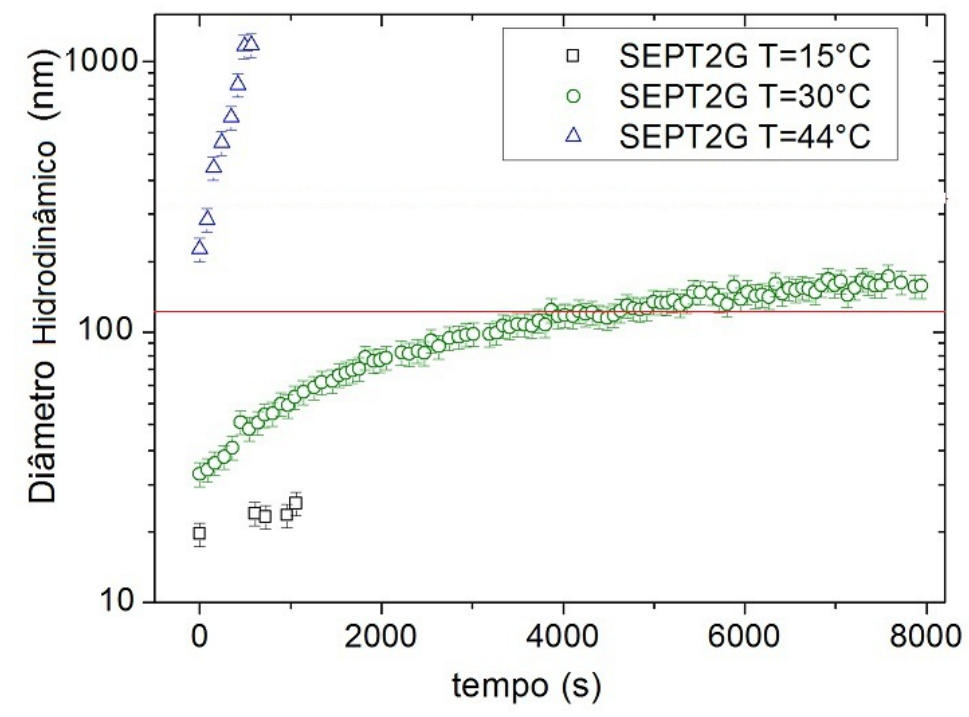

Figura 3.25: Evolução temporal do diâmetro hidrodinâmico obtido através de espalhamento de luz dinâmico para a SEPT2G a $1 \mathrm{mg} / \mathrm{mL}$ variando a temperatura entre 15,30 e $44^{\circ} \mathrm{C}$. A linha vermelha indica a dimensão máxima que a técnica de SAXS nos permite observar.

Observando a Figura 3.25 é possível perceber que para a SEPT2G, nas três temperaturas estudadas o diâmetro hidrodinâmico aumenta com o passar do tempo. Entretanto, a evolução no tamanho dos agregados é mais acentuada conforme aumentamos a temperatura. Para $15^{\circ} \mathrm{C}$ quase não temos variação ao longo de 1000 s sendo que o valor obtido (20 nm) é da mesma ordem de grandeza que o raio de giro obtido por SAXS em condições semelhantes. Se considerarmos o mesmo intervalo para $30^{\circ} \mathrm{C}$, o diâmetro hidrodinâmico aumenta de cerca de $30 \mathrm{~nm}$ para $60 \mathrm{~nm}$. Para $44^{\circ} \mathrm{C}$, a diferença é ainda maior: o agregado que tinha $200 \mathrm{~nm}$ no instante inicial tem um diâmetro de aproximadamente $1000 \mathrm{~nm}$ após o mesmo intervalo de medida. Visando uma comparação da resolução das duas técnicas, a linha vermelha nessa mesma figura indica a dimensão máxima que a técnica de SAXS nos permite observar. Não foi possível realizar medidas de espalhamento em temperaturas mais baixas que $15^{\circ} \mathrm{C}$, devido 
ao sistema de resfriamento do equipamento. Apesar disso, estudos anteriores realizados por Damalio e colaboradores [36, 37], demonstraram que não é possível verificar diferenças no espalhamento de luz obtido para temperaturas menores que $15^{\circ} \mathrm{C}$.

Ao compararmos os resultados de espalhamento de luz obtidos neste trabalho e os resultados descritos pelo Dr. Julio Damalio [36, 37], podemos verificar que existe um efeito de concentração, além da temperatura e evolução temporal. Resultados de Damalio e colaboradores, revelaram um espalhamento constante para a SEPT2G a $15^{\circ} \mathrm{C}$ nas concentrações de aproximadamente 0,17 e $0,34 \mathrm{mg} / \mathrm{mL}$ mesmo após 5500s de observação. Também foi verificado pelo mesmo grupo que o aumento das dimensões das partículas espalhadoras é mais acentuado conforme a concentração aumenta.

Utilizando a técnica de DLS, pudemos observar um aumento no diâmetro hidrodinâmico mesmo em intervalos de cerca de 1 minuto. Portanto, o tamanho do agregado se altera com o tempo e, lembrando que as medidas de SAXS foram realizadas em um intervalo de tempo mínimo de 2 minutos, podemos afirmar que as dimensões finais obtidas por SAXS correspondem a uma média temporal principalmente para altas temperaturas. 


\subsection{Conclusões Parciais}

A partir da análise do raio de giro verificamos que quando a uma concentração de 0,5 $\mathrm{mg} / \mathrm{mL}$ e temperatura igual a $4^{\circ} \mathrm{C}$, a SEPT2G apresenta um valor compatível com o esperado para a proteína na forma dimérica. Da mesma maneira, a análise de massa molecular e função $p(r)$ apresentou resultados compatíveis com os esperados para o dimero da SEPT2G.

Assim como para $0,5 \mathrm{mg} / \mathrm{mL}$ a proteína a $4^{\circ} \mathrm{C}$ e $1 \mathrm{mg} / \mathrm{mL}$ não apresentou mudanças ao longo de 3300s. Apesar disso, os resultados de raio de giro, massa molecular e função $p(r)$ indicam a presença de uma estrutura alongada coexistindo com o dímero em solução.

Foi possível verificar através das funções $p(r)$, não apenas o efeito da concentração, mas também que um aumento na temperatura induz as partículas espalhadoras a aumentarem não apenas sua dimensão máxima, mas também sua secção transversal.

Ao investigarmos as amostras a 37 e $45^{\circ} \mathrm{C}$ nas duas concentrações estudadas, não foi possível perceber diferenças significativas tanto nos valores de massa molecular quanto nas funções $p(r)$.

Os resultados de espalhamento de luz reforçam os resultados de SAXS, indicando novamente um aumento nas dimensões das partículas espalhadoras com o passar do tempo e uma aceleração nesse processo dependente da temperatura. Vemos ainda que os agregados a temperaturas maiores que $30^{\circ} \mathrm{C}$ têm dimensões maiores que o limite de resolução da técnica de SAXS permite distinguir.

Com base nas informações obtidas até este ponto podemos afirmar que temos dímeros de SEPT2G coexistindo com estruturas alongadas que não se dissociam, apenas aumentam seu tamanho com o passar do tempo. No capítulo seguinte poderemos quantificar cada uma das populações na solução através do uso de modelos. 


\section{Capítulo 4}

\section{Análise Modelo-Dependente e Discussão}

Tendo em vista os resultados obtidos para a massa molecular, Raio de Giro e função $p(r)$ dos dados apresentados no Capítulo anterior e na busca de estágios intermediários de agregação entre dímeros e fibras alongadas amilóides, propomos o ajuste das curvas experimentais utilizando a composição de três modelos: uma estrutura básica dada pelo dimero da proteína, um objeto cilíndrico e agregados maiores cujas dimensões ultrapassam o limite da técnica experimental e o espalhamento observado no intervalo de $q$ estudado segue a lei $I(q) \propto q^{-4}$ (região de Porod). Além desses modelos, se fez necessário também a inclusão de uma intensidade de fundo constante devido ao ruído eletrônico do detector, tal que:

$$
I(q)=I_{\text {dimero }}(q)+I_{\text {agregado do tipo cilindro }}(q)+I_{\text {agregado do tipo Porod }}(q)+\text { fundo }
$$

As contribuições dos diferentes modelos foram avaliadas através dos parâmetros indicados na Seção 2.2.5. Na Tabela 4.1 estão apresentados todos os parâmetros obtidos nos ajustes das curvas experimentais das amostras com uma concentração igual a $0,5 \mathrm{mg} / \mathrm{mL}$. De maneira análoga, na Tabela 4.3 temos os parâmetros de ajuste aos dados experimentais obtidos para as amostras a $1 \mathrm{mg} / \mathrm{mL}$.

Com base nos resultados dos ajustes das curvas de espalhamento mostrados na Tabela 4.1 e Tabela 4.3 (para $0,5 \mathrm{mg} / \mathrm{mL}$ e $1 \mathrm{mg} / \mathrm{mL}$, respectivamente) alguns outros parâmetros foram calculados para uma melhor interpretação do sistema. São eles: a porcentagem de proteína na forma de dímero $\left(\%_{\text {dímero }}\right)$, de agregados do tipo cilindro $\left(\%_{\text {cilindro }}\right)$ e agregados do tipo 
Porod $\left(\%_{\text {porod }}\right)$, além da fração volume de proteína nos cilindros $(\phi)$ e quantos monômeros essa fração representa $\left(N_{\text {agreg }}\right)$, assim como o número de moléculas de água por monômero $\left(\frac{N_{\mathrm{H}_{2} \mathrm{O}}}{N_{\text {agreg }}}\right)$. As equações e relações utilizadas para o cálculo desses parâmetros estão descritas a Seção 2.2 .5 e os valores obtidos podem ser apreciados nas Tabelas 4.2 e 4.4 para $0,5 \mathrm{mg} / \mathrm{mL}$ e $1 \mathrm{mg} / \mathrm{mL}$, respectivamente.

\subsection{Exemplo de ajuste teórico aos dados de SAXS utili- zando modelos}

Como exemplo de ajuste utilizando o programa GENFIT, a Figura 4.1 mostra a curva experimental para a SEPT2G a $1 \mathrm{mg} / \mathrm{mL}$ e $25^{\circ} \mathrm{C}$. A linha contínua em azul indica o ajuste aos dados experimentais da curva utilizando a composição dos três modelos e o fundo. Por sua vez, as linhas descontínuas indicam cada modelo isoladamente. Podemos perceber que a contribuição do dímero (curva tracejada em verde)se mostra dominante na região de $q \geq 0,035$. A adição de um fundo (linha pontilhada em laranja) se mostra necessária ao observarmos que o comportamento da região $q \geq 0,15 \AA^{-1}$ é dada basicamente pelo dímero, a menos de uma pequena diferença entre a curva experimental e a simulada do dímero.

Sabemos que a contribuição de agregados grandes, ajustados pelo modelo de Porod (curva tracejada e pontilhada em cinza), é observada na região de valores pequenos de $q$, entretanto a faixa de $q \leq 0,035 \AA^{-1}$ não é proporcional à $q^{-4}$. Com isso, podemos ver que o modelo de cilindro (curva tracejada e pontilhada em rosa) também tem uma grande contribuição nessa região de $q$. 


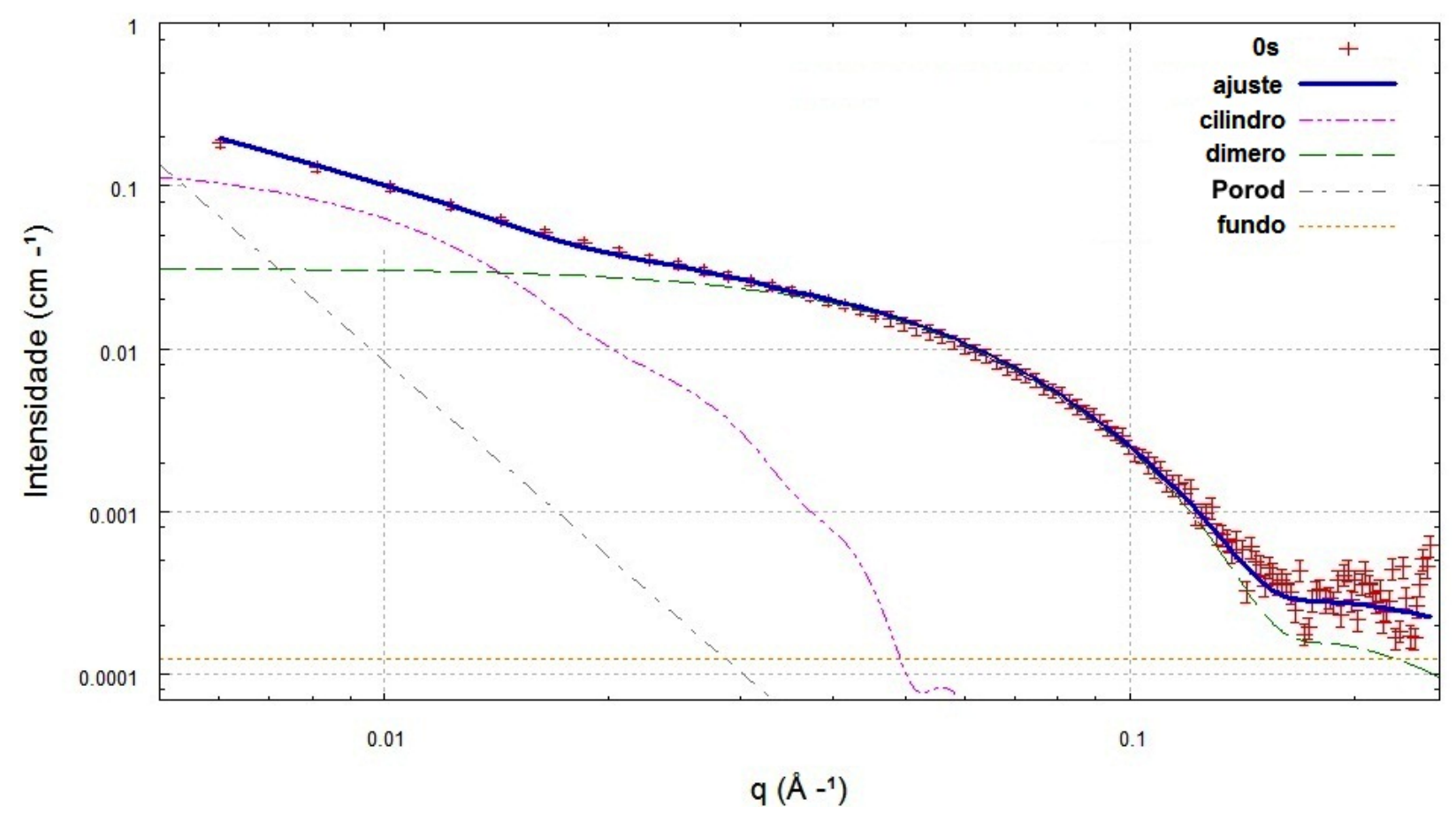

Figura 4.1: Exemplo de ajuste da curva de SAXS para a proteína SEPT2G a uma concentração de $1 \mathrm{mg} / \mathrm{mL}$ e $\mathrm{T}=25^{\circ} \mathrm{C}$ no instante $\mathrm{t}=0 \mathrm{~s}$ utilizando os modelos de dímero (Figura 2.6), agregado do tipo cilindro e do tipo Porod, com contribuições de 67\%, 2,6\% e 30,4\%, respectivamente (Tabela 4.4). 


\subsection{Amostras a $0,5 \mathrm{mg} / \mathrm{mL}$}

Na Figura 4.2 mostramos os dados de espalhamento referente à média dos dados obtidos no intervalo de medida da SEPT2G a $0,5 \mathrm{mg} / \mathrm{mL}$ e $4^{\circ} \mathrm{C}$ e o ajuste utilizando o modelo de dímero da estrutura cristalográfica (Figura 2.6) acrescido de $9 \%$ em seu volume. Conforme podemos perceber, o modelo do dímero da SEPT2G ajusta-se muito bem aos dados experimentais a $4^{\circ} \mathrm{C}$, em concordância com a função $p(r)$, valores de Raio de Giro e massa molecular obtidos no Capítulo 3. O valor obtido para o parâmetro de ajuste de densidade eletrônica relativa da camada de hidratação foi $d_{c o r} \approx 1,0$, indicando um valor compatível com a densidade eletrônica do solvente.

Além disso, para o ajuste de todas as curvas de SAXS da SEPT2G a $0,5 \mathrm{mg} / \mathrm{mL}$, foi adicionado uma intensidade de fundo da ordem de $10^{-4} \mathrm{~cm}^{-} 1$.

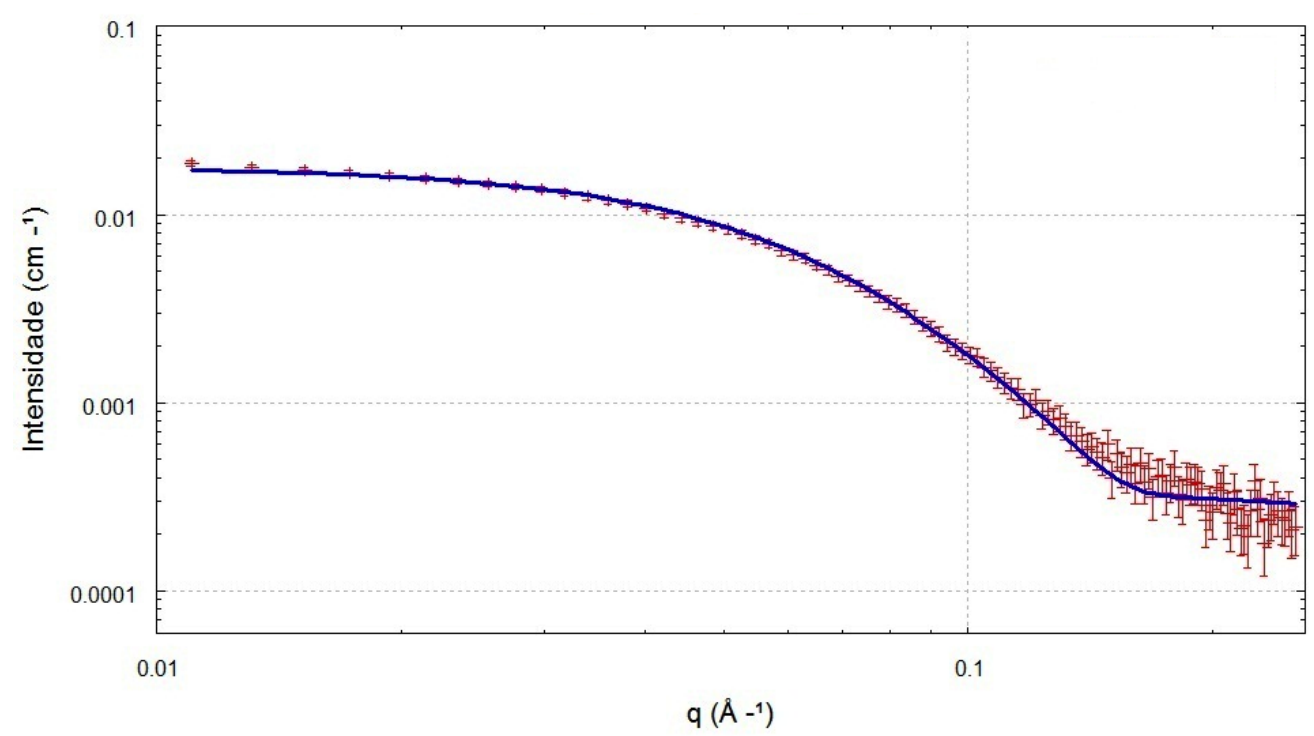

Figura 4.2: Melhor ajuste (linha contínua) aos dados experimentais de SAXS da SEPT2G a $0,5 \mathrm{mg} / \mathrm{mL}$ e $\mathrm{T}=4^{\circ} \mathrm{C}(+)$, utilizando o modelo do dímero da SEPT2G (Figura 2.6).

A Figura 4.3 mostra curvas de SAXS a $15^{\circ} \mathrm{C}$ em três instantes diferentes (0, 900 e $\left.1800 \mathrm{~s}\right)$ e os melhores ajustes aos dados experimentais utilizando os três modelos citados anteriormente (Eq. 4.1). Nesta temperatura já começamos a perceber a presença de outras populações coexistindo com o dímero em solução (Tabela 4.1). Logo no instante inicial a porcentagem de dímeros é aproximadamente de $88 \%$, sendo que 10,6\% da proteína em solução se agrega 
em um arranjo tipo cilindro. Ainda, coexistindo com os dimeros e estes agregados, temos aproximadamente $2 \%$ de septinas compondo agregados do tipo Porod (Tabela 4.2). Nessa temperatura e concentração, o parâmetro $d_{\text {cor }}$ novamente forneceu um valor que evidencia uma densidade eletrônica compatível com a do solvente(Tabela 4.1).

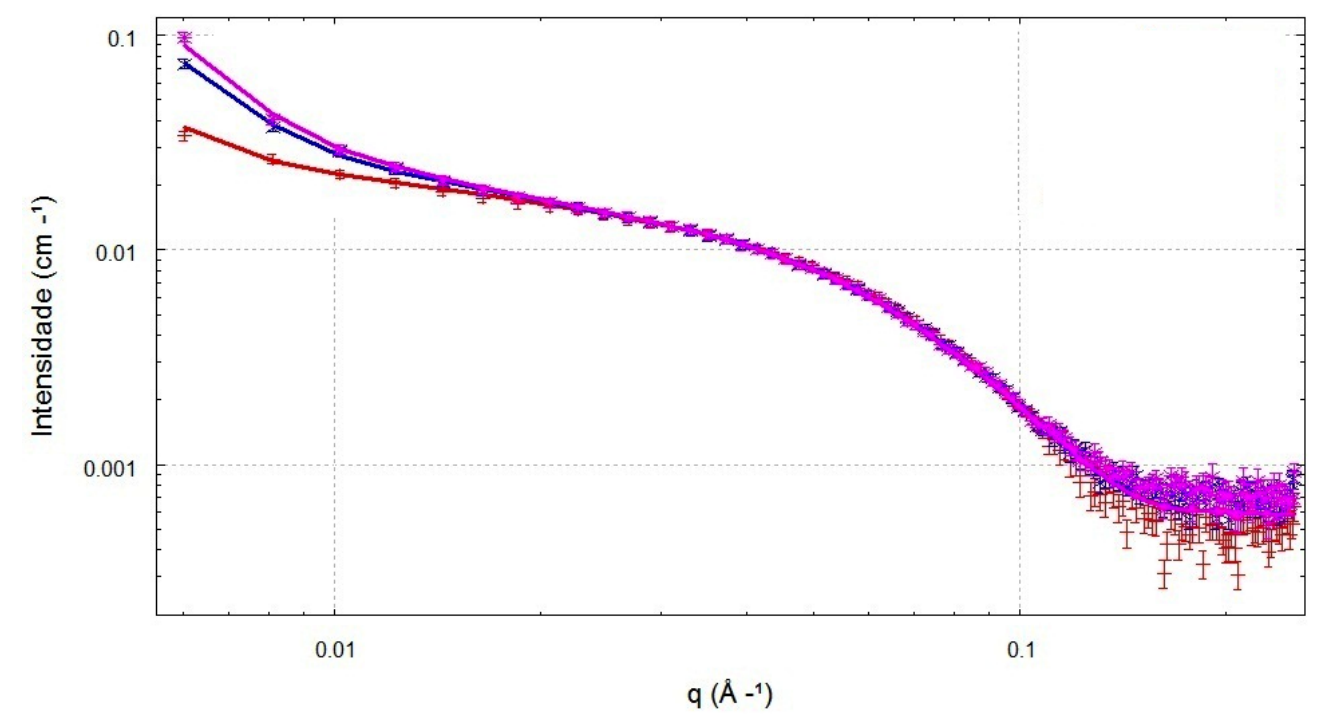

Figura 4.3: Melhor ajuste (linhas contínuas) SAXS da SEPT2G a $0,5 \mathrm{mg} / \mathrm{mL}$ e $\mathrm{T}=15^{\circ} \mathrm{C}$ nos instantes $\mathrm{t}=0(+), 900(\times)$ e 1800 s $(*)$ agregado do tipo cilindro e agregado do tipo Porod.

Podemos observar que ao longo de 1800s de medida, a porcentagem de dímero diminui cerca de $8 \%$ (Tabela 4.2), que passam a contribuir com o espalhamento de agregados do tipo Porod. A contribuição dos agregados do tipo cilindro mantém-se constante por volta de $12 \%$.

O agregado cilíndrico encontrado em solução tem aproximadamente $27 \AA$ e $306 \AA$ de raio e comprimento, respectivamente (Tabela 4.1). Observamos que não houve alteração desses valores com o passar do tempo para tais condições de temperatura e concentração. A densidade eletrônica correspondente foi de $\rho_{\text {cilindro }}=0,404 \frac{e^{-}}{\AA^{3}}$, que é um valor menor do que o valor esperado para uma proteína de $\rho=0,42 \frac{e^{-}}{\AA^{3}}$ [45]. Sendo assim, podemos estimar uma quantidade de água (solvente) preenchendo este envelope cilíndrico, resultando numa fração de volume de proteína $\phi$ de $82 \%$ (Tabela 4.2 contida nesse envelope. Além disso, cada agregado cilíndrico tem número de agregação $N=14$, com cerca de 320 moléculas de água(Tabela 4.2). 
Pensando em um modelo de agregação para este envelope cilíndrico e considerando as dimensões já conhecidas de dados de cristalografia de raio-X na literatura para o arranjo dimérico de septinas (Figuras 1.5 e 2.6) e hexamérico (Figura 1.6), observamos que a altura do cilindro é compatível com a associação linear de sete monômeros de SEPT2G, enquanto a seção transversal pode conter duas fileiras de heptâmeros.

Com o intuito de verificarmos essa hipótese, simulamos a curva de espalhamento para uma estrutura formada por 14 monômeros de SEPT2G, sendo estes dispostos em duas colunas de sete monômeros com associação lateral (Figura 1.6), compondo um agregado com dimensões compatíveis com o cilindro obtido, conforme esquematizado na Figura 4.4. Essa curva de espalhamento bem como a curva teórica para o envelope cilíndrico são mostrados para efeito de comparação na Figura 4.5. Podemos verificar assim que a curva obtida a partir do arranjo de 14 monômeros está de acordo com a do cilindro teórico, reforçando a hipótese que os monômeros se associam lado a lado para formar o agregado do tipo cilindro. 


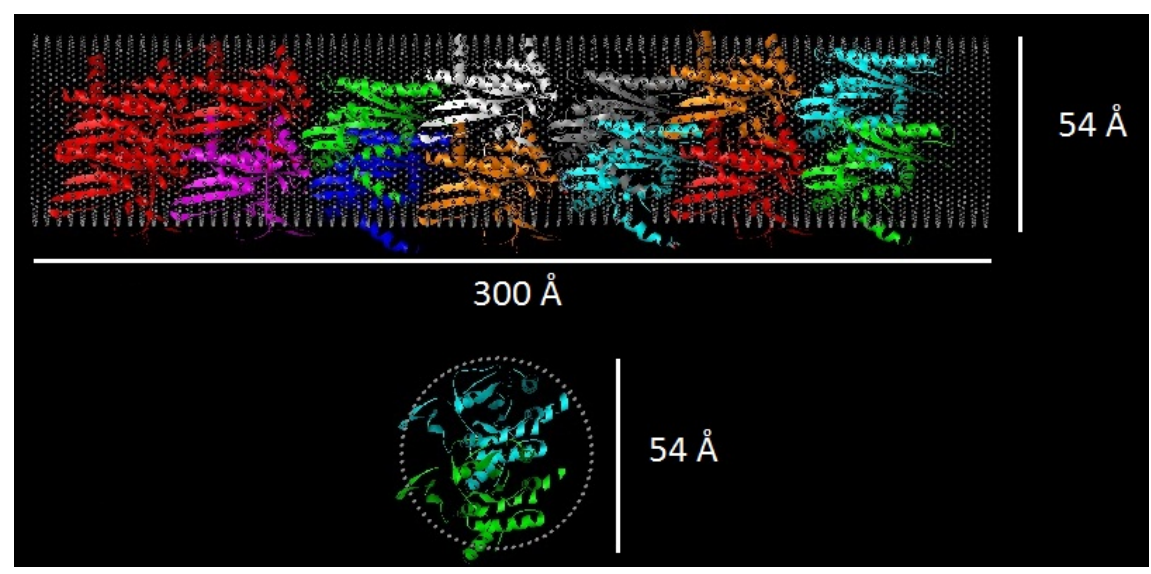

Figura 4.4: Estrutura formada por 14 monômeros de SEPT2G juntamente com o envelope cilíndrico obtido através dos ajustes aos dados experimentais da SEPT2G a $15^{\circ} \mathrm{C}$ e 0,5 $\mathrm{mg} / \mathrm{mL}$.

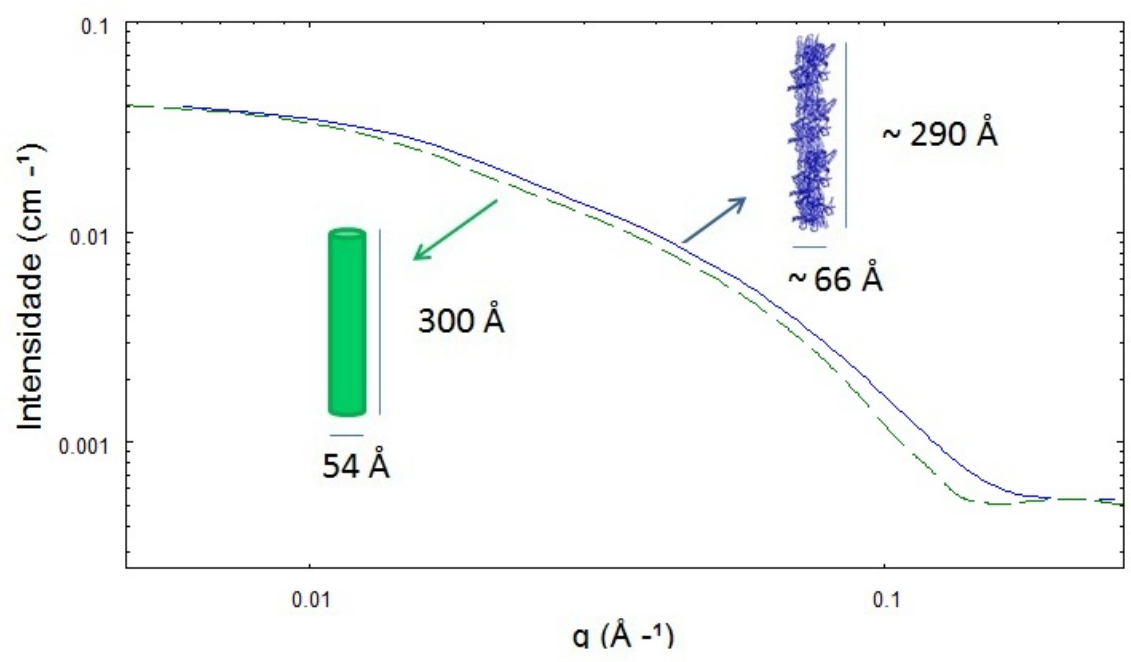

Figura 4.5: Curva de SAXS simulada a partir de um envelope cilíndrico (linha tracejada em verde) com dimensões obtidas através dos ajustes aos dados experimentais da SEPT2G a $15^{\circ} \mathrm{C}$ e $0,5 \mathrm{mg} / \mathrm{mL}$ (Tabela 4.1 ) juntamente com a curva simulada a partir da estrutura formada pela composição de 14 monômeros (linha contínua em azul). 
Para o agregado do tipo Porod $\rho_{\text {Porod }}$ (Tabela 4.1) indica novamente a presença de água nos agregados e/ou estruturas irregulares. Como podemos observar na Tabela 4.1, o valor da densidade eletrônica dos agregados do tipo Porod não sofre alterações significativas para todas as temperaturas e intervalos estudados para a SEPT2G a 0,5 mg/mL. O valor de $\sigma$ (relação entre a superfície e o volume do agregado) tem ordem de grandeza de $10^{-3}$.

Na Figura 4.6 temos os dados experimentais de SAXS a $25^{\circ} \mathrm{C}$ em três instantes diferentes $(0,1200$ e $2100 \mathrm{~s})$ e os melhores ajustes aos dados experimentais para essas curvas conforme a Eq. 4.1.

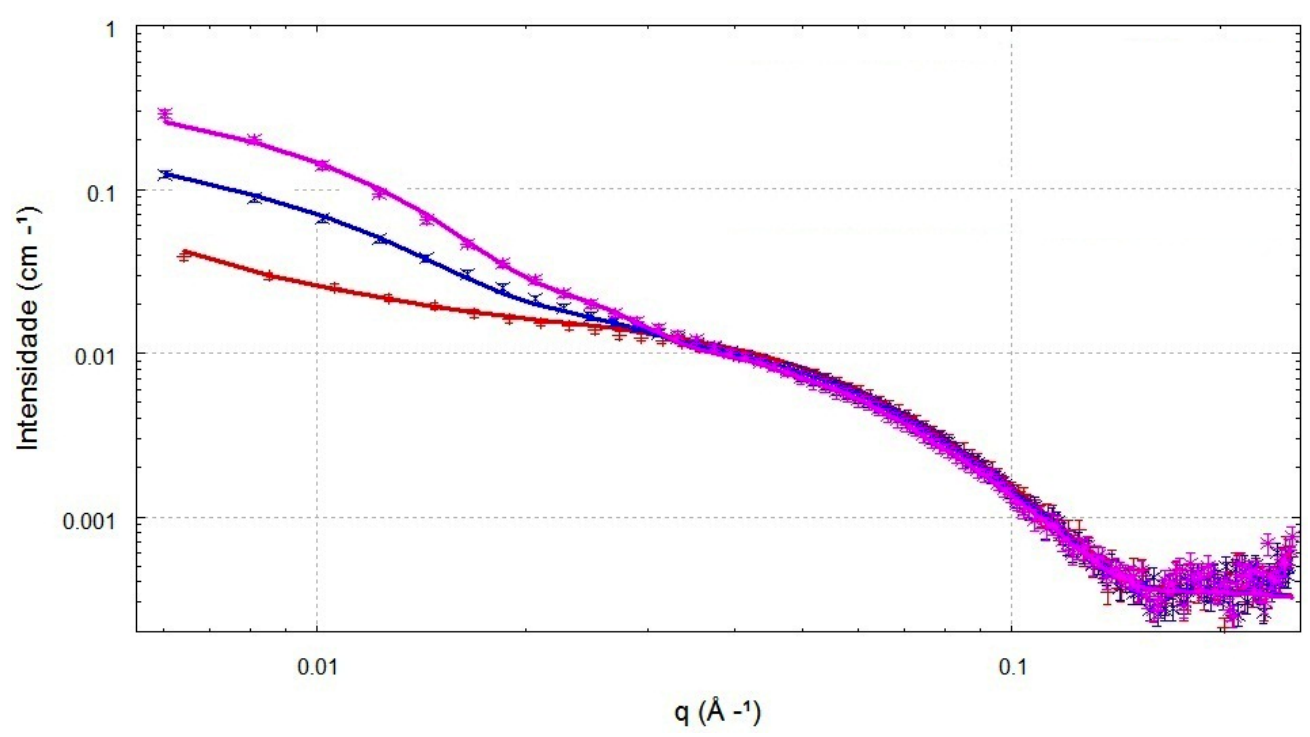

Figura 4.6: Melhor ajuste (linhas contínuas) aos dados experimentais de SAXS da SEPT2G a $0,5 \mathrm{mg} / \mathrm{mL}$ e $\mathrm{T}=25^{\circ} \mathrm{C}$ nos instantes $\mathrm{t}=0(+), 1200(\times)$ e $2100 \mathrm{~s}(*)$, utilizando os modelos de dímero da SEPT2G (Figura 2.6), agregado do tipo cilindro e agregado do tipo Porod.

No instante inicial, a SEPT $2 \mathrm{G}$ a $25^{\circ} \mathrm{C}$ apresenta aproximadamente $70 \%$ de dímeros, enquanto que a $15^{\circ} \mathrm{C}$, como vimos anteriormente, esse valor era de cerca de $90 \%$ (Tabela 4.2). Além disso, o valor obtido para a densidade relativa da camada de hidratação da SEPT2G na forma dimérica, indica um aumento de 15\% da densidade eletrônica com relação ao solvente (Tabela 4.1).

Apesar das dimensões dos agregados do tipo cilindro aumentarem com relação a $15^{\circ} \mathrm{C}$, em termos do total das partículas espalhadoras, sua contribuição é de apenas $0,5 \%$. Por sua 
vez, a porcentagem dos agregados do tipo Porod é de cerca de $30 \%$ já no instante inicial, não apresentando alterações significativas ao longo do intervalo de tempo medido. A evolução temporal é vista nos modelos de dímero e agregados do tipo cilindro: a porcentagem de dímeros apresenta um decréscimo de cerca de $70 \%$ para cerca de $60 \%$ ao longo de 2100 s de medida, ao passo que a contribuição dos cilindros aumenta de 0,5 para aproximadamente $10 \%$ (Tabela 4.2 .

Ao comparamos os resultados obtidos a 15 e $25^{\circ} \mathrm{C}$ podemos observar não apenas uma diferença na contribuição na intensidade de espalhamento dependente dos agregados do tipo cilindro , mas também uma mudança no envelope cilindrico: para $15^{\circ} \mathrm{C}$ o agregado obtido tinha a forma de um canudo, ou seja, sua altura era maior que seu diâmetro. Para $25^{\circ} \mathrm{C}$, o agregado do tipo cilindro toma a forma de um disco, com diâmetro maior que sua altura com valores de $210 \AA$ e $154 \AA$ para raio e comprimento, respectivamente (Tabela 4.1). Além disso, como consequência do aumento das dimensões do agregado cilíndrico, temos um aumento no número de agregação para 432 monômeros compondo o agregado, com cerca de 290 moléculas de água por monômero, valor compatível com o encontrado na temperatura anterior (Tabela 4.2 .

Na Figura 4.7 observamos os dados experimentais de SAXS da SEPT2G a $0,5 \mathrm{mg} / \mathrm{mL}$ e $\mathrm{T}=37^{\circ} \mathrm{C}$ nos instantes $\mathrm{t}=0,1200$ e 2100s. Nesta mesma Figura também temos os melhores ajustes experimentais, que desta vez foi composto apenas pelo modelo de dímero e agregados do tipo Porod $\left(x_{\text {cilindro }}=0\right)$. A ausência de cilindros pode ser indício de uma aceleração no processo de agregação, ou seja, pode ser que haja a formação de cilindros, mas estes passam a compor um agregado maior em um intervalo menor que 3 minutos, que é o tempo de aquisição de dados.

A densidade eletrônica relativa da camada de hidratação da proteína na forma dimérica obtida para essa temperatura indica que temos um valor de densidade eletrônica cerca de $10 \%$ maior que a do solvente (Tabela 4.1).

Ao compararmos a quantidade de dímeros no instante inicial a $37^{\circ} \mathrm{C}$ com os resultados a uma temperatura de $25^{\circ} \mathrm{C}$, vemos um decréscimo de aproximadamente $70 \%$ para $65 \%$ (Tabela 4.2). A grande diferença entre as duas temperaturas mostra-se na evolução do agregado com o passar do tempo: ao passo que a $25^{\circ} \mathrm{C}$ a quantidade de agregados do tipo Porod mantínha-se constante, para $37^{\circ} \mathrm{C}$ a porcentagem aumentou de cerca de $35 \%$ para $81 \%$ em 35 minutos. 


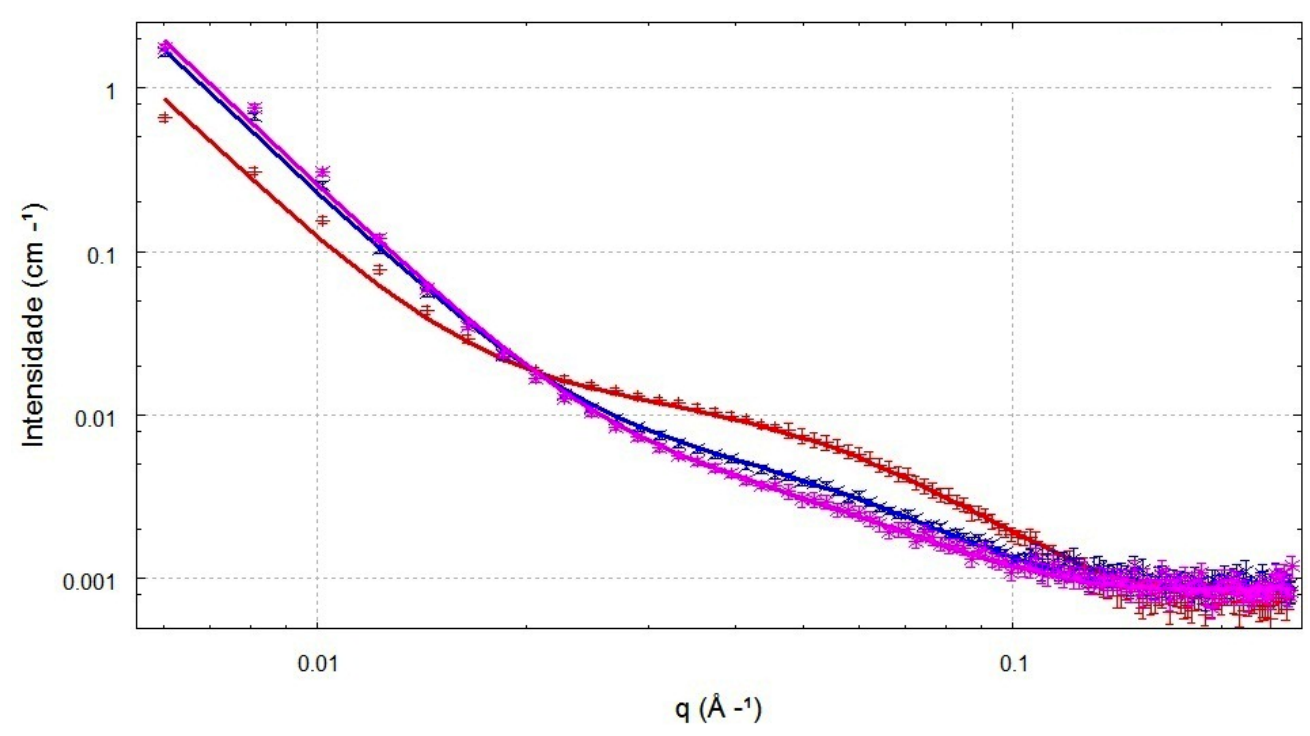

Figura 4.7: Melhor ajuste (linhas contínuas) aos dados experimentais de SAXS da SEPT2G a $0,5 \mathrm{mg} / \mathrm{mL}$ e $\mathrm{T}=37^{\circ} \mathrm{C}$ nos instantes $\mathrm{t}=0(+), 1200(\times)$ e $2100 \mathrm{~s}(*)$, utilizando os modelos de dímero da SEPT2G (Figura 2.6) e agregado do tipo Porod.

O comportamento da SEPT2G a $45^{\circ} \mathrm{C}$, como podemos ver na Figura 4.8, é similar a $37^{\circ} \mathrm{C}$, uma vez que novamente não temos a presença de agregados do tipo cilindro logo no instante inicial. O processo de agregação, no entanto, mostra-se ainda mais acentuado: ao longo de 20 minutos a porcentagem de agregados grandes aumenta de 41 para $94 \%$, ou seja, praticamente toda a proteína em solução encontra-se altamente agregada. 


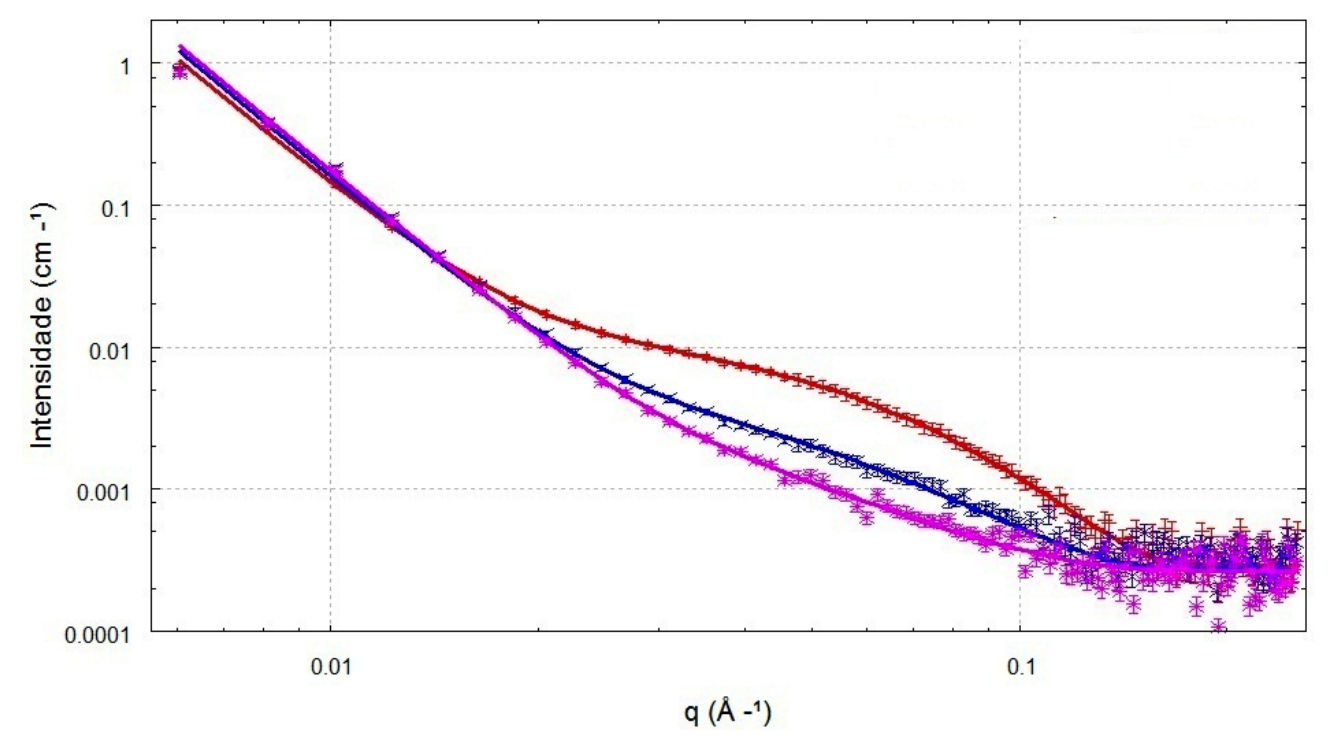

Figura 4.8: Melhor ajuste (linhas contínuas) aos dados experimentais de SAXS da SEPT2G a $0,5 \mathrm{mg} / \mathrm{mL}$ e $\mathrm{T}=45^{\circ} \mathrm{C}$ nos instantes $\mathrm{t}=0(+), 600(\times)$ e $1200 \mathrm{~s}(*)$, utilizando os modelos de dímero da SEPT2G (Figura 2.6) e agregado do tipo Porod. 


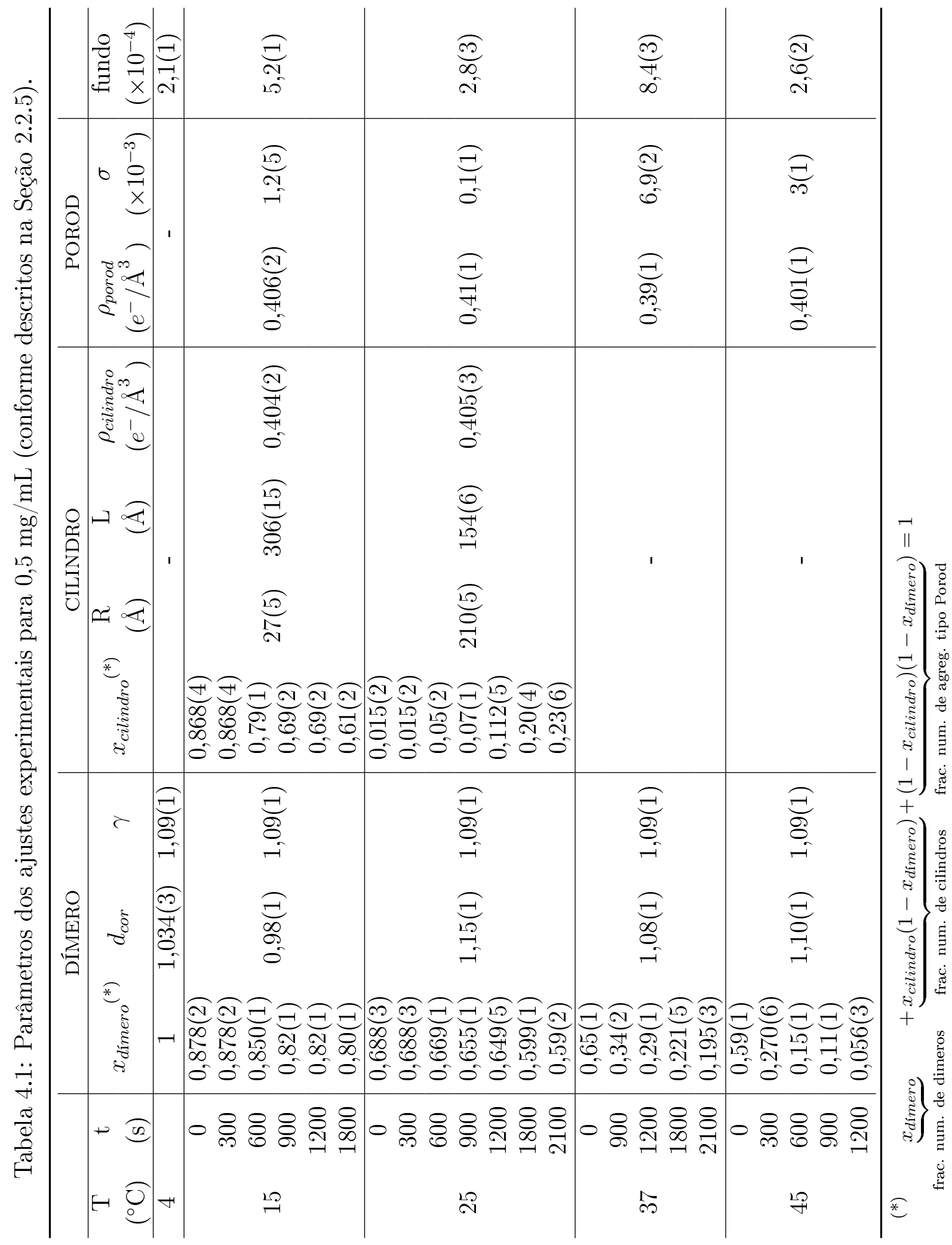


Tabela 4.2: Parâmetros calculados a partir dos ajustes experimentais para $0,5 \mathrm{mg} / \mathrm{mL}$ (conforme descritos na Seção 2.2.5).

\begin{tabular}{|c|c|c|c|c|c|c|c|}
\hline \multirow[b]{2}{*}{$\begin{array}{c}\mathrm{T} \\
\left({ }^{\circ} \mathrm{C}\right)\end{array}$} & \multirow[b]{2}{*}{$\begin{array}{c}\mathrm{t} \\
(\mathrm{s})\end{array}$} & \multirow{2}{*}{$\begin{array}{l}\text { DÍMERO } \\
\% \text { dímero }\end{array}$} & \multicolumn{4}{|c|}{ CILINDRO } & \multirow{2}{*}{$\frac{\text { POROD }}{\%_{\text {porod }}}$} \\
\hline & & & $\%_{\text {cilindro }}$ & $N_{\text {agreg }}$ & $\frac{N_{\mathrm{H}_{2} \mathrm{O}}}{N_{\text {agreg }}}$ & $\begin{array}{c}\phi \\
(\%)\end{array}$ & \\
\hline 4 & & 100 & & - & & & - \\
\hline \multirow{6}{*}{15} & 0 & $87,8(2)$ & $10,6(2)$ & $14(5)$ & $312(90)$ & $82(3)$ & $1,6(1)$ \\
\hline & 300 & $87,8(2)$ & $10,6(2)$ & $14(5)$ & $312(90)$ & $82(3)$ & $1,6(1)$ \\
\hline & 600 & $85,0(1)$ & $11,8(2)$ & $14(5)$ & $312(90)$ & $82(3)$ & $3,2(2)$ \\
\hline & 900 & $82(1)$ & $12(1)$ & $14(5)$ & $312(90)$ & $82(3)$ & $6(1)$ \\
\hline & 1200 & $82(1)$ & $12(1)$ & $14(5)$ & $312(90)$ & $82(3)$ & $6(1)$ \\
\hline & 1800 & $80(1)$ & $12(1)$ & $14(5)$ & $312(90)$ & $82(3)$ & $8(1)$ \\
\hline \multirow{7}{*}{25} & 0 & $68,8(3)$ & $0,5(1)$ & $432(27)$ & 291(18) & $83(2)$ & $30,7(3)$ \\
\hline & 300 & $68,8(3)$ & $0,5(1)$ & $432(27)$ & 291(18) & $83(2)$ & $30,7(3)$ \\
\hline & 600 & $66,9(1)$ & $1,7(7)$ & $432(27)$ & 291(18) & $83(2)$ & $31,4(7)$ \\
\hline & 900 & $65,5(1)$ & $2,4(3)$ & $432(27)$ & 291(18) & $83(2)$ & $32,1(4)$ \\
\hline & 1200 & $64,9(5)$ & $3,9(2)$ & $432(27)$ & 291(18) & $83(2)$ & $31,2(5)$ \\
\hline & 1800 & $60,0(1)$ & $8(2)$ & $432(27)$ & 291(18) & $83(2)$ & $32(2)$ \\
\hline & 2100 & $59(2)$ & $9(2)$ & $432(27)$ & 291(18) & $83(2)$ & $32(3)$ \\
\hline \multirow{5}{*}{37} & 0 & $65(1)$ & & & $35(1)$ \\
\hline & 900 & $34(2)$ & & & & & $66(2)$ \\
\hline & 1200 & $29(1)$ & & & & & $71(1)$ \\
\hline & 1800 & $22,1(5)$ & & & & & $77,9(5)$ \\
\hline & 2100 & $19,5(3)$ & & & & & $80,5(3)$ \\
\hline \multirow{5}{*}{45} & 0 & $59(1)$ & & \multirow{5}{*}{-} & & & $41(1)$ \\
\hline & 300 & $27(1)$ & & & & & $73(1)$ \\
\hline & 600 & $15(1)$ & & & & & $85(1)$ \\
\hline & 900 & $10(1)$ & & & & & $90(1)$ \\
\hline & 1200 & $5,6(3)$ & & & & & $94,4(3)$ \\
\hline
\end{tabular}


A partir das porcentagens mostradas na Tabela 4.2, organizamos as informações em gráficos para uma melhor visualização da evolução do processo de agregação com o tempo de aquisição de dados para as diferentes temperaturas, como pode ser visto na Figura 4.9

Para a amostra a $0,5 \mathrm{mg} / \mathrm{mL}$ e $4^{\circ} \mathrm{C}$ como podemos observar na Figura 4.9. A, a proteína em solução estava em sua totalidade na forma dimérica e essa condição se mostrou estável ao longo de meia hora (1800s). Dados de microscopia eletrônica da SEPT2 a $4^{\circ} \mathrm{C}$ medidos por Damalio e colaboradores [36], mostram que apenas após 48h de incubação é possivel visualizar filamentos de aproximadamente $200 \AA$ de diâmetro. Após $120 \mathrm{~h}$ de incubação verificaram-se agregados irregulares de dimensões de aproximadamente de $300 \mathrm{~nm}$.

Na Figura 4.9.B podemos observar que a $15^{\circ} \mathrm{C}$, ao se passarem 15 minutos (900s) de medida, a porcentagem dos dímeros diminui para aproximadamente $80 \%$ e com isso temos um aumento na quantidade de proteína na forma de agregados do tipo Porod. Nos 15 minutos seguintes a configuração das estruturas em solução permanece estável. Comparando com os dados de dicroismo circular (CD) de Damalio e colaboradores [36], para SEPT2G também a $15^{\circ} \mathrm{C}$ e a uma concentração de $0,34 \mathrm{mg} / \mathrm{mL}$, têm-se a presença de $25 \%$ de $\alpha$-hélice, $24 \%$ de folhas- $\beta$ e $50 \%$ de estruturas irregulares, para tais condições não podemos afirmar que os agregados cilíndricos medidos por SAXS formam arranjos tipo-amilóides. Para efeito de comparação, temos que a sequência secundária da SEPT2G apresenta $32 \%$ de $\alpha$-hélice, $15 \%$ de folhas- $\beta$ e $53 \%$ de estruturas irregulares [36].

Podemos comparar esses resultados com dados de fluorescência de Tioflavina $\mathrm{T}$ (ThT) para a SEPT2G em mesma concentração e temperaturas (dados fornecidos pelo Dr. Julio Damalio, Figura 4.10) . A ThT é um cromóforo que se intercala às estruturas do tipo "cross- $\beta$ ", sendo conhecida por ser um marcador de agregados amilóides, uma vez que tais estruturas são predominante nestes agregados [54].

Podemos observar na Figura 4.10 que a $15^{\circ} \mathrm{C}$ não temos uma mudança significativa na intensidade de fluorescência. Isso é um indicativo que as estruturas cilíndricas identificadas por SAXS apresentam uma quantidade muito pequena de ligações "cross- $\beta$ ", abaixo do que é possível detectar com o fluorímetro. 
A $25^{\circ} \mathrm{C}$ (Figura 4.9.C) observamos que no instante inicial temos uma porção ínfima de agregados do tipo cilindro, entretanto, a porcentagem de agregados do tipo Porod no instante inicial é de aproximadamente $30 \%$ e mantém-se constante por todo o intervalo de medida. Ao longo de 35 minutos (2100s) observamos uma diminuição de $10 \%$ nas estruturas diméricas e mesmo aumento nos agregados do tipo cilindro.

Ao compararmos com os dados de ThT (Figura 4.10), podemos verificar que durante o mesmo período estudado por SAXS (2100s), não observamos alteração significativa na intensidade de fluorescência. Para períodos maiores que 2500s, vemos um pequeno aumento na intensidade, indicando um aumento de ligações "cross- $\beta$ ".

Ao aumentarmos a temperatura para $37^{\circ} \mathrm{C}$, como podemos observar na Figura 4.9.D, a porcentagem inicial de dímeros é semelhante à $25^{\circ} \mathrm{C}$, a grande diferença se mostra na ausência de estruturas cilíndricas e aumento de cerca de $30 \%$ de agregados do tipo Porod. Rapidamente há uma inversão nas proporções de dímeros e agregados: já em 15 minutos temos mais de $60 \%$ da proteína formando agregados do tipo Porod e essa porcentagem aumenta ao longo de todo o intervalo de medida, chegando até $80 \%$ ao longo de 35 minutos.

Uma das vias de agregação mostrada do esquema da Figura 1.1 é justamente a da proteína na estrutura nativa passando diretamente a compor fibras. É importante ressaltar que os agregados do tipo Porod representam objetos espalhadores com dimensões maiores que $1200 \AA$, entretanto não podemos afirmar se temos apenas fibras ou também a presença de agregados amorfos utilizando apenas a técnica de SAXS. Não podemos, contudo, descartar totalmente a possibilidade de termos estágios intermediários de agregação em intervalos menores que o de aquisição de dados (que para esta concentração foi de 3 minutos), uma vez que verificamos através da técnica de DLS que em períodos de 50s é possível observar alterações no diâmetro efetivo dos objetos espalhadores.

Além disso, a partir de $37^{\circ} \mathrm{C}$ observamos um aumento praticamente linear na intensidade de fluorescência de ThT (Figura 4.10), indicando um aumento na quantidade de ligações cross- $\beta$. Ao compararmos com os dados de SAXS, verificamos que nessa temperatura não conseguimos mais distinguir os estágios intermediários de agregação, ou seja, ou agregados do tipo cilindro, em solução.

A $45^{\circ} \mathrm{C}$, como pode ser visto na Figura 4.9 E o comportamento é semelhante à $37^{\circ} \mathrm{C}$, mas a cinética é ainda mais rápida: no instante inicial temos $60 \%$ de dímeros mas, em 300s, cerca de $70 \%$ da proteína já encontra-se compondo agregados do tipo Porod e em 1200s 
cerca de $95 \%$ já está muito ou totalmente agregada. Por sua vez, resultados de CD [36] da SEPT2G a $0,34 \mathrm{mg} / \mathrm{mL}$ indicam um aumento para $35 \%$ nas estruturas folha- $\beta$, sendo um indicativo que os agregados encontrados nessas condições podem estar em uma conformação amilóide. Os dados de fluorescência de ThT (Figura 4.10) a $45^{\circ} \mathrm{C}$ mostram um aumento mais acentuado na intensidade até aproximadamente 2100s. Após esse período, podemos perceber que a intensidade de emissão começa a estabilizar.

Os resultados de SAXS mostraram a formação de agregados cilíndricos que evoluem para agregados do tipo Porod com o passar do tempo. Ao compararmos com os dados de dicroismo circular e fluorescência de ThT nas mesmas temperaturas e concentrações próximas, foi possivel identificar a presença predominante de folhas- $\beta$, arranjadas de maneira a formar ligações cross- $\beta$ para as temperaturas de 37 e $45^{\circ} \mathrm{C}$. Assim sendo, podemos inferir que a SEPT2G em tais condições pode apresentar características amilóides. Estes estariam sendo detectados como grandes agregados (tipo Porod) nos nossos dados.

Vale a pena ressaltar ainda que dados de microscopia do Dr. Julio Damalio [36] evidenciaram a formação de fibras longas a uma concentração de $0,44 \mathrm{mg} / \mathrm{mL}$ e $4^{\circ} \mathrm{C}$ com secção transversal da ordem de 20 a $50 \mathrm{~nm}$. Note que a secção transversal dos cilindros encontrados a uma temperatura de $25^{\circ} \mathrm{C}$ é da ordem de $40 \mathrm{~nm}$ (Figura 4.9). Talvez tais cilindros sejam precursores de fibras alongadas que crescem axialmente, dando origem a fibras amilóides a temperaturas maiores $\left(\mathrm{T}=37\right.$ e $45^{\circ} \mathrm{C}$ ). Dos dados de $\sigma$ (Tabela 4.1 ), da ordem de $10^{-3}$, temos que a relação $\sigma=\frac{S}{V}=\frac{2}{R}$ (cilindros longos), indicaria estruturas fibrilares com $R \approx 200 \mathrm{~nm}$. 

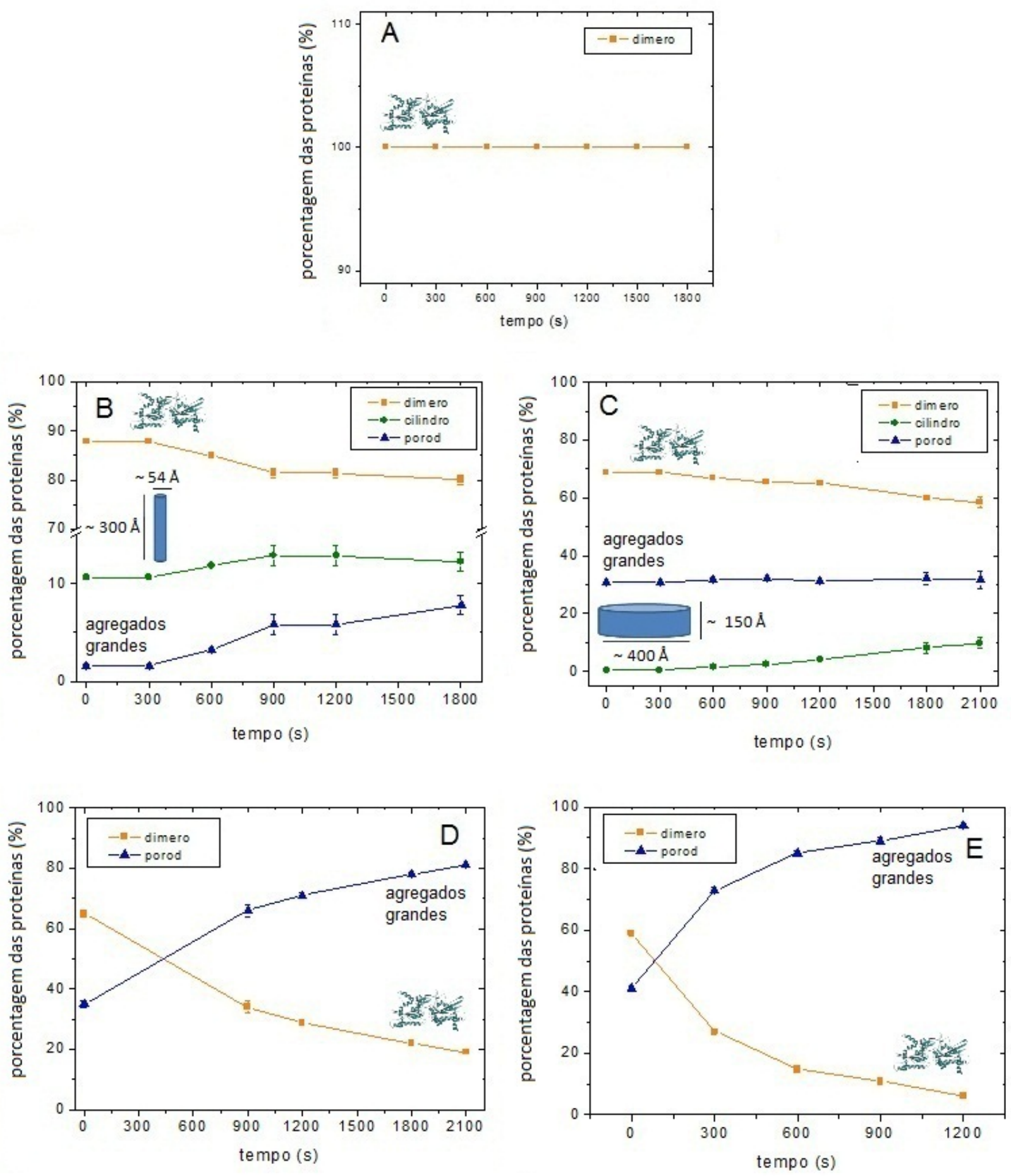

Figura 4.9: Porcentagens da proteína na forma de dímero, agregados do tipo cilindro e agregados do tipo Porod para $0,5 \mathrm{mg} / \mathrm{mL}$ em temperaturas de $(\mathrm{A}): 4^{\circ} \mathrm{C} ;(\mathrm{B}): 15^{\circ} \mathrm{C} ;(\mathrm{C})$ : $25^{\circ} \mathrm{C}$; (D): $37^{\circ} \mathrm{C}$ e $(\mathrm{E}): 45^{\circ} \mathrm{C}$. Os cilindros representados estão em escala entre si, mas não com a representação do dímero. 


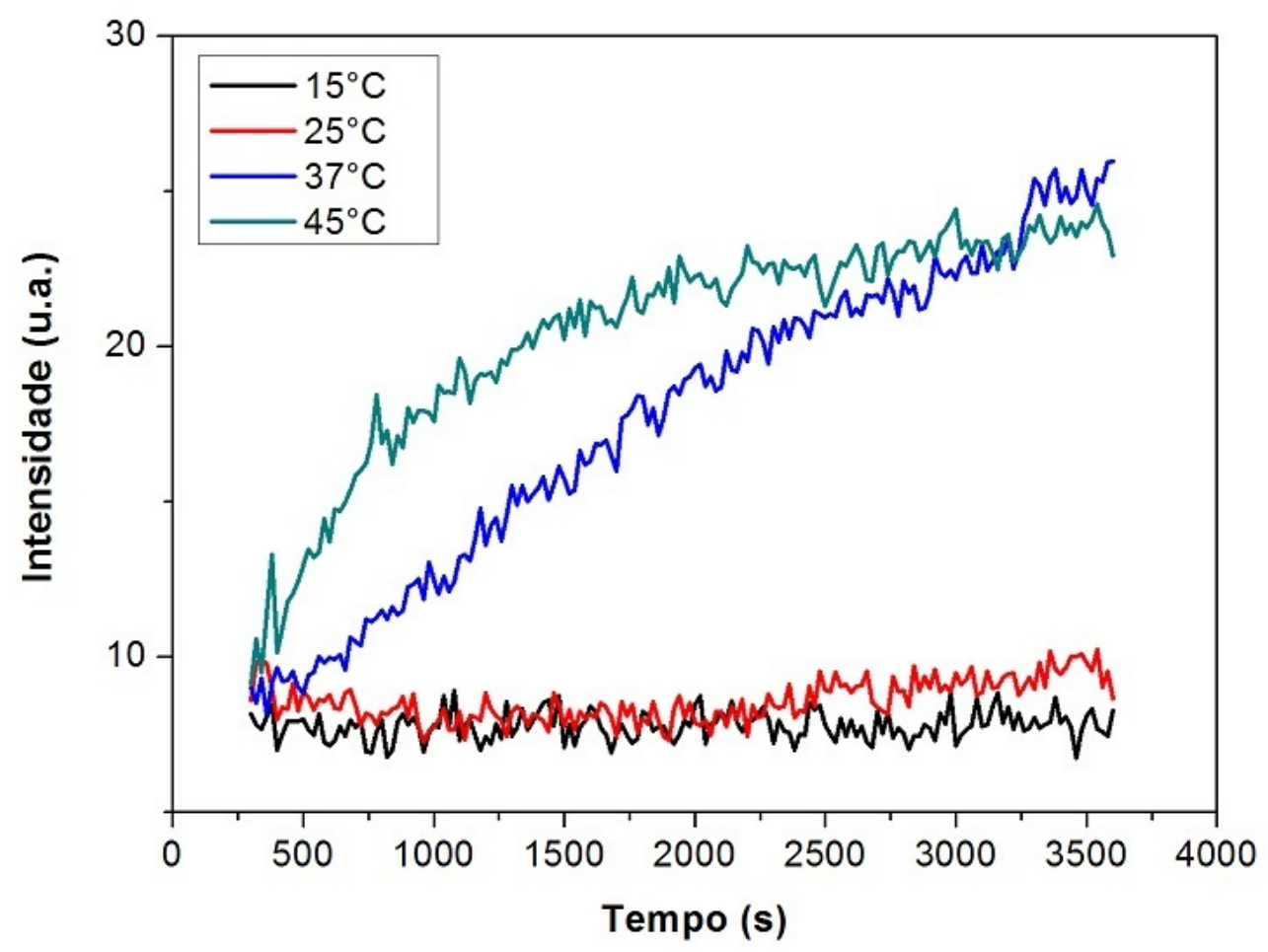

Figura 4.10: Evolução temporal da intensidade de fluorescência de ThT em uma solução de SEPT2G a $0,5 \mathrm{mg} / \mathrm{mL}$ e diferentes temperaturas. Dados fornecidos pelo Dr. Julio Damalio (IFSC-USP). 


\subsection{Amostras a $1 \mathrm{mg} / \mathrm{mL}$}

Na Figura 4.11 temos a média das curvas de espalhamento para a SEPT2G a $4^{\circ} \mathrm{C}$ e 1 $\mathrm{mg} / \mathrm{mL}$ (uma vez que as curvas de espalhamento não apresentaram mudanças significativas ao longo de 3300s) e o ajuste feito utilizando os modelos de dímero e cilindro com $146 \AA$ e $61 \AA$ de raio e comprimento, respectivamente, como podemos observar na Tabela 4.3 . Ao compararmos com a curva de menor concentração e mesma temperatura, vemos que a proteína já se encontra mais agregada, uma vez que no caso anterior a curva foi bem ajustada apenas com o modelo de dímero.

Podemos observar que o processo de agregação ocorre de maneira diferente do que a 0,5 $\mathrm{mg} / \mathrm{mL}$, uma vez que a presença de agregados do tipo cilindro só foi observada a $15^{\circ} \mathrm{C}$ e ainda assim as dimensões dos cilindros eram menores (Tabela 4.1 e Tabela 4.3). O parâmetro $\rho_{\text {cilindro }} \approx 0,4 \frac{e}{\AA^{3}}$ indica a presença de água em seu interior da mesma maneira que observado anteriormente para $0,5 \mathrm{mg} / \mathrm{mL}$. Em termos de porcentagem de SEPT2G dentro do envelope cilíndrico, essas dimensões e densidade eletrônica representam um agregado composto por $76 \%$ de proteína, onde temos 76 monômeros de SEPT2G e 442 moléculas de água para cada monômero Tabela 4.4 .

Assim como para $0,5 \mathrm{mg} / \mathrm{mL}$, a densidade eletrônica relativa da camada de hidratação tem valor $d_{c o r} \approx 1$ (Tabela 4.3), indicando que a densidade eletrônica é compatível com a do solvente.

Esses resultados estão de acordo com a análise modelo-independente realizada no Capítulo 3. Para valores de massa molecular e raio de giro, tínhamos um indicativo de que os valores eram resultado da média de objetos maiores coexistindo com o dímero em solução. Pela função $\mathrm{p}(\mathrm{r})$ verificamos que este objeto alongado tinha dimensão máxima de aproximadamente $400 \AA$, compatível com a dimensão encontrada para o agregado do tipo cilindro. 


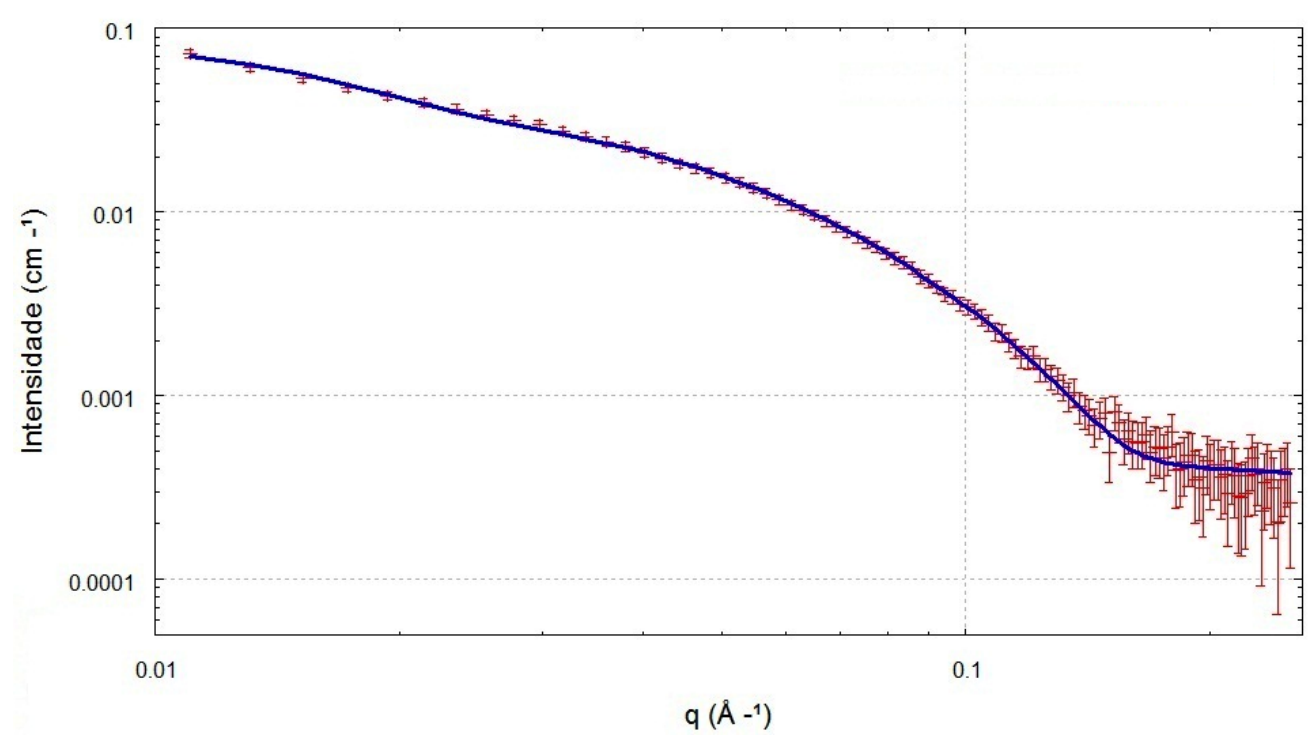

Figura 4.11: Melhor ajuste (linha contínua) aos dados experimentais de SAXS da SEPT2G a $1 \mathrm{mg} / \mathrm{mL}$ e $\mathrm{T}=4^{\circ} \mathrm{C}(+)$.

A Figura 4.12 mostra as curvas de espalhamento e os respectivos ajustes para as amostras a $1 \mathrm{mg} / \mathrm{mL}$ e $15^{\circ} \mathrm{C}$ nos instantes $\mathrm{t}=0,1200$ e 2100s. Podemos observar um aumento de cerca de 5 para $12 \%$ nos agregados do tipo cilindro (Tabela 4.4). O comprimento do agregado cilíndrico não sofre alterações significativas quando comparamos com a amostra a $4^{\circ} \mathrm{C}$, mas seu raio aumenta de 146 para $198 \AA$ (Tabela 4.3). A densidade eletrônica do agregado do tipo cilindro se mantém praticamente constante. Esses cilindros são compostos por $79 \%$ de proteína e seu volume representa um agregado composto por 139 monômeros, com 375 moléculas de água para cada monômero (Tabela 4.4).

Ao compararmos as amostras com mesma temperatura e concentrações diferentes, verificamos que a porcentagem de proteína na forma dimérica é similar para as duas concentrações em uma temperatura de $15^{\circ} \mathrm{C}$ (Tabelas 4.2 e 4.4). Porém, para $1 \mathrm{mg} / \mathrm{mL}$, já temos uma quantidade maior de agregados do tipo Porod logo no instante inicial.

Assim como visto para $0,5 \mathrm{mg} / \mathrm{mL}$, para todas as temperaturas onde foi observada a presença do agregado do tipo Porod, a densidade eletrônica desse agregado apresenta um valor aproximado de $\rho_{\text {Porod }}=0,4 \frac{e}{\AA^{3}}$, indicando novamente a presença de água e/ou agregados proteicos não densos. 


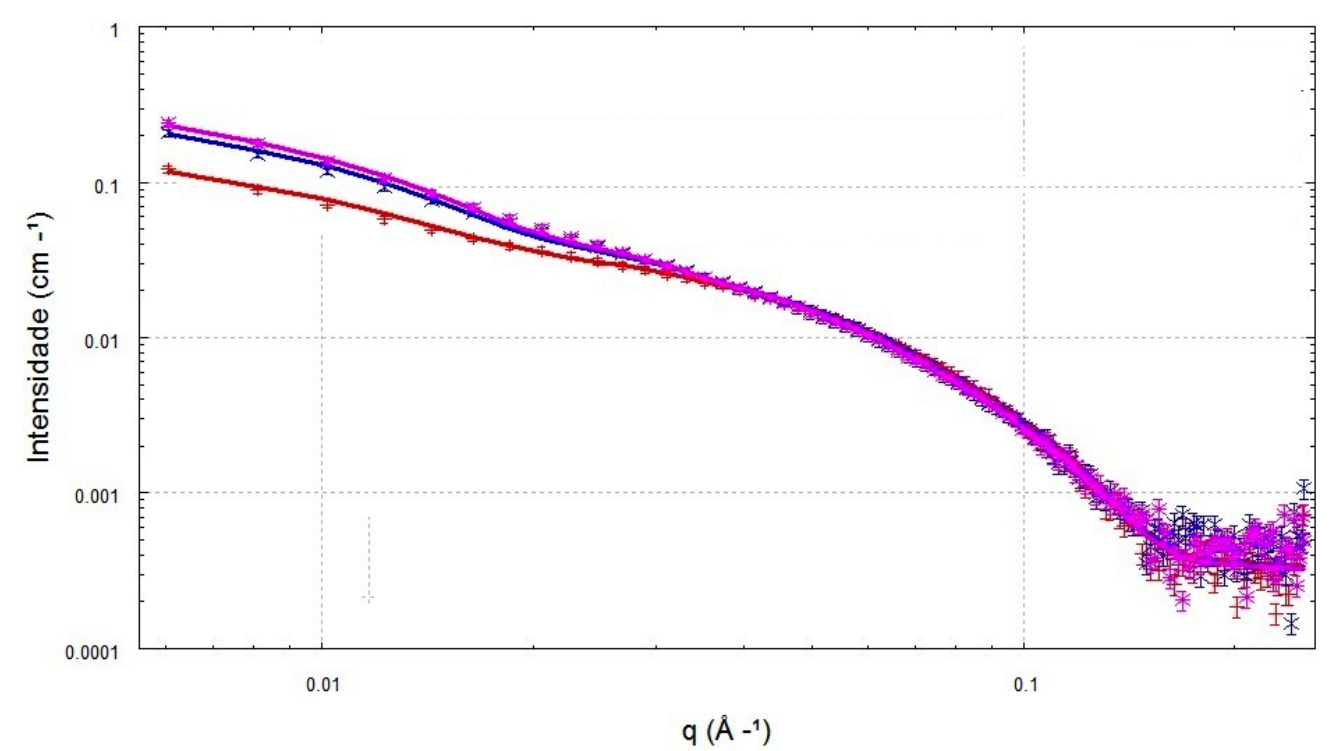

Figura 4.12: Melhor ajuste (linhas contínuas) aos dados experimentais de SAXS da SEPT2G a $1 \mathrm{mg} / \mathrm{mL}$ e $\mathrm{T}=15^{\circ} \mathrm{C}$ nos instantes $\mathrm{t}=0(+), 1200(\times)$ e $2100 \mathrm{~s}(*)$, utilizando os modelos de dímero da SEPT2G (Figura 2.6), agregado do tipo cilindro e agregado do tipo Porod.

Observando as curvas de espalhamento das amostras a $1 \mathrm{mg} / \mathrm{mL}$ e $25^{\circ} \mathrm{C}$ (Figura 4.13), percebemos uma diferença significativa entre elas com o passar do tempo na região de $q \leq 0,03 \AA^{-1}$, indicando um aumento na intensidade de espalhamento nessa região. Ao ajustarmos as curvas, percebemos que esse aumento se dá basicamente nas dimensões e porcentagens de agregados do tipo cilindro, uma vez que com o passar de 2100s não observamos alteração significativa na quantidade de agregados do tipo Porod (Tabela 4.4). Mais precisamente, ao longo do intervalo de medida verificamos que as dimensões aumentam de 209 e $113 \AA$ de raio e comprimento, respectivamente, para 255 e $258 \AA$ (Tabela 4.3) . Em termos de quantidade dos agregados do tipo cilindro, a porcentagem aumentou de 2,5 para cerca de $15 \%$ no mesmo intervalo (Tabela 4.4). 
Como podemos observar na Tabela 4.4, um agregado do tipo cilindro com essas dimensões e densidade eletrônica tem em sua composição $92 \%$ de proteína, valor pouco maior do que obtido a $15^{\circ} \mathrm{C}$. Nesta mesma Tabela vemos que o número de monômeros contido nesse volume é de 353 com 113 moléculas de água para cada monômero, sendo que o número de agregação aumenta até cerca de 1200 monômeros, mas a quantidade de moléculas de água por monômero mantém-se constante. Assim sendo, começamos a observar uma diminuição na hidratação do agregado do tipo cilindro dependente da temperatura.

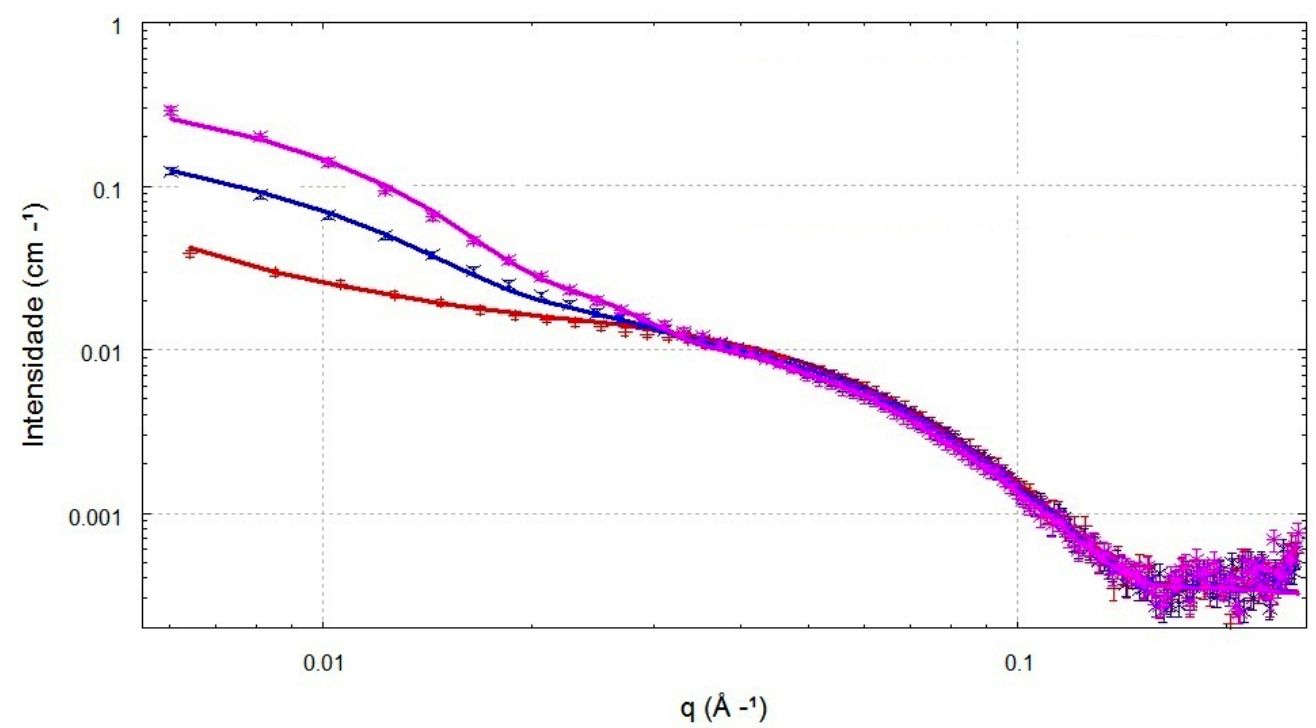

Figura 4.13: Melhor ajuste (linhas contínuas) aos dados experimentais de SAXS da SEPT2G a $1 \mathrm{mg} / \mathrm{mL}$ e $\mathrm{T}=25^{\circ} \mathrm{C}$ nos instantes $\mathrm{t}=0(+), 1200(\times)$ e $2100 \mathrm{~s}(*)$, utilizando os modelos de dímero da SEPT2G (Figura 2.6), agregado do tipo cilindro e agregado do tipo Porod.

De maneira análoga ao que foi visto para a SEPT2G a $0,5 \mathrm{mg} / \mathrm{mL}$ e $37^{\circ}$, a $1 \mathrm{mg} / \mathrm{mL}$ nessa mesma temperatura temos apenas dímeros e agregados do tipo Porod (Figura 4.14) sendo que a porcentagem inicial de dímeros é de $53 \%$ e decresce para cerca de $24 \%$ ao longo de 1200 s de medida (Tabela 4.4). Por sua vez, o parâmetro $d_{c o r} \approx 1,1$ indica uma densidade eletrônica de hidratação $10 \%$ maior que a do solvente. 
É importante ressaltar que o tempo de aquisição de dados para as amostras com concentração igual a $1 \mathrm{mg} / \mathrm{mL}$ foi de 120s. Novamente, poderíamos ter estágios intermediários de agregação como visto em temperaturas inferiores, porém em um intervalo menor que 2 minutos.

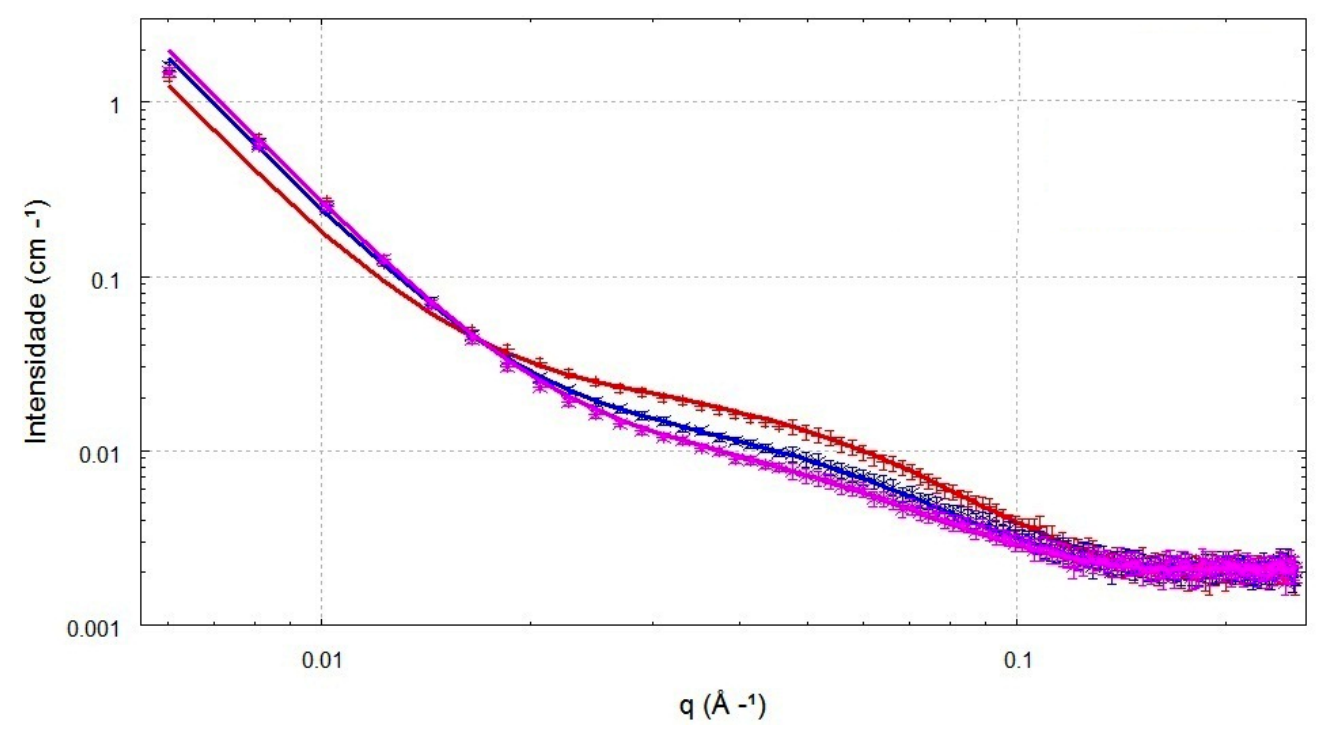

Figura 4.14: Melhor ajuste (linhas contínuas) aos dados experimentais de SAXS da SEPT2G a $1 \mathrm{mg} / \mathrm{mL}$ e $\mathrm{T}=37^{\circ} \mathrm{C}$ nos instantes $\mathrm{t}=0(+), 600(\times)$ e $1200 \mathrm{~s}(*)$, utilizando os modelos de dímero da SEPT2G (Figura 2.6) e agregado do tipo Porod.

Para a SEPT2G a $45^{\circ} \mathrm{C}$ e $1 \mathrm{mg} / \mathrm{mL}$ já temos apenas $32 \%$ de dímeros no instante inicial. Em apenas 20 minutos essa porcentagem cai para apenas 5\% (Tabela 4.4). Novamente, temos $d_{c o r}=1,13$, que indica um aumento de cerca de $13 \%$ com relação ao solvente (Tabela 4.3).

Se compararmos esses resultados com o que foi visto a $0,5 \mathrm{mg} / \mathrm{mL}$ (Tabela 4.2 podemos verificar que apesar de no instante inicial termos cerca de $60 \%$ de dímeros, a porcentagem após 1200 s é compatível com a obtida para $1 \mathrm{mg} / \mathrm{mL}$.

Além disso, não apenas os resultados da análise modelo-dependente, mas também as funções $p(r)$ (Capítulo 3), mostraram que SEPT2G a 37 e $45^{\circ} \mathrm{C}$ nas duas concentrações estudadas apresenta comportamento semelhante. 


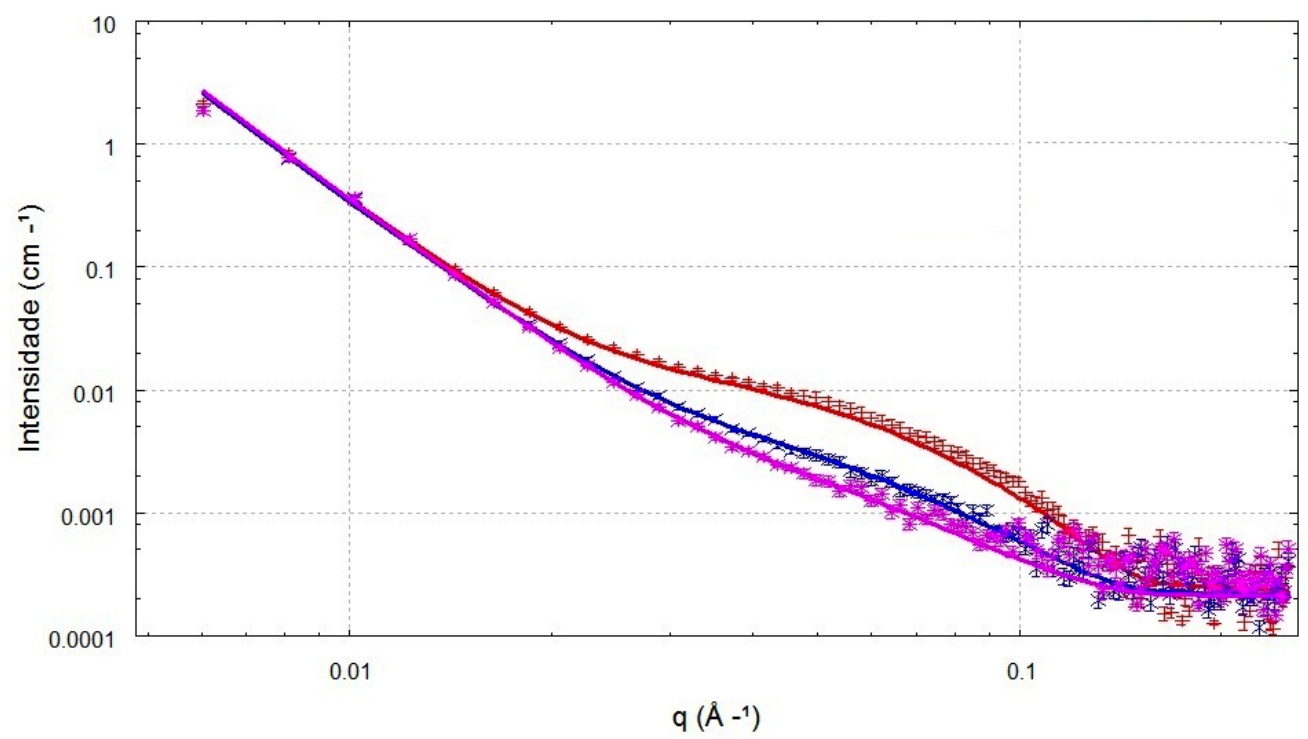

Figura 4.15: Melhor ajuste (linhas contínuas) aos dados experimentais de SAXS da SEPT2G a $1 \mathrm{mg} / \mathrm{mL}$ e $\mathrm{T}=45^{\circ} \mathrm{C}$ nos instantes $\mathrm{t}=0(+), 600(\times)$ e $1200 \mathrm{~s}(*)$, utilizando os modelos de dímero da SEPT2G (Figura 2.6) e agregado do tipo Porod. 


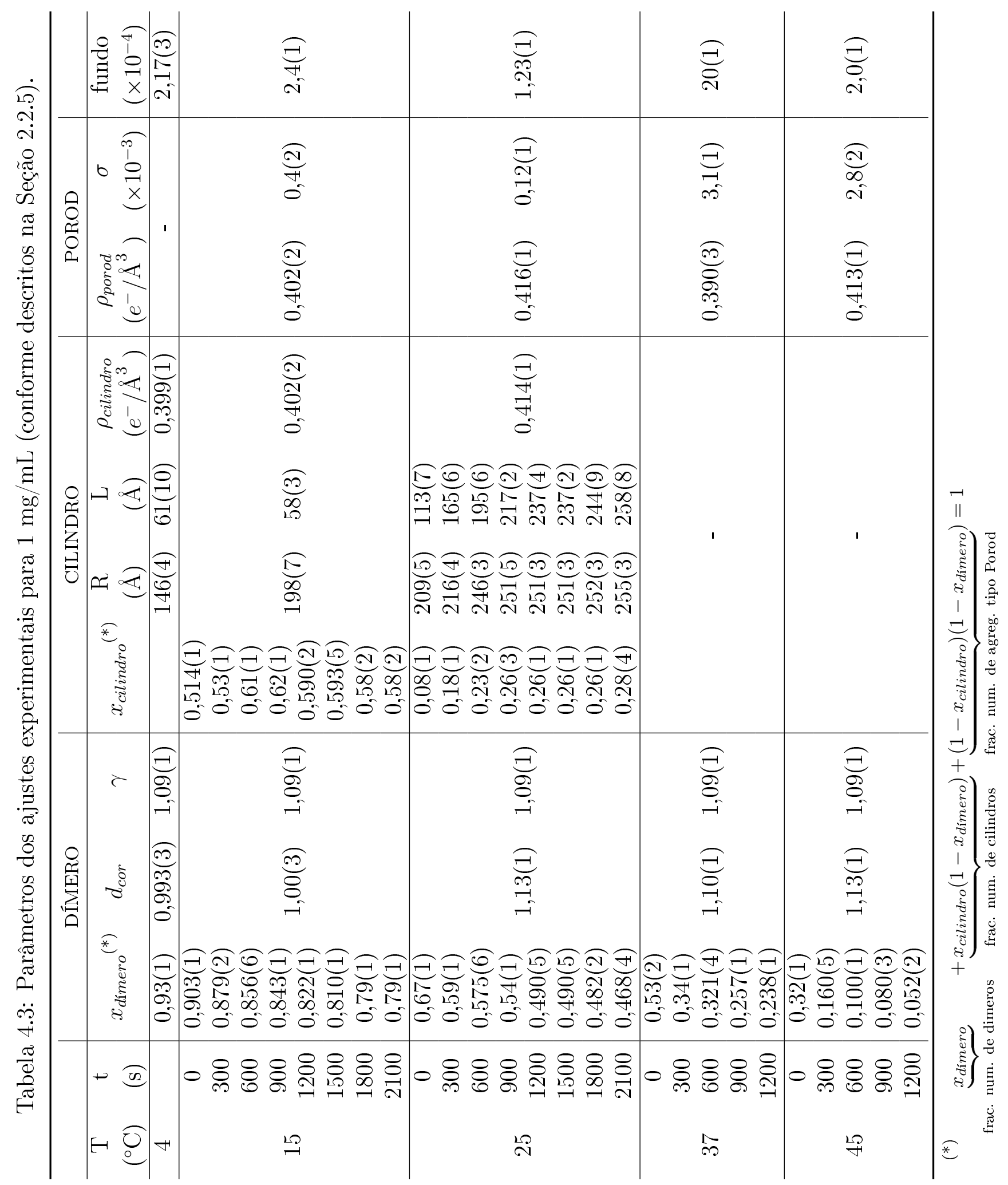


Tabela 4.4: Parâmetros calculados a partir dos ajustes experimentais para $1 \mathrm{mg} / \mathrm{mL}$ (conforme descritos na Seção 2.2.5).

\begin{tabular}{|c|c|c|c|c|c|c|c|}
\hline & & DÍMERO & \multicolumn{4}{|c|}{ CILINDRO } & POROD \\
\hline $\begin{array}{c}\mathrm{T} \\
\left({ }^{\circ} \mathrm{C}\right)\end{array}$ & $\begin{array}{c}\mathrm{t} \\
(\mathrm{s})\end{array}$ & $\%_{\text {dímero }}$ & $\%_{\text {cilindro }}$ & $N_{\text {agreg }}$ & $\frac{N_{\mathrm{H}_{2} \mathrm{O}}}{N_{\text {agreg }}}$ & $\begin{array}{c}\phi \\
(\%)\end{array}$ & $\%_{\text {porod }}$ \\
\hline 4 & & $93(1)$ & $7(1)$ & $76(13)$ & $442(75)$ & $76(1)$ & - \\
\hline \multirow{8}{*}{15} & 0 & $90,3(1)$ & $5,0(1)$ & $139(12)$ & $375(32)$ & $79(1)$ & $4,7(1)$ \\
\hline & 300 & $87,9(2)$ & $6,4(2)$ & $139(12)$ & $375(32)$ & $79(1)$ & $5,7(2)$ \\
\hline & 600 & $85,6(6)$ & $8,8(4)$ & $139(12)$ & $375(32)$ & $79(1)$ & $5,6(2)$ \\
\hline & 900 & $84,3(1)$ & $9,7(1)$ & $139(12)$ & $375(32)$ & $79(1)$ & $6,0(1)$ \\
\hline & 1200 & $82,2(1)$ & $10,5(1)$ & $139(12)$ & $375(32)$ & $79(1)$ & $7,3(1)$ \\
\hline & 1500 & $81,0(1)$ & $11,3(1)$ & $139(12)$ & $375(32)$ & $79(1)$ & $7,7(1)$ \\
\hline & 1800 & $79(1)$ & $12(1)$ & $139(12)$ & $375(32)$ & $79(1)$ & $9(1)$ \\
\hline & 2100 & $79(1)$ & $12(1)$ & $139(12)$ & $375(32)$ & $79(1)$ & $9(1)$ \\
\hline \multirow{8}{*}{25} & 0 & $67(1)$ & $2,6(3)$ & $353(28)$ & $113(8)$ & $92(1)$ & $30,4(5)$ \\
\hline & 300 & $59(1)$ & $7,4(4)$ & $549(29)$ & $113(8)$ & $92(1)$ & $33,6(9)$ \\
\hline & 600 & $57(1)$ & $10(1)$ & $844(33)$ & $113(8)$ & $92(1)$ & $33(1)$ \\
\hline & 900 & $54(1)$ & $12(1)$ & $980(40)$ & $113(8)$ & $92(1)$ & $34(2)$ \\
\hline & 1200 & $49,0(5)$ & $13,3(5)$ & $1071(31)$ & $113(8)$ & $92(1)$ & $37,7(6)$ \\
\hline & 1500 & $49,0(5)$ & $13,3(5)$ & $1071(31)$ & $113(8)$ & $92(1)$ & $37,7(6)$ \\
\hline & 1800 & $48,2(2)$ & $13,5(5)$ & $1108(49)$ & $113(8)$ & $92(1)$ & $38,3(5)$ \\
\hline & 2100 & $47(1)$ & $15(2)$ & $1198(47)$ & $113(8)$ & $92(1)$ & $38(2)$ \\
\hline \multirow{5}{*}{37} & 0 & $53(2)$ & \multirow{5}{*}{\multicolumn{4}{|c|}{ (1) }} & $47(2)$ \\
\hline & 300 & $34(2)$ & & & & & $66(1)$ \\
\hline & 600 & $32,1(4)$ & & & & & $67,9(4)$ \\
\hline & 900 & $25,7(1)$ & & & & & $74,3(1)$ \\
\hline & 1200 & $23,8(1)$ & & & & & $76,2(1)$ \\
\hline \multirow{5}{*}{45} & 0 & $32(1)$ & \multirow{5}{*}{\multicolumn{4}{|c|}{-}} & $68(1)$ \\
\hline & 300 & $16,0(5)$ & & & & & $84,0(5)$ \\
\hline & 600 & $10,0(1)$ & & & & & $90,0(1)$ \\
\hline & 900 & $8,0(3)$ & & & & & $92,0(3)$ \\
\hline & 1200 & $5,2(2)$ & & & & & $94,8(2)$ \\
\hline
\end{tabular}


Com base nos dados da Tabela 4.4, podemos observar a evolução do processo de agregação para as amostras de SEPT2G a 1mg/mL e diferentes temperaturas na Figura 4.16 .

Assim como para $0,5 \mathrm{mg} / \mathrm{mL}$, observamos que a proteína a $1 \mathrm{mg} / \mathrm{mL}$ permanece estável ao longo de 30 minutos (1800s) a $4^{\circ} \mathrm{C}$ (Figura 4.16.A). Entretanto, a concentração acelera o processo de agregação, uma vez que nesse caso já temos $7 \%$ em estruturas cilíndricas.

Como vemos na Figura 4.16. B, ao aumentarmos a temperatura para $15^{\circ} \mathrm{C}$, a quantidade de dímeros é de cerca de $90 \%$, assim como visto para $4^{\circ} \mathrm{C}$. Entretanto, já é possível observar $5 \%$ de agregados do tipo Porod coexistindo com outros 5\% de agregados do tipo cilindro em solução. Em um intervalo de 1800s a porcentagem de dímeros decresce para cerca de $80 \%$; a porcentagem de agregados intermediários do tipo cilindro chega aproximadamente $12 \%$ e a de agregados do tipo Porod atinge cerca de $8 \%$.

Ao observarmos os resultados referentes à $25^{\circ} \mathrm{C}$ (Figura 4.16. C), verificamos um comportamento um pouco diferente. A porcentagem de agregados do tipo Porod já supera a agregados do tipo cilindro logo no instante inicial, temos $30 \%$ para o agregado do tipo Porod e uma quantidade irrisória de estruturas cilíndricas. A porcentagem de agregados do tipo cilindro aumenta para $10 \%$ ao longo de 2100 s de medida e além disso também podemos observar um aumento no volume dos cilindros.

Esse aumento no volume pode ser visto no gráfico (curva rosa) da Figura 4.17, onde vemos a evolução temporal do volume de todos os agregados cilíndricos. Podemos verificar que o estágio intermediário de agregação descrito pelas estruturas cilíndricas ocorre para a SEPT2G a 15 e $25^{\circ} \mathrm{C}$ para a concentração de $0,5 \mathrm{mg} / \mathrm{mL}$ e a 4,15 e $25^{\circ} \mathrm{C}$ para a concentração de $1 \mathrm{mg} / \mathrm{mL}$. Podemos perceber um aumento no volume em função da concentração e temperatura, mas apenas a $25^{\circ} \mathrm{C}$ e $1 \mathrm{mg} / \mathrm{mL}$ este volume apresenta uma evolução temporal.

Ainda levando em conta os resultados a $25^{\circ} \mathrm{C}$ (Figura 4.16. C), a porcentagem de agregados do tipo Porod chega a cerca de $40 \%$ ao longo dos 35 minutos de medida. É importante ressaltar que esses agregados do tipo Porod representam um agregado composto por muito mais que 1200 monômeros, uma vez que essa é a composição do maior agregado do tipo cilindro identificado nas amostras a $25^{\circ} \mathrm{C}$ e $1 \mathrm{mg} / \mathrm{mL}$. Vale a pena reforçar que as dimensões máximas desse agregado cilíndrico é de aproximadamente metade da dimensão máxima observada pela técnica de SAXS (Tabela 4.3).

Na Figura 4.16.D, é possível visualizar a cinética a $37^{\circ} \mathrm{C}$ da amostra com concentração igual a $1 \mathrm{mg} / \mathrm{mL}$ e, como na concentração inferior, não distinguimos mais as estruturas cilíndricas; a proteína em solução se divide em porções quase iguais de dimeros e agregados 
do tipo Porod (55 e 45\%, respectivamente). Em apenas 300s já temos 60\% da proteína agregada. Se compararmos com os resultados a $0,5 \mathrm{mg} / \mathrm{mL}$, era preciso $900 \mathrm{~s}$ para atingir a mesma porcentagem. Ao longo de apenas 20 minutos $75 \%$ da proteína já compõe os agregados do tipo Porod.

Para $45^{\circ} \mathrm{C}$ o comportamento da SEPT2G nas duas concentrações é bastante parecido, exceto que a $1 \mathrm{mg} / \mathrm{mL}$ (Figura 4.16.E) a proteína já se encontra mais agregada: temos $70 \%$ de agregados do tipo Porod a $1 \mathrm{mg} / \mathrm{mL}$ contra $60 \%$ a $0,5 \mathrm{mg} / \mathrm{mL}$. Um dado interessante que podemos notar é que o efeito da concentração se mostra bastante influente no início do processo de agregação. Com o passar do tempo, para temperatura igual ou acima da fisiológica, a proporção entre dímeros e agregados tende a ser a mesma para as duas concentrações. 

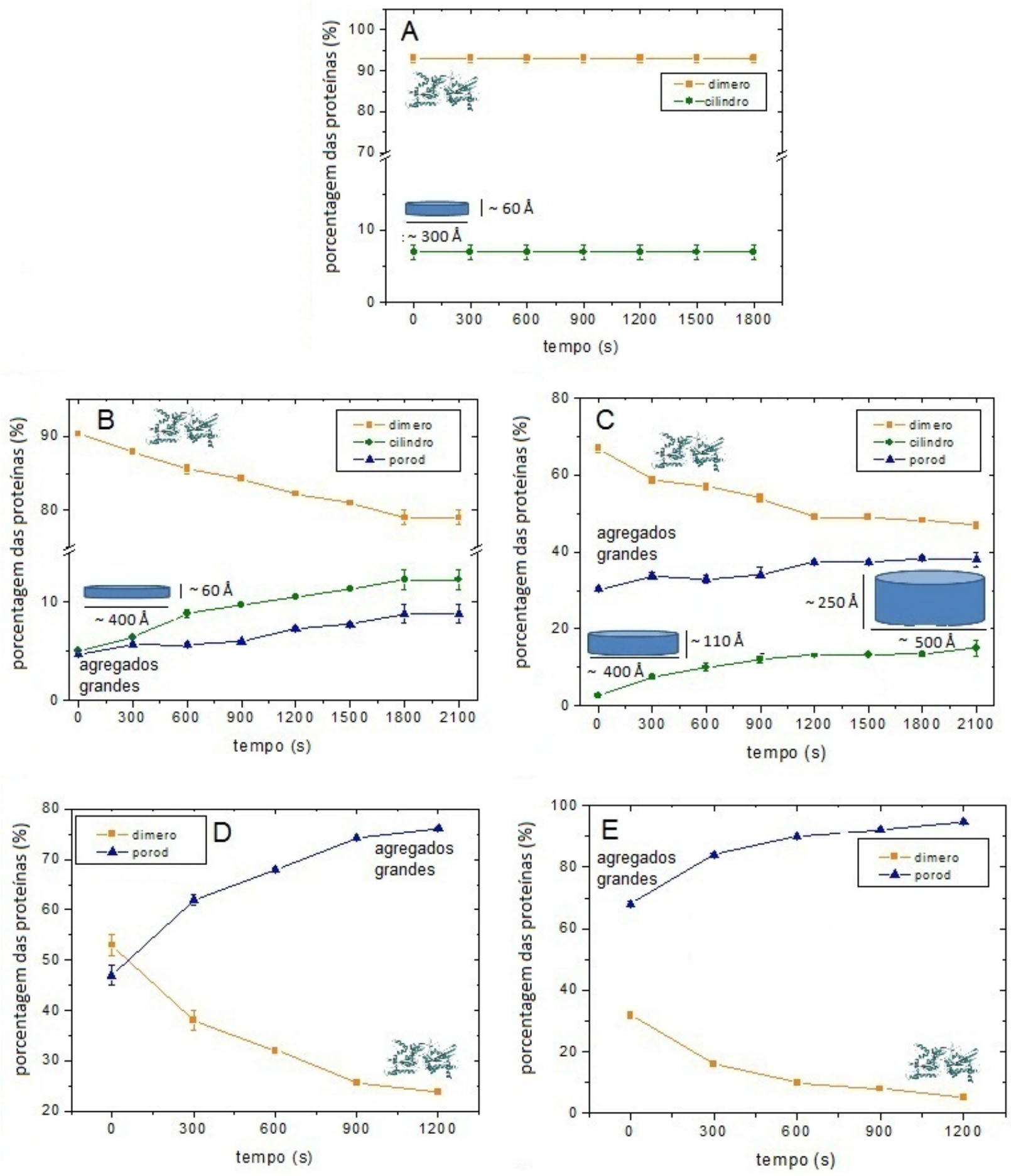

Figura 4.16: Porcentagens de dímero, agregado do tipo cilindro e agregado do tipo Porod para $1 \mathrm{mg} / \mathrm{mL}$ em temperaturas de $(\mathrm{A}): 4^{\circ} \mathrm{C}$; (B): $15^{\circ} \mathrm{C} ;(\mathrm{C}): 25^{\circ} \mathrm{C} ;(\mathrm{D}): 37^{\circ} \mathrm{C}$ e $(\mathrm{E}): 45^{\circ} \mathrm{C}$. Os cilindros representados estão em escala entre si, mas não com a representação do dímero. Em (C) temos a representação de dois cilindros, indicando a evolução desta estrutura no intervalo de medida. 


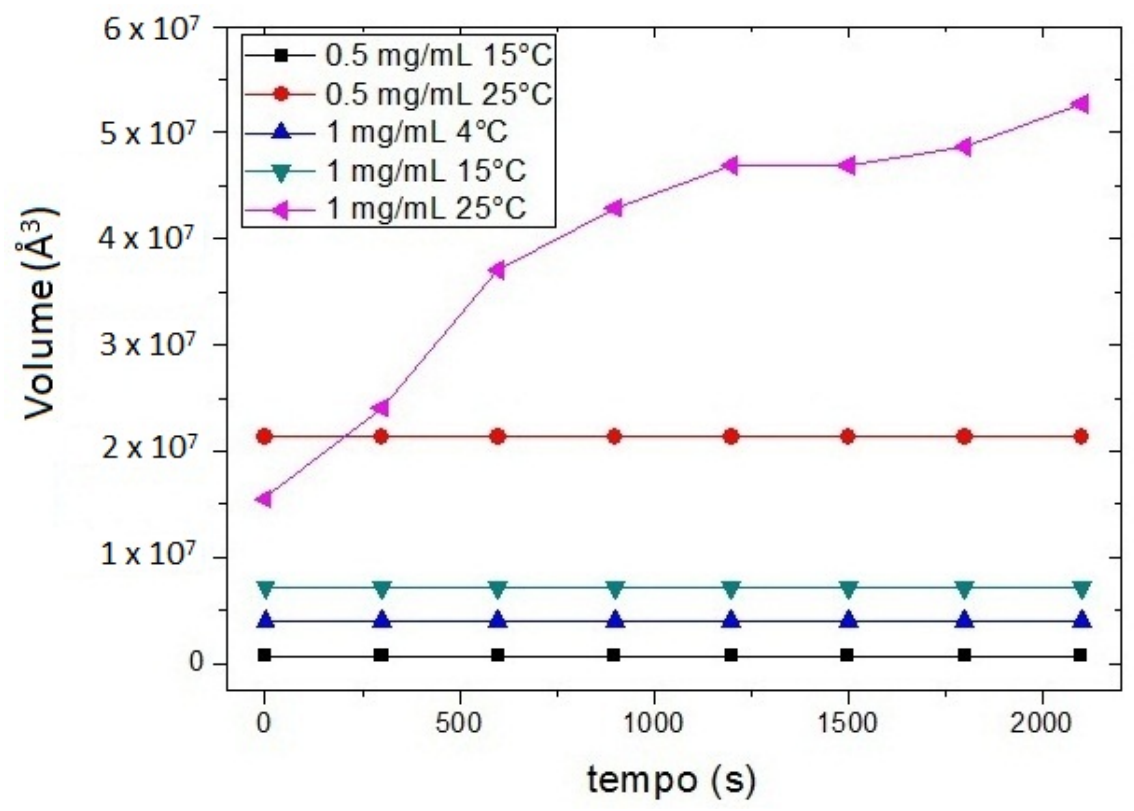

Figura 4.17: Evolução temporal do volume do agregado do tipo cilindro. 


\section{Capítulo 5}

\section{Conclusão}

Este trabalho investigou o processo de agregação do domínio GTPase da septina 2 (SEPT2G) dependente da concentração, temperatura e com o passar do tempo.

Através de resultados de Raio de Giro, massa molecular, $p(r)$ e análise modelo-dependente dos dados experimentais de espalhamento de raios-X a baixos ângulos podemos concluir que a $0,5 \mathrm{mg} / \mathrm{mL}$ e $4^{\circ} \mathrm{C}$ a proteína encontra-se na forma dimérica. Com o aumento da temperatura e concentração, observamos a formação de agregados em estruturas cilíndricas que coexistem com agregados maiores que o limite da técnica de espalhamento de raios-X, descritos como agregado do tipo Porod. Com suporte de resultados de fluorescência de tioflavina, podemos considerar que esses cilindros podem ser uma forma pré-fibrilar que ainda não apresenta uma quantidade significativa de folhas- $\beta$ num arranjo tipo amiloidal.

A partir de $37^{\circ} \mathrm{C}$ para as duas concentrações estudadas, não observamos mais a presença desses agregados cilindricos: uma parte da proteína em solução se encontra na forma dimérica e a outra em agregados com dimensão maior que $120 \mathrm{~nm}$. Ao compararmos os resultados de SAXS com dados de dicroísmo circular [36] e fluorescência de ThT (Figura 4.10), podemos verificar que nessas condições temos um aumento de folhas- $\beta$, arranjadas de maneira que ocorre um aumento do sinal de fluorescência de ThT, indicativo de estruturas amilóides.

Para 37 e $45^{\circ} \mathrm{C}$ nas duas concentrações estudadas, já não conseguimos perceber diferenças significativas do processo de agregação, tanto através da função $p(r)$, quanto na análise modelo-dependente. A única diferença entre esses conjuntos de amostras é a evolução temporal do processo de agregação, que se mostra mais acentuada conforme aumentamos a temperatura e a concentração. 
Podemos concluir então que nossos resultados mostraram que o processo de agregação da SEPT2G depende não apenas da temperatura e concentração, mas também mostra um aumento de estruturas grandes, que apresentaram características amilóides para 37 e $45^{\circ} \mathrm{C}$, em um intervalo de tempo de 20 minutos.

A cinética de agregação é tal que foi possível perceber pela técnica de SAXS a presença de agregados pré-fibrilares em equilíbrio com dímeros e grandes agregados a temperaturas de $15^{\circ} \mathrm{C}$ e $25^{\circ} \mathrm{C}$ durante o tempo de medida (da ordem de 30 minutos). Em nenhum caso observamos a dissociação de dímeros para posterior reassociação.

Por outro lado, para temperaturas maiores que $37^{\circ} \mathrm{C}$, já não foi observada a presença de estágios intermediários de agregação, mas apenas um equilíbrio entre dímeros e grandes agregados que se desloca rapidamente com o tempo.

Portanto, podemos concluir que existe uma temperatura entre $25^{\circ} \mathrm{C}$ e $37^{\circ} \mathrm{C}$ que acentua o mecanismo de associação da SEPT2G, provavelmente mediado por interações hidrofóbicas, levando a formação de grandes agregados. No caso da proteína a $0,5 \mathrm{mg} / \mathrm{mL}$ concluímos que a condição termodinâmica do sistema é tal que favorece a formação de estruturas tipoamilóides. 


\section{Referências Bibliográficas}

[1] L. C. Serpell, M. Sunde, and C. C. F. Blake, "The molecular basis of amyloidosis," Cellular and Molecular Life Sciences 53 (1997) 871-887.

[2] F. Chiti and C. M. Dobson, "Protein misfolding, functional amyloid, and human disease," Annual Review of Biochemistry 75 (2006) 333-66.

[3] G. M. Hirschfield and P. N. Hawkins, "Amyloidosis: New strategies for treatment," The International Journal of Biochemistry \& Cell Biology 35 (2003) 1608-13.

[4] A. T. Alexandrescu, "Amyloid accomplices and enforcers," Protein Science 14 (2005) $1-12$.

[5] L. Nielsen, S. Frokjaer, J. E. Carpenter, and J. Brange, "Studies of the structure of insulin fibrils by fourier transform infrared (FTIR) spectroscopy and electron microscopy," Journal of Pharmaceutical Sciences 90(1) (2001) 28-37.

[6] W. Wang, "Protein aggregation and its inhibition in biopharmaceutics," International Journal of Pharmaceutics 289 (2005) 1-30.

[7] M. Bucciantini, E. Giannoni, F. Chiti, F. Baroni, L. Formigli, J. Zurdo, N. Taddei, G. Ramponi, C. M. Dobson, and M. Stefani, "Inherent toxicity of aggregates implies a common mechanism for protein misfolding diseases," Nature 416 (2002) 507-511.

[8] B. Caughey and P. T. Lansbury, "Protofibrils, pores, fibrils, and neurogeneration: Separating the responsible protein aggregates from the innocent bystanders," Annual Review of Neuroscience 26 (2003) 267-298. 
[9] S. B. Padrick and A. D. Miranker, "Islet amyloid: phase partitioning and secondary nucleation are central to the mechanism of fibrillogenesis," Biochemistry 41 (2002) 4694-4703.

[10] L. Nielsen, R. Khurana, A. Coats, S. Frokjaer, J. Brange, S. Vyas, V. N. Uversky, and A. L. Fink, "Effect of environmental factors on the kinetics of insulin fibril formation: elucidation of the molecular mechanism," Biochemistry 40 (2001) 6036-6046.

[11] F. Chiti and C. M. Dobson, "Amyloid formation by globular proteins under native conditions," Nature Chemical Biology 5 (2009) 15-22.

[12] B. Vestergaard, M. Groenning, M. Roessle, J. S. Kastrup, M. van de Weert, J. M. Flink, S. Frokjaer, M. Gajhede, and D. I. Svergun, "A helical structural nucleus is the primary elongating unit of insulin amyloid fibrils," PLoS Biology 5 (2007) e134.

[13] "Pesquisa realizada no site www.sciencedirect.com, correlacionando as palavras SAXS e amyloid. Acesso em 12/01/2012.."

[14] A. Nayak, M. Sorci, S. Krueger, and G. Belfort, "A universal pathway for amyloid nucleus and precursor formation for insulin," Proteins 74 (2009) 556-565.

[15] A. Rekas, R. B. Knott, A. Sokolova, K. J. Barnham, K. A. Perez, C. L. Masters, S. C. Drew, R. Cappai, C. C. Curtain, and C. L. L. Pham, "The structure of dopamine induced $\alpha$-synuclein oligomers," European Biophysics Journal 39 (2010) 1407-1419.

[16] M. Tashiro, M. Kojima, H. Kihara, K. Kasai, T. Kamiyoshihara, K. Uéda, and S. Shimotakahara, "Characterization of fibrillation process of $\alpha$-synuclein at the initial stage," Biochemical and Biophysical Research Communications 369 (2008) 910-914.

[17] L. Redecke, M. von Bergen, J. Clos, P. V. Konarev, D. I. Svergun, U. E. Fittschen, J. A. Broekaert, O. Bruns, D. Georgieva, E. Mandelkow, N. Genov, and C. Betzel, "Structural characterization of $\beta$-sheeted oligomers formed on the pathway of oxidative prion protein aggregation in vitro," Journal of Structural Biology 157 (2007) 308-320.

[18] M. Gralle, C. L. P. Oliveira, L. H. Guerreiro, W. J. McKinstry, D. Galatis, C. L. Masters, R. Cappai, M. W. Parker, C. H. I. Ramos, I. Torriani, and S. T. Ferreira, "Solution conformation and heparin-induced dimerization of the full-length 
extracellular domain of the human amyloid precursor protein," Journal of Molecular Biology 357 (2006) 493-508.

[19] P. Thiyagarajan, T. S. Burkoth, V. Urban, S. Seifert, T. L. S. Benzinger, D. M. Morgan, D. Gordon, S. C. Meredith, and D. G. Lynn, "pH dependent self assembly of $\beta$-amyloid(10-35) and $\beta$-amyloid(10-35)-peg3000," Journal of Applied Crystallography 33 (2000) 535-539.

[20] C. L. P. Oliveira, M. A. Behrens, J. S. Pedersen, K. Erlacher, D. Otzen, and J. S. Pedersen, "A SAXS study of glucagon fibrillation," Journal of Molecular Biology 387 (2009) 147-161.

[21] C. M. Torres-Bugeau, R. Raisman-Vozari, D. Papy-Garcia, R. Itri, L. R. S. Barbosa, L. M. Cortez, V. L. Sim, and R. N. Chehín, "Characterization of heparin-induced glyceraldehyde-3-phosphate dehydrogenase early amyloid-like oligomers and their implication in $\alpha$-synuclein aggregation," The Journal of Biological Chemistry 287(4) (2012) 2398-2409.

[22] L. Zhu, H. Kihara, M. Kojima, J.-M. Zhou, and S. Perrett, "Small angle X-ray scattering study of the yeast prion ure2p," Biochemical and Biophysical Research Communications 311 (2003) 525-532.

[23] W. Garcia, A. P. U. Araújo, M. Oliveira-Neto, M. R. M. Ballestero, I. Polikarpov, M. Tanaka, T. Tanaka, and R. C. Garratt, "Dissection of a human septin: Definition and characterization of distinct domains within human SEPT4," Biochemistry 45(46) (2006) 13918-13931.

[24] W. Garcia, N. C. Rodrigues, M. Oliveira-Neto, A. P. U. Araújo, I. Polikarpov, M. Tanaka, T. Tanaka, and R. C. Garratt, "The stability and aggregation properties of the GTPase domain from human SEPT4," Biochimica et Biophysica Act $\mathbf{1 7 8 4}$ (2008) 1720-1727.

[25] M. G. Ortore, F. Spinozzi, S. Vilasi, I. Sirangelo, G. Irace, A. Shukla, T. Narayanan, R. Sinibaldi, and P. Mariani, "Time-resolved small-angle X-ray scattering study of the early stage of amyloid formation of an apomyoglobin mutant," Physical Review E $\mathbf{8 4}$ (2011) 061904-1-10. 
[26] M. Sirajuddin, M. Farkasovsky, F. Hauer, D. Ku“hlmann, I. G. Macara, M. Weyand, H. Stark, and A. Wittinghofer, "Structural insight into filament formation by mammalian septins," Nature 449 (2007) 311-315.

[27] B. Kartmann and D. Roth, "Novel roles for mammalian septins: from vesicle trafficking to oncogenesis," Journal of Cell Science 114 n. 5 (2001) 839-844.

[28] N. Beise and W. Trimble, "Septins at a glance," Journal of Cell Science 124 (2011) 4141-4146.

[29] F. Pan, R. L. Malmberg, and M. Momany, "Analysis of septins across kingdoms reveals orthology and new motifs," BMC Evolutionary Biology 7:103 (2007).

[30] C. Martínez, J. Corral, J. A. Dent, L. Sesma, V. Vicente, and J. Ware, "Platelet septin complexes form rings and associate with the microtubular network," . Journal of Thrombosis and Haemostasis 4 n. 6 (2006) 1388-1395.

[31] E. T. Spiliotis, "Regulation of microtubule organization and functions by septin GTPases," Cytoskeleton 67 (2010) 339-345.

[32] S. K. Ford and J. R. Pringle, "Cellular morphogenesis in the saccharomyces cerevisiae cell cycle: Localization of the CDC11 gene product and the timing of events at the budding site," Developmental Genetics 12(4) (1991) 281-292.

[33] M. E. Pablo-Hernando, Y. Arnaiz-Pita, H. Tachikawa, F. del Rey, A. M. Neiman, and C. R. V. de Aldana, "Septins localize to microtubules during nutritional limitation in saccharomyces cerevisiae," BMC Cell Biology 9 (2008) 55.

[34] A. Kinoshita, M. Kinoshita, H. Akiyama, H. Tomimoto, I. Akiguchi, S. Kumar, M. Noda, and J. Kimura, "Identification of septins in neurofibrillary tanglesin Alzheimer disease," American Journal of Pathology 153(5) (1998) 1551-1560.

[35] E. A. Peterson and E. M. Petty, "Conquering the complex world of human septins: implications for health and disease," Clinical Genetics 77 (2010) 511-524.

[36] J. C. P. Damalio, W. Garcia, J. N. A. Macedo, I. de Almeida Marques, J. M. Andreu, R. Giraldo, R. C. Garratt, and A. P. U. Araújo, "Self assembly of human septin 2 into amyloid filaments," Biochimie 11 (2011) 1-9. 
[37] J. C. P. Damalio, Estudos bioquimicos, funcionais e estruturais da septina humana SEPT2: fatores que determinam a formação de agregados. Tese de doutorado, IFSC, 2011.

[38] L. R. S. Barbosa, Estudo de sistemas de relevancia biológica por espalhamento de raios-X a baixos ângulos. Tese de doutorado, IFUSP, 2008.

[39] O. Glatter and O. Kratky, Small Angle X-ray Scattering. Academic Press, 1982.

[40] D. I. Svergun and L. A. Feigin, Structure analysis by Small-angle X-ray and Neutron Scattering. Plenum Press, NY, 1987.

[41] A. Guinier and G. Fournet, Small Angle Scattering of X-Rays. Wiley, New York, 1955.

[42] D. I. Svergun and M. H. J. Koch, "Small-angle scattering studies of biological macromolecules in solution," Reports on Progress in Physics 66 (2003) 1735-1782.

[43] H. D. T. Martens and D. I. Svergun, "Structural characterization of proteins and complexes using small-angle X-ray solution scattering," Journal of Structural Biology 172 (2010) 128-141.

[44] E. Mylonas and D. I. Svergun, "Accuracy of molecular mass determination of proteins in solution by small-angle X-ray scattering," Journal of Applied Crystallography $\mathbf{4 0}$ (2007) s245-s249.

[45] L. R. S. Barbosa, M. G. Ortore, F. Spinozzi, P. Mariani, S. Bernstorff, and R. Itri, "The importance of protein-protein interactions on the pH-Induced conformational changes of bovine serum albumin: A small-angle X-Ray scattering study," Biophysical Journal 98 (2010) 147-157.

[46] D. I. Svergun, "Mathematical methods in small-angle scattering data analysis," Journal of Applied Crystallografy 24 (1991) 485-492.

[47] M. G. Ortore, F. Spinozzi, P. Mariani, A. Paciaroni, L. R. S. Barbosa, H. Amenitsch, M. Steinhart, J. Ollivier, and D. Russo, "Combining structure and dynamics: non denaturating high-pressure effect on lysozyme in solution," Journal of Royal Society Interface 6 (2009) S619-S634. 
[48] J. Pedersen, "Analysis of small-angle scattering data from colloids and polymer solutions: modeling and least-squares fitting," Advances in Colloid and Interface Science 70 (1997) 171-210.

[49] F. M. Richards, "The interpretation of protein structures: Total volume, group volume distributions and packing density," Journal of Molecular Biology 82 (1974) 1-14.

[50] "Manual for the use of the brookhaven light scattering instrument, http://cls.uthscsa.edu/manual/manual.html. acesso em 13/10/2011."

[51] B. J. Berne and R. Pecora, Dynamic light scattering: with applications to chemistry, biology, and physics. Dover, 2000.

[52] S.F.Sun, Physical Chemistry of Macromolecules: Basic Principles and Issues. John Wiley, 2004.

[53] P. T. Campana, L. R. S. Barbosa, and R. Itri, "Conformational stability of peanut agglutinin using small angle X-ray scattering," International Journal of Biological Macromolecules 48 (2011) 398-402.

[54] H. Levine 3rd, "Thioflavine t interaction with synthetic Alzheimer's disease $\beta$-amyloid peptides: Detection of amyloid aggregation in solution," Protein Science 2 (1993) 404-410. 